\title{
VISCOELASTIC EFFECTS IN BOUNDARY LUBRICATION
}

\author{
BY
}

\section{MARJORIE ANN CARLSON GREEN}

B.A.Sc., The University of British Columbia, Vancouver, British Columbia, 1967

M.A.Sc., The University of British Columbia, Vancouver, British Columbia, 1971

A THESIS SUBMITTED IN PARTIAL FULFILMENT OF THE REQUIREMENTS FOR THE DEGREE OF DOCTOR OF PHILOSOPHY in the Department of Mechanical Engineering

We accept this thesis as conforming to the required standard

\footnotetext{
THE UNIVERSITY OF BRITISH COLUMBIA
} 
In presenting this thesis in partial fulfilment of the requirements for an advanced degree at The University of British Columbia, I agree that the Library shall make it freely available for reference and study. I further agree that permission for extensive copying of this thesis for scholarly purposes may be granted by the Head of my Department or by his representatives. It is understood that publication, in part or in whole, or the copying of this thesis for financial gain shall not be allowed without my written permission.

Marjorie Ann Carlson Green

Department of Mechanical Engineering

The University of British Columbia

Vancouver, B.C.

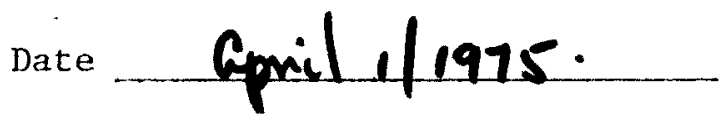


ABSTRACT

The static friction of steel under boundary lubricated conditions was investigated both experimentally and theoretically.

The theoretical model was developed using the assumption that during the application of a tangential load to a friction couple, the real area of contact grows in a viscoelastic manner until a critical shear stress is reached. Using this model, it was possible to distinguish the effect of static and dynamic contact time on area growth and thus to show why the traditional "time dependence of static friction" theories have limited validity. The model predicts that $\mu_{s}$, the static friction coefficient, is a function of the rate parameter $\dot{\theta}$, and that a relaxation time can be assigned to a given interface.

Subsequent experimental work using steel surfaces in vacuum as well as steel surfaces lubricated by various surface films showed that surface conditions play a large role in determining the exact $\mu_{s}-\dot{\theta}$ relationship for a given friction couple. Over the range of $\dot{\theta}$ investigated the static friction coefficient of steel is constant if certain surface films are present; for other films the static friction coefficient vs $\dot{\theta}$ curve shows an upper and lower asymptote. In the latter case a relaxation time was assigned to each boundary lubricant. For given asymptotes these relaxation times can be used to predict whether the film will be a useful lubricant at a particular $\dot{\theta}$. A subsequent investigation showed that the relaxation times are strongly affected by temperature. Since raising the substratum temperature results in smaller relaxation times, it is obvious that a particular lubricant may become ineffective as the substratum temperature changes. 
Both the experimental and theoretical work clearly demonstrate that the static friction of steel can be significantly modified by the application of appropriate boundary lubricants. 
TABLE OF CONTENTS

Page

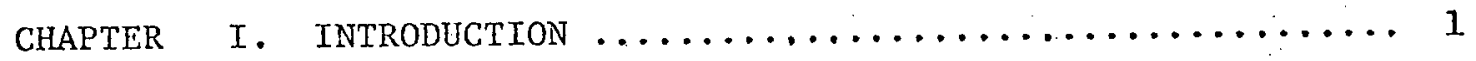

CHAPTER II. HISTORTCAL BACKGROUND $\ldots \ldots \ldots \ldots \ldots \ldots \ldots \ldots \ldots \ldots$

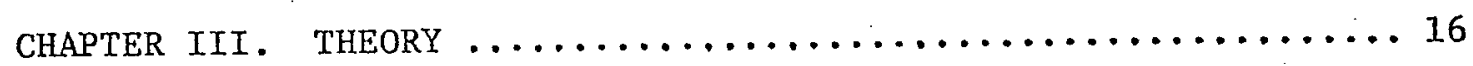

3.1 Introduction $\ldots \ldots \ldots \ldots \ldots \ldots \ldots \ldots \ldots \ldots \ldots \ldots \ldots \ldots$

3.2. Models for Static Friction ............ 18

3.3 The Non-dimensional $\mu_{s}$ vs $\tau *$ Plot $\ldots . . . \ldots 23$

3.4 Changing the Relaxation Time of an

Interface $\ldots \ldots \ldots \ldots \ldots \ldots \ldots \ldots \ldots . \ldots . \ldots 24$

3.5 The Effect of Temperature on $\tau$ Values .......28

CHAPTER IV. EXPERIMENTAL APPARATUS AND EXPERIMENTAL

PROCEDURE . ......................... 32

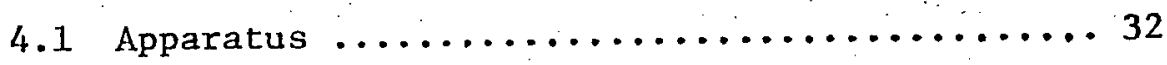

4.2 Pretest Preparation of Samples .......... 41

4.3 General Experimental Procedure ......... 46

CHAPTER V. RESULTS AND DISCUSSION $\ldots \ldots \ldots \ldots \ldots \ldots \ldots \ldots \ldots \ldots$

5.1 Introduction $\ldots \ldots \ldots \ldots \ldots \ldots \ldots \ldots \ldots \ldots \ldots \ldots \ldots \ldots \ldots$

5.2 obtaining Static Friction Information for
the Steel/Steel System $\ldots \ldots \ldots \ldots \ldots \ldots \ldots \ldots$

5.3 Discussion of $\mu_{s}-\dot{\theta}$ Results $\ldots \ldots \ldots \ldots \ldots 5$

5.4 Dimensionless $\mu_{s}-\dot{\theta}$ Curves $\ldots \ldots \ldots \ldots \ldots \ldots 64$

5.5 Effect of Temperature on Static Friction ....6 65 
CHAPTER VI. SUMMARY AND GENERAL DISCUSSION OF RESULTS ......6 69

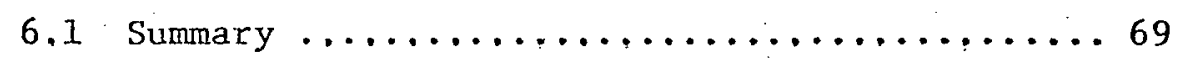

6.2 The Contact Area at slip ............. 70

6.3 Applicability of Results to Lubricant

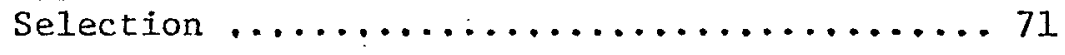

6.4 A Note on the Time-dependence of Static

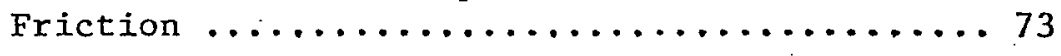

CHAPTER VII. CONCLUSIONS $\ldots \ldots \ldots \ldots \ldots \ldots \ldots \ldots \ldots \ldots \ldots \ldots \ldots$

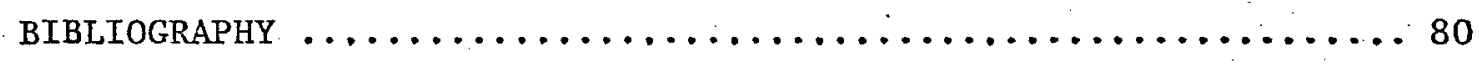

APPENDIX I. THE VACUUM SYSTEM $\ldots \ldots \ldots \ldots \ldots \ldots \ldots \ldots \ldots \ldots \ldots \ldots$

APPENDIX II. PROPERTIES OF REAGENTS USED ............. 88

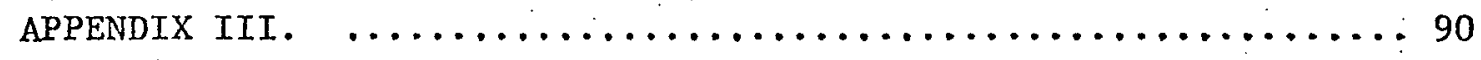

FIGURES $\ldots \ldots \ldots \ldots \ldots \ldots \ldots \ldots \ldots \ldots \ldots \ldots \ldots \ldots \ldots \ldots \ldots \ldots \ldots \ldots \ldots \ldots$ 


\section{LIST OF TABLES}

Page

TABLE I. Calculated Values of Relaxation Time, Viscosity, Elastic Modulus and Shear Strength for the 2-Parameter Model

TABLE II. Elastic Modulii and Viscosity Values as a Function of $\mathrm{T}_{\mathrm{o}} / \mathrm{p}_{\mathrm{m}}$ for the 3-Parameter Model .......662

TABLE III. Viscosities of Some Materials ............... 63 
LIST OF FIGURES

Page

FIGURE 1. Viscoelastic Model of Static Friction Developed by Johannes [19] ....................... 91

FIGURE 2a. The Contact Area Between Two Solid Surfaces is the Sum of the Small Discrete Areas of Contact Formed Where Opposing Asperities Meet .............. 92

FIGURE 2b. The Area of Contact and the Shear Strength as Functions of the Rate of Application of the Tangential Shearing Force ................ 93

FIGURE 3. Tangential Loading During a Static Friction Test .... 94 FIGURE 4. Models for Static Friction ................ 95

FIGURE 5. General Form of the $\mu_{s}-\dot{\theta}$ Curve $\ldots \ldots \ldots \ldots \ldots \ldots \ldots$

FIGURE 6. Changing c Results in a Family of $\mu_{s}-\dot{\theta}$ Curves .... 97 FIGURE 7. The General Static Friction Curve ............. 98

FIGURE 8. General Arrangement of Vacuum System and Experimental Apparatus ................................ 99

FIGURE 9. Isometric Diagram of Experimental Apparatus $\ldots . \ldots \ldots 100$

FIGURE 10. Schematic of the Hydraulic Control system ........ 101

FIGURE 11. Isometric Sketch of Friction Couple ........... 102

FIGURE 12, Static Friction of c1020 Steel in Vacuum of

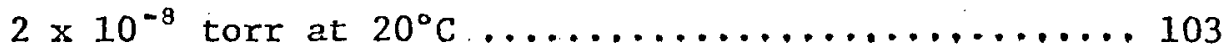

FIGURE 13. Static Friction of C1020 Steel in Vacuum and After

Exposure to Atmosphere ...................... 104

FIGURE 14. Comparison of Static Friction of C1020 Steel in

Vacuum ................................. 105

FIGURE 15. Static Friction of c1020 Steel Covered with Oxide Films ............................. 106

FIGURE 16. Comparison of Static Friction of Oxide-covered

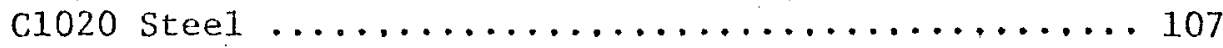

FIGURE 17. Static Friction of C1020 Steel After Abrading Surface Under Stearic Acid-Hexane Solution ........ 108

FIGURE 18. Static Friction of C1020 Steel Covered with a Monolayer of Either a Basic Iron Stearate or a

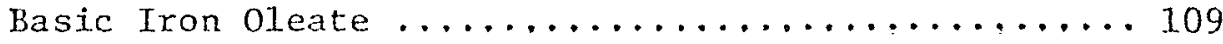


FIGURE 19. The Effect of a $\mathrm{Ca}(\mathrm{St})_{2}$ Monolayer on Static Friction as Compared to the Effect of an $\mathrm{Fe}(\mathrm{OH})_{2} \mathrm{St}$ Mono-

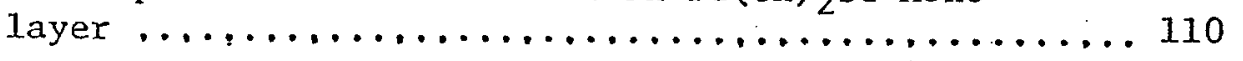

FIGURE 20. The Effect of a $\mathrm{Ca}(\mathrm{Ol})_{2}$ Monolayer on Static Friction Compared to the Effect of an $\mathrm{Fe}(\mathrm{OH})_{2}$ Ol Monolayer ... 111

FIGURE 21. Experimental Data and Theoretical $\mu_{s}-\dot{\theta}$ Curve for Static Friction: $\mathrm{Fe}(\mathrm{OH})_{2} \mathrm{St}$ Monolayer $\ldots \ldots \ldots \ldots \ldots 112$

FIGURE 22. Experimental Data and Theoretical $\mu_{s}-\dot{\theta}$ Curve for Static Friction: $\mathrm{Ca}(\mathrm{St}){ }_{2}$ Monolayer $^{\mathrm{N}} \ldots \ldots \ldots \ldots \ldots \ldots 113$

FIGURE 23. Experimental Data and Theoretical $\mu_{s}-\dot{\theta}$ Curve for Static Friction: $\mathrm{Fe}(\mathrm{OH})_{2}$ ol Monolayer ........... 114

FIGURE 24. Experimental Data and Theoretical $\mu_{s}-\dot{\theta}$ Curve for

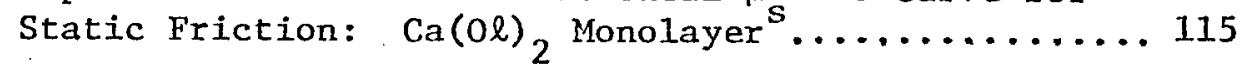

FIGURE 25. Experimental Data Collapses on General $\mu-\tau^{*}$ Curve Predicted from Mathematical Model .......... 116

FIGURE 26. Effect of Raising Surface Temperature to $35^{\circ} \mathrm{C}$. Ca Stearate Soap Monolayer .................. 117

FIGURE 27. Effect of Raising Surface Temperature to $50^{\circ} \mathrm{C}$. Ca Stearate Soap Monolayer .................. 118

FIGURE 28. Log c vs $1 / T$ for Calcium Stearate Soap Monolayers ... 119

FIGURE 29. $\mu_{s}-\dot{\theta}-\mathrm{T}$ Surfaces for Various Conditions $\ldots \ldots \ldots \ldots 120$

FIGURE 30. $\mu_{s}-T$ Characteristics of Steel Covered with Calcium Stearate Monalayer ..................... 121

FIGURE 31. Experimental. Temperature-Friction Data for Calcium Stearate Monolayer Covered Surface ............ 122

FIGURE 32. Loading History During Delayed Stick ........... 123

FIGURE 33. Area Growth Due to Delay Time if the System has a

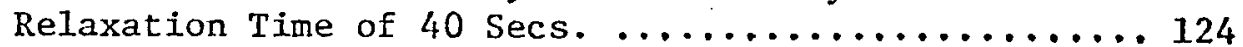


ACKNOWLEDGEMENT

The experimental part of this program was carried out in the Tribology Laboratory of the Department of Mechanical Engineering at The University of British Columbia. The author wishes to thank Dr. C.A. Brockley for his advice and encouragement during the program. Special thanks are due Dr. E.G. Hauptmann of the Department of Mechanical Engineering and Dr. J. Leja of the Department of Mineral Engineering for their suggestions and comments.

Financial assistance was received through the National Research Council of Canada and is gratefully acknowledged. 
LIST OF SYMBOLS

Symbol

Units

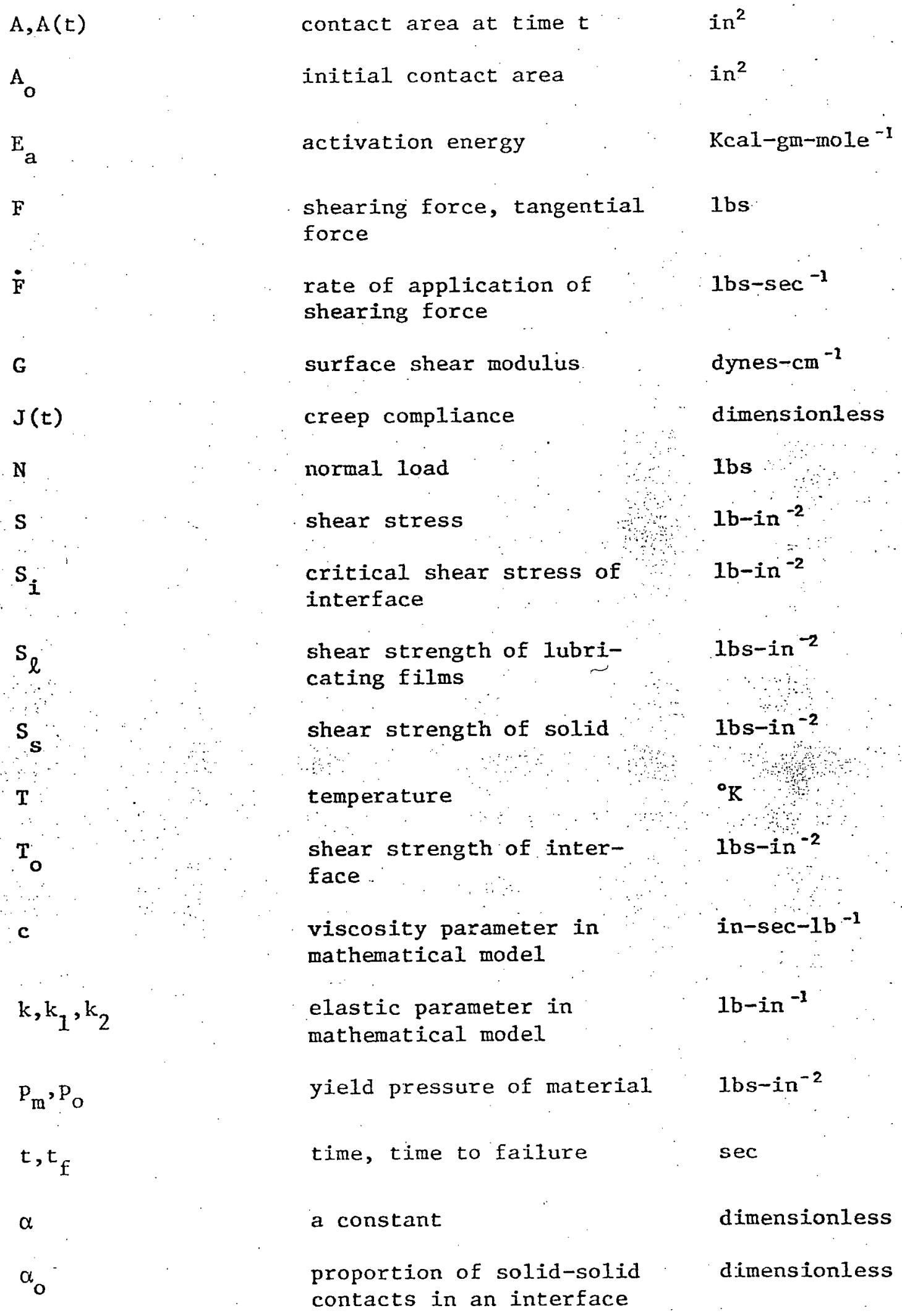


Symbol

Units

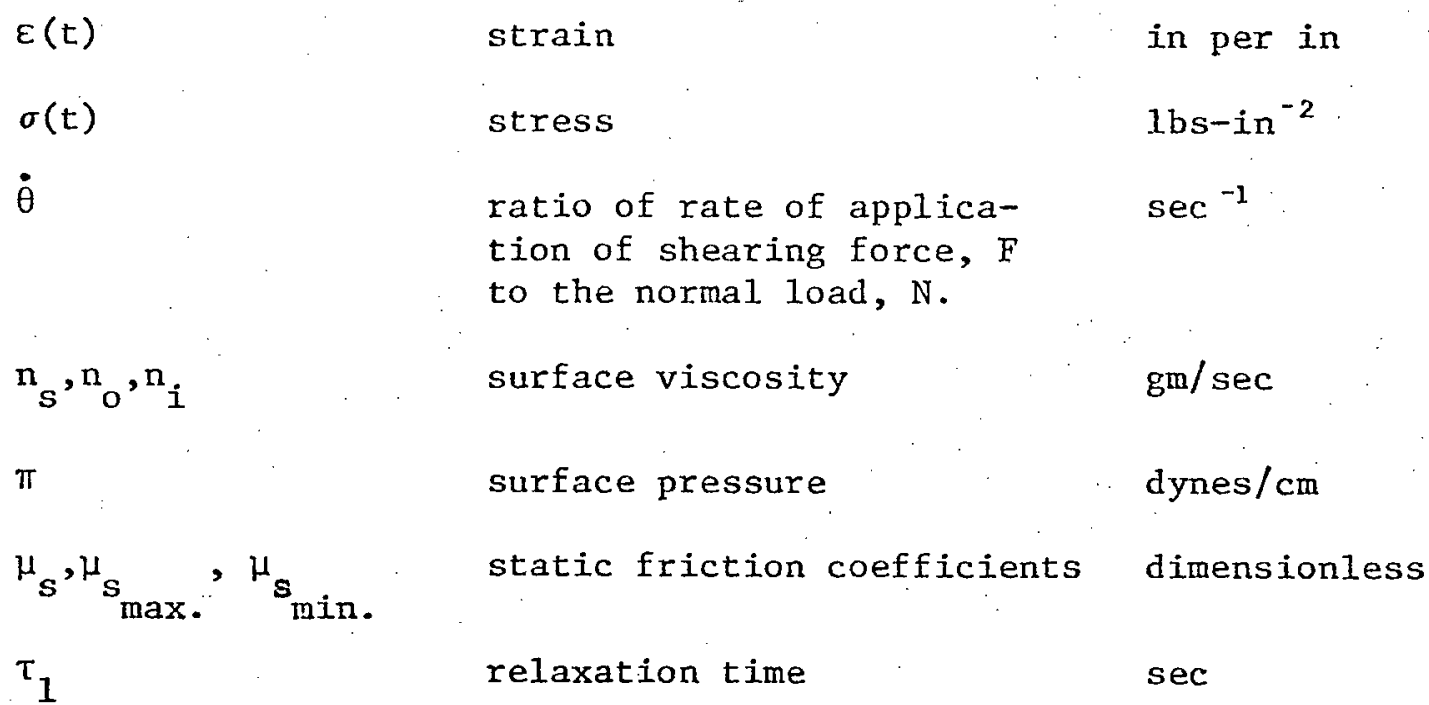




\section{INTRODUCTION}

Given the long history of friction-oriented research, to the casual observer it might appear that friction and lubrication are well understood. Certainly there is ample evidence to show that even early civilizations were aware of friction and knew enough about it to pour lubricating liquids in front of sledges and to use rollers to move heavy loads.

This same observer might also point to the extensive 18th Century work of a number of European scientists including Coulomb and Amontons. The three "fundamental laws of friction" - friction is proportional to load but independent of area and sliding velocity -arose from this work.

Unfortunately, friction is not the simple phenomenon that these laws would suggest and in certain situations the laws are not valid. Thus friction studies still continue, not just to define the exceptions to Amontons' 1aws, but because modern basic research seeks a much better understanding of the mechanisms of friction and its allied phenomena, lubrication, wear and adhesion than either these "laws" or the previous research can provide.

One reason why friction research has progressed so slowly is that suitable research tools have been developed only lately. Instruments such as the electron microscope and surface roughness indicators have aided friction research immensely in the short time they have been available.

In addition, the recent demand for sophisticated machinery capable of operating in space, at high terperatures, at high speeds or 
in adverse environments, has stimulated friction research. Although some of the research has been of an ad hoc type, carried out to provide immediate design data on different material combinations, systematic scientific work was also funded. The lack of design data pointed out the most serious shortcoming of friction research: an inability to predict friction values. This problem is particularly acute for systems operating under boundary lubricated conditions. One particular aspect of boundary lubrication, the static friction of metals coated with thin films, was examined in the present study.

Unlike hydrodynamic lubrication where the sliding surfaces are fully separated by a fluid film and the friction losses in the system are due to the viscosity of the fluid, boundary lubrication occurs when the separating film is only a few molecules thick. Slow sliding speeds and high loads may cause lubrication to be of the boundary lubrication type. In any case, the important fact is that the friction is determined by both the properties of the film and by the chemical and physical nature of the solids in contact.

When discussing boundary lubrication, it is usual to recognize two kinds of boundary friction -. static friction and kinetic friction. Static friction is defined as the force required to cause one of the contacting surfaces to begin to slide over the other. Kinetic friction is the force required to keep the surfaces sliding with a constant velocity.

Besides the usual sliding tests, static and kinetic friction can be studied using a type of friction-induced vibration called relaxation oscillations. From data obtained in this way, and from sliding tests, it was generally believed that static friction was time-dependent and that 
kinetic friction was velocity dependent. The explanation of the timedependency of static friction centered around the assumption that the actual contact area between the surfaces increased during the "static" loading time that preceeded gross slip. The contact area was thought to be increased by the creep induced by the normal load.

On critically examining the previous work, especially that of Johannes [19], it becomes obvious that the "time-dependent" explanation has some severe limitations. By interrupting a friction test for a given period of time, then restarting the test Johannes demonstrated that the effect of creep time on static friction was minimal. No significant increases in static friction were noted: This observation encouraged him to reject the older explanation and to consider a single asperity as a viscoelastic body so that the increase in contact area is due to the load rate sensitive deformation of that body when the shearing force is applied.

Obviously, time is involved in this model too, since the strain of a viscoelastic body is completely determined by its loading history, but it is also obvious that equal amounts of loading time and creep time cannot have the same effect on the contact area. This approach to static friction is very promising. The use of the loading rate parameter, $\dot{\theta}=\left[\frac{\text { rate of application of shearing force }}{\text { normal load }}\right]$ immensely simplifies reporting friction results. The use of elastic and viscous parameters indicates which properties of a friction couple might affect static friction.

Under boundary lubrication conditions, the friction is determined by the properties of the lubricating film and by the physical and chemical properties of the underlying solid. For a given solid, it is 
well known that surface films of both organic and inorganic compounds can marked1y affect its friction characteristics. The aim of the present work is to expand the theoretical base and to identify the origins of the observed viscoelastic effects in static friction. 


\section{HISTORICAL BACKGROUND}

Although friction phenomena have been studied for a long time, it is only during the last 60 years that real advances have been made in our understanding of the fundamental physical and chemical processes involved in friction and lubrication. A comprehensive review of every contribution would be impossible because of the volume of material generated and unnecessary because several good reviews [22] already exist. Because of this and because published papers can vary greatly, both in quality and applicability to a specific problem, this survey will be limited to a selection of papers considered to be most significant contributions to static friction research.

Most static friction research would fall into one of two general categories. In the first category, are studies concerned with the chemical and physical properties of surfaces. Research in this category is primarily concerned with the effects of surface films, both naturally occurring and deliberately applied, on friction. The experimental results of this research are used mainly for descriptive purposes. They tend to be more useful in predicting trends than in predicting actual boundary friction values. Because of efforts in this direction, however, the boundary-lubricating qualities of various organic and inorganic compounds have been widely recognized and successfully applied. At the same time, certain aspects of solid-state and friction welding and other processes which require high friction values, were clarified by this research.

In the second category, the research tends to be oriented towards the mathematical modelling of static friction. Placed in this category, is the large volume of published work dealing with the various 
aspects of friction-induced oscillations, time-dependent static friction and several attempts at modelling static friction. One of the goals of this type of research, besides a better understanding of friction, is to find a way to predict quantitatively boundary friction values.

The study of boundary lubrication was pioneered by Hardy [23] during the period 1918-1932. By 1920, both Hardy and Langmuir [56], a chemist, had recognized that small amounts of certain organic compounds were capable of reducing static friction. Langmirir was the first to demonstrate that even a single monolayer could lubricate a surface while Hardy was the first to prove that the molecular weight of an organic compound was an important factor in reducing static friction. His systematic investigation of a series of organic acids, alcohols, and straight chain paraffins, showed that increasing the chain length of an organic compound progressively decreased the static friction coefficient. Hardy went on to develop a theory of boundary 1ubrication in which adsorbed films of hydrocarbons played a major role. He visualized the opposing surfaces as being completely separated by adsorbed monolayers of the surfactant.

His theory further specified that there was no solid-solid contact over any part of the interface between the sliding solids and that the frictional resistance was solely due to the sliding of one boundary layer over the other.

The work of Hardy and Langmuir stimulated further research in boundary lubrication and in surfactant adsorption on solid surfaces. Their work generated an interest in the chemistry of adsorption, the structure and mechanical properties of surface films, the reactivity and topography of solid surfaces and the mechanics of surface-surface inter- 
action that continues today.

During the course of later research on boundary friction, Hardy's original theory was considered to be an over-simplification of actual friction conditions and it was subsequently modified. The current theories of boundary friction and Iubrication accept Hardy's idea that surface-active substance can adsorb onto surfaces to form low shear strength films but they also specify that a certain amount of solidsolid contact must be expected. This modification was largely the result of several studies of wear particles, surface damage and material transfer generated during sliding under boundary lubricated conditions [20] . Although the amount of wear is drastically reduced by the addition of surfactants, the fact that it still occurs strongly supports the argument that there is solid-solid contact through the film. The modified boundary lubrication theory attributes the friction force to the combined resistance of the solid-solid and film-film contact areas in the following way.

If $\alpha_{0}$ represents the proportion of solid-solid contacts in an interface having a total contact area $A$, then the friction force is $\bar{F}=A\left[\alpha_{0} s_{s}+\left(1-\alpha_{0}\right) s_{\ell}\right]$, where $s_{s}$ and $s_{\ell}$ are the shear strengths of the solid and the lubricating film respectively: Assigning an exact value to $S_{\ell}$ is difficult because the mechanical properties of lubricating films are difficult to measure. Akhmatov [17], Bailey and Courtney-Pratt [58] and Scruton [47] have been able to determine a number of properties, such as the shear modulus and the yield stress, of the films. Scruton's recent work on metallic soaps is particularly applicable to boundary friction because it shows that the shear strength of metal stearates is not a constant value but that it is strongly affected by the contact 
pressure. At $1 \mathrm{Kg} / \mathrm{mm}^{2}$, for example, the shear strength of calcium stearate is $.2 \mathrm{Kg} / \mathrm{mm}^{2}$, but when the contact pressure is $200 \mathrm{Kg} / \mathrm{mm}^{2}$, the shear strength is increased by a factor of 50 , to $10 \mathrm{Kg} / \mathrm{mm}^{2}$.

Another interesting aspect of boundary friction involves the chemistry of surfactant-solid reactions. Some organic compounds are much more effective as Iubricants than others and, on the other hand, some metals are more "reactive" than others. Bowden and Leben [16], Greenhil] [46], Schulman et al. [24] and many other investigators have used a variety of techniques to study the formation and effectiveness of boundary films. The general conclusions (specifically applicable to the present study) to be drawn from their work are:

1) Organic compounds can form oriented, highly structured films on metal surfaces. These films will reduce friction and wear. Depending on the metal involved, the surfactant can be chemically or physically adsorbed onto the surface. With specific reference to fatty acids, a particular fatty acid may react with the substrata to form a metallic soap or it may only be physically adsorbed. Also, depending on the surfactant concentration and the time of exposure, the surface may be covered with a partial monolayer, a monolayer or multilayers of adsorbed species.

2). The effect of heating the substrata is to change the structure of the film [20]. Over a critical temperature range, the static friction coefficient will increase markedly. Upon cooling, the effect is reversible [20]. For some metals, the critical temperature is approximately equal to the bulk melting point of the fatty acid; for others, the 
temperature corresponds to the bulk melting point of the appropriate organometallic'soap.

3) The mechanical disruption of the surface during a friction test can have two effects. If the surfactant is no longer available to the surface, then the lubricant layers are worn away by repeated testing and higher static friction values will result $[16]$.

In some situations, however, mechanical disruption of the surface assists in the formation of chemisorbed films of metal soaps [53]. Besides making fresh metal available to the surfactant, the disruption may cause the surfaces to be "mechanically activated". This is known as the Kramer effect and it enhances the chemical reactivity of a surface. Smith and Allan [52] and Smith and McGill [53] investigated this effect for a series of metals using n-nonadecanoic acid as the surfactant.

They estimated that the Kraner effect energy can supply about $23 \mathrm{~K} \mathrm{cal} / \mathrm{mole}$ so that metal-acid reactions that would not proceed spontaneously under normal circumstances may occur if the surface is disrupted while in contact with the surfactant. Therefore, repetitive runs across a surface might decrease the static friction coefficient. Alternately, machining a metal surface under a solution containing a surfactant would be a reasonable way of depositing a monolayer of metallic soap on that surface.

A favorite method of studying the lubricating effect of various organic acid monolayers and multilayers is to deposit them on a solid surface using the Langmuir-Blodgett technique. Many investigators have 
used this technique to study the effects of molecular weight, substrata temperature, contact pressure, etc., on film durability and on boundary friction. Because of extensive research on monolayers, it is now recognized that the pH and metal ion content of the water substrata determine the chemical composition and physical properties of the monolayer formed on its surface [32], [34], [41]. In view of the fact that these developments in monolayer science occurred after 1950, it is probably wise to interpret the earlier work on the friction of Langmuir-Blodgett monolayers with care. Prior to 1950, investigators could not have been fully aware of the effects that $\mathrm{pH}$ or small amounts of stray metal ions can produce. For example, it is possible that a monolayer designated as a stearic acid monolayer may in fact be a calcium stearate or copper stearate soap monolayer as these metallic ions are common imputities in water.

In the foregoing discussion of the chemical aspects of boundary friction, the distinction between static and kinetic friction has not been stressed. Actually there is a growing feeling that the distinction between them is artificial [2], [59]. It is generally agreed that a very sensitive velocity or displacement transducer, set up to measure any relative movement between two surfaces, would show that, beginning with the first application of tangential force, there is always a small. amount of displacement (of the order of micro-inches) between the surfaces. Thus, the surfaces are never in a true "static" contact situation. Recognizing this fact, some researchers [59] argue that the "static" friction coefficient is merely the local maximum on the "kinetic" friction curve.

On the other hand, the term static friction is useful because it does distinguish the force needed to get an object moving from rest 
from the force needed to keep it moving at a constant rate. Also, if one observes stick-slip oscillations, then the difference between static and kinetic friction becomes quite distinct: the slider appears to remain stationary for a period of time, then it is suddenly released as the elastic forces in the system overcome the "static" frictional forces at the interface. With regard to the present study, it is recognized, 1) that sma11 displacements "microslips" take place prior to gross sliding, and 2) that it is difficult to define exactly when the "static" period ends. However, the terms static and kinetic friction will still be used .

In the second part of this review of static friction research, attention will be focussed on the theories of static friction.

The simplest model, outlined by Bowden and Tabor [3] includes. the effect of boundary films in the following way.

Using a plastic flow criterion to describe the area growth of a contact region of original area $A_{0}$, that is subjected to a normal load $\mathrm{N}$ and tangential force $\mathrm{F}$ gives:

$$
\left|\frac{N}{A}\right|^{2}+\alpha\left|\frac{F}{A}\right|^{2}=\left|\frac{N}{A_{0}}\right|^{2}
$$

where $\mathrm{A}$ is the instantaneous area of contact. The normal pressure $\mathrm{p}$, at any instant is $\mathrm{p}=\mathrm{N} / \mathrm{A}$ and the shear stress is $\mathrm{S}=\mathrm{F} / \mathrm{A}$ so that:

$$
\mathrm{p}^{2}+\alpha \mathrm{s}^{2}=\mathrm{p}_{\mathrm{c}}^{2}
$$

This is the equation for junction growth [3]. Values of $\alpha$ have been determined for various metals [3]. Selecting $\alpha=9$ as a reasonable value, then:

$$
\mathrm{p}^{2}+9 \mathrm{~s}^{2}=\mathrm{p}_{\mathrm{o}}^{2}
$$


However, this equation does.not predict when junction growth will end. Bowden and Tabor arrive at a condition for macroscopic sliding of lubricated contacts by considering the interfacial material to have a critical shear stress, $S_{i}$, which is less than $S_{M}$, the critical shear stress of the metal. Therefore, if $S_{i}=\gamma S_{M}$, then the failure condition is:

$$
\mathrm{p}^{2}+9 \gamma^{2} \cdot \mathrm{s}_{\mathrm{M}}^{2}=\mathrm{p}_{\mathrm{o}}^{2}
$$

The yield pressure $p_{0}$ is related to the critical shear stress of metal: $\mathbf{p}_{\mathrm{o}}=3 \mathrm{~S}_{\mathrm{M}}[3]$. Therefore, gross sliding accurs when:

$$
p^{2}+9 S_{i}^{2}=9 S_{i}^{2} \gamma^{-2}
$$

or

$$
\frac{S_{i}}{p}=\frac{1}{3\left(\gamma^{-2}-1\right)^{1 / 2}}
$$

and the coefficient of static friction is:

$$
\mu=\frac{F}{W}=\frac{S_{i} A}{p A}=\frac{1}{3\left(\gamma^{-2}-1\right)^{1 / 2}}
$$

Considering $\gamma$ to be a measure of the "cleanliness" of the surfaces leads to the following conclusions:

1) if $\gamma=1$ (for "perfectly clean" surfaces where $s_{i}=s_{m}$ ), then $\mu=\infty$ and junction growth continues indefinitely;

2) if $\gamma=0: 8, \mu=0.45$ so that a small decrease in interfacial shear strength markedly affects the static friction. Although Bowden and Tabor's explanation clearly shows the critical influence of interfacial strength on the static friction coefficient, it fails to explain how the static friction coefficient could be influenced by the loading history. From studies of stick-slip type 
vibrations, a number of investigators have concluded that static friction is time dependent because creep takes place during the period before failure -- that is during "the static contact time".

At least five different groups have investigated this static friction-time phenomenon and three different relationships have been proposed:

1. $\mu_{s}=\mu_{k}+\frac{c t s}{d+t_{s}}$

2. $\mu_{s}=\mu_{k}+\left[\mu_{s \infty}-\mu_{k}\right]\left[1-e^{-c t s}\right]$

3. $\mu_{s}=\mu_{k}+a t_{s}^{b}$
Derjaguin, Push and Tolstoi (1957) [61].

Howe et al (1955) [62] and Kosterin and Kragelskii (1962) [63].

Rabinowicz (1940 [64] and Brockley and Davis (1965) [12] .

These semi-empirical relationships share two assumptions:

(1) that at zero time of stick $\left(t_{s}=0\right)$, the static coefficient of friction $\mu_{s}$ is equivalent to the kinetic coefficient, $\mu_{k}$, and (2) most important -- that the normal force, not tangential loading force, is the controlling factor in increasing the static friction coefficient.

Results of. model studies by Spurr [65] and Moore and Tabor [66] supported a "junction growth by creep" explanation of increased static friction with increasing static contact time. The common consensus was that the contact area increased with time under the action of the normal load. Hardness-time (the geometry of the indenter-surface interaction is similar to the asperity-surface interaction) and hardness-temperature experiments also supported the argument that the junction growth was due to creep: Atkins, Silverio and Tabor [67], Mulhearn and Tabor [68]. However, Johannes [19] conclusively demonstrated that the creep explanation had limited validity. By interrupting a static friction test 
during the static contact period and holding the friction couple under a constant normal and tangential load for various periods of time, he was able to show that no appreciable increase in static friction force occurred. From this, he concluded that the contact area growth due to creep was minima1. Further examination of the parameters involved in static friction tests led him to consider that a viscoelastic model of area growth would be more appropriate and that the tangential loading rate is an important parameter in determining static friction. Of course, time is involved in any viscoelastic model, but the equations of viscoelastic deformation clearly show that creep times and loading times are not equivalent in terms of the strains they produce. Using the KelvinVoigt viscoelastic model to explain area growth, Johannes was able to derive a mathematical model for static friction that fitted his experimental results reasonably well. This model will be discussed in greater detail in Chapter III.

Although Johannes was the first to apply a viscoelastic deformation model to static friction, a number of people had suggested that the contact area could grow in a viscoelastic fashion. Schredrov [30] and Seireg and Weiter [57], for example, were interested in the microslip that precedes gross slipping. Schredrov developed a mathematical model for microslip which assumed that the interface could be considered as a viscoelastic body. Unfortunately, he did not present any experimental proof of his theory. Seireg and Weiter used very sensitive displacement transducers to monitor the horizontal creep which occurred when they applied a constant tangential force to the interface for given periods of time. They found that a 3-parameter (Boltzmann) viscoelastic model described their results. 
It is interesting to consider further why static friction might show a viscoelastic type of behaviour. With specific reference to mild steel, there is some evidence that the strain rate can affect the deformation properties (fracture strength and ductility) of steels [69]. A rough calculation would show, however, that the net effect on static friction would be quite small - at low strain rates where the ductility is maximum, the fracture strength is at a minimum and vice versa.

When considering static friction studies, it is also interesting to note that all tests in which rate-effects were reported were conducted under boundary lubricated conditions. From previous investigations [16] it is known that organic compounds have a profound influence on static friction -- adding certain surfactants can even suppress stick-slip oscillations. Identifying the source of the viscoelastic behaviour could prove useful both in lubricant selection or in pressure welding and adhesion where maximum surface contact is desired.

Thus, part of the present study is a study of static friction under vacuum conditions (the best way of determining if the static friction of "clean" steel was rate dependent) and a study of the effect of oxides on metallic soap monolayers on static friction. The theoretical base was also expanded. 


\section{THEORY}

\subsection{Introduction}

As discussed in Chapter II, the time dependency of static friction has been a subject for a certain amount of experimental and theoretical work. Besides the static friction measurements themselves, other independent experimental evidence substantiates claims that the static friction coefficient for a given friction couple is not necessarily a constant. Different values for identical samples may be obtained because the breakaway force" (and thus the static friction coefficient) is determined by parameters which involve rate, or the duration of the pre-slip test period. For example, it is well known that a small amount of horizontal displacement or "microslip" of the order of 40 micro inches takes place during the "static" contact period which precedes slip. This microslip reflects the junction growth occurring at the interface. Shchedrov pointed out that the amount of microslip varies from one test to another and in his 1957 paper [30], he derived a function which predicted the amount of microslip. His derivation, involving specific contact pressure, tangential load and time of tangential loading was based on the assumption that the deforming zone behaved like a Kelvin-Voigt solid after its elastic limit was reached. More recently, measurements of the electrical resistance of the interface have shown that the metallic contact area is not a univalued function of the applied tangential load but for given normal and tangential loads, it is larger if the tangential load has been applied at a slower rate [15]. As might be expected, the static friction values paralleled this increase in metallic contact area of the various mathematical models that have been postulated 
to explain the observed $\mu_{s}$ behaviour, models which incorporate the well established concept of contact area growth and the idea that this area growth occurs because the interface deforms in a manner consistent with the deformation of a linear viscoelastic body seem to be the most promising. There is ample evidence that other people besides Shchedrov [30], Ahkmatov [17] and Seireg and Weiter [57] for example, recognized that the interface between contacting bodies might be capable of displaying viscoelastic behaviour. Also, as noted in the preceding sections, the effect of viscoelasticity on the friction of elastomeric materials has been well established [27] by experimental and theoretical work over the last 20 years. However, Johannes [19] was the first to apply this idea to the static friction of steel and to show that the appropriate variable involving time was $\dot{\theta}$, where:

$$
\dot{\theta}=\left[\frac{\text { rate of application of shearing force, } \dot{\mathrm{F}}}{\text { normal load, N }}\right] \text {. }
$$

The goal of the present work was to expand the theoretical base and to identify the origins of the observed viscoelastic effects in static Eriction.

Johannes did not assign elastic or viscous properties to any specific components of the interface but instead viewed it as a unit undergoing deformation because of the shearing force, F. This unit responds to the shear stress as a linear, 2-parameter viscoelastic substance (a Kelvin-Voigt solid) which has an ultimate shear strength per unit area represented by a Prandt1-type element. The model he used is shown in Figure 1. While a Kelvin-Voigt model is the simplest mechanical model which describes solid-like behaviour and it represents some substances (cork and rubber) reasonably we11, a 3-parameter model has been found to provide a much better approximation to the behaviour of 
most materials. It is regarded as the "general linear solid" model. The Kelvin-Voigt model is a special case of this general 1inear solid model.

In the absence of any other information such as creep test or relaxation test data (materials of the general linear solid type show limited stress relaxation behaviour during long loading times whereas Kelvin-Voigt solids do not), choosing which model best represents the viscoelastic properties of the interfaces considered here is difficult. When the experimental data are analyzed and numerical values are assigned to each of the elastic and viscous components of the interface, the choice between models will be easier. In the interim, both models were considered.

\subsection{Models for Static Friction}

When the 2 samples are first placed together, $N$ establishes the initial contact area $A_{0}$, between the surfaces so that $A_{0}=\left(N / p_{m}\right)$ where $\mathrm{p}_{\mathrm{m}}$, the local plastic yield pressure, has a value of about 3 times the yield stress [3]. This area is made up of the numerous small, discrete areas where opposing asperities méet, see Figure 2(a). $\mathrm{F}$ is applied perpendicular to $\mathrm{N}$, and at $\mathrm{t}=0, \mathrm{~F}=0 . \mathrm{F}$ is applied at a constant rate, $\dot{F}$, so that $F(t)=\dot{F} t$. The corresponding stress on the interface is $\sigma(t)=\left(\dot{F} t / A_{0}\right)$ as shown in Figure 3. The effect of $\mathrm{F}$ on each discrete area is to cause that area to grow, increasing the original length in the direction of $F$. The extent of the area growth is determined by the appropriate viscoelastic deformation law defining $A(t)$. For a given normal load $N$ over a range of rates $\dot{F}$, the area growth at failure would resemble that shown in Figure 2(b). $\mathrm{F}$ is applied at a constant rate $\dot{\mathrm{F}}$ until the shear strength 
per unit area, $\mathrm{T}_{0}$, of the interface is reached and failure (gross movement) results at time $t_{f}$. Note that in this model it is assumed that $\mathrm{T}_{0}$ does not change with $\dot{\mathrm{F}}$, so that the shear strength per unit area remains constant across the full range of $\dot{\mathrm{F}}$ as shown in Figure $2(\mathrm{~b})$. Therefore, any increase in the static friction coefficient would be due only to increases in the contact area.

Thus, the problem is to determine $\mu_{s}$ in terms of $\dot{\theta}$ given the type of viscoelastic deformation expected. The following definitions and functions are used for both the Kelvin-Voigt and general linear solid models:

$$
\begin{gathered}
\mathrm{A}_{\mathrm{o}}=\frac{\mathrm{N}}{\mathrm{p}_{\mathrm{m}}} \\
\dot{\theta}=\frac{\dot{\mathrm{F}}}{\mathrm{N}} \\
\mu_{\mathrm{s}}=\frac{\mathrm{F}_{\mathrm{fina1}}}{\mathrm{N}}=\frac{\dot{\mathrm{F}}_{\mathrm{f}}}{\mathrm{N}} \\
\sigma(\mathrm{t})=\frac{\dot{\mathrm{F}}}{\mathrm{A}_{\mathrm{o}}} \mathrm{t}=\frac{\sigma_{\mathrm{f}}}{\mathrm{t}_{\mathrm{f}}} \mathrm{t} \\
\sigma_{\mathrm{f}}=\frac{\mathrm{F}_{\mathrm{fina}}}{\mathrm{A}_{\mathrm{o}}}=\frac{\dot{\mathrm{F}}_{\mathrm{f}}}{\mathrm{A}_{\mathrm{o}}}=\mathrm{T}_{\mathrm{o}} \\
\mathrm{T}_{\mathrm{o}}=\text { shear strength per unit area of the interface }
\end{gathered}
$$

The criterion for failure (gross slipping) is:

$$
T_{0} A_{o}\left(1+\varepsilon\left(t_{f}\right)\right)=\dot{F} t_{f}
$$

For a linear viscoelastic body under general loading, $\varepsilon(t)$ is found using an hereditary integral in the following form [31]: 


$$
\varepsilon(t)=\sigma(t) J(0)+\int_{0}^{t} \sigma\left(t^{\prime}\right) \frac{d J\left(t-t^{\prime}\right)}{d\left(t-t^{\prime}\right)} d t^{\prime}
$$

where $J(t)$, the creep compliance, is the strain per unit area due to the applied applied unit stress. It describes completely the stress-strain behaviour of a given material up to the failure point.

\subsubsection{Kelvin-Voigt Body}

For a 2-parameter solid, where the viscoelasticity is represented by a spring and dashpot, if $k$ is the elastic modulus of the spring member and $c$ is the viscosity of the dashpot, the creep compliance is:

$$
J(t)=\frac{1}{k}\left[1-e^{-\frac{k}{c} t}\right]
$$

The ratio $\mathrm{c} / \mathrm{k}$ is called the retardation time for a Kelvin-Voigt body. After substituting equation (4) into equation (3) and integrating, it is found that the increased area at slip is:

$$
A_{0} \varepsilon\left(t_{f}\right)=\frac{\sigma_{f}}{t_{f} k^{2}}\left[k t_{f}-c+c e^{-\frac{k}{c} t_{f}}\right]
$$

From the failure condition in equation (2) and the identities in (1), $\mu_{s}$ is obtained as a function of $\dot{\theta}$ and the physical properties $\mathrm{T}_{\mathrm{o}}, \mathrm{P}_{\mathrm{m}}$ of the interface:

$$
-\frac{\mathrm{k}}{\mathrm{p}_{\mathrm{m}}}+\dot{\theta} \frac{\mathrm{c}}{\mathrm{k}}\left[1-\mathrm{e}^{-\frac{\mathrm{k}}{\mathrm{c}} \frac{\mu_{\mathrm{s}}}{\dot{\theta}}}\right]+\left[\frac{\mathrm{k}}{\mathrm{T}_{\mathrm{o}}}-1\right] \mu_{\mathrm{s}}=0
$$

In examining equation (6) further, it is found that:

1) the $\mu_{s}-\dot{\theta}$ curve exhibits upper and lower asymptotes 
corresponding to very small and very large values of $\dot{\theta}$ respectively. The upper asymptote is:

$$
\frac{\mathrm{T}_{\mathrm{o}}}{\mathrm{p}_{\mathrm{m}}}\left[\frac{\mathrm{k}}{\mathrm{k}-\mathrm{T}_{\mathrm{o}}}\right]=\mu_{\mathrm{s} \max } \text {. }
$$

while the lower asymptote is $\mu_{\mathrm{s} \text { min. }}=\left(\mathrm{T}_{\mathrm{o}} / \mathrm{p}_{\mathrm{m}}\right)$. These values are independent of the viscosity parameter $c$.

2) if $c$ changes, the retardation time, $c / k$, changes and the $\mu_{s}$ vs $\dot{\theta}$ curve may be shifted to the right or to the left, but it remains between the boundaries described by the upper and lower asymptotes:

$$
\text { lower asymptote: } \frac{\mathrm{T}_{\mathrm{o}}}{\mathrm{p}_{\mathrm{m}}}=\mu_{\mathrm{s} \text { min. }}
$$

and

$$
\text { upper asymptote: } \frac{k T_{o}}{p_{m}\left(k-T_{o}\right)}=\mu_{s \max }
$$

3) if there is no viscosity $c / k \rightarrow 0$ and the $\mu_{s}$ vs $\dot{\theta}$ curve becomes a straight line lying on the upper asymptote. From (5), the growth in area is $A_{o} \varepsilon(t)=\left(\sigma_{f} / k\right)=$ $\left(\mathrm{T}_{\mathrm{o}} / \mathrm{k}\right)$ in this case. The general form of the $\mu_{s}$ vs $\dot{\theta}$ curve which this model predicts for a value of $c / k>0$ is shown in Figure 5.

\subsubsection{3-parameter General Linear Solid}

For a 3-parameter solid where $k_{1}, k_{2}$ are the elastic parameters, and $\mathrm{c}$ is the viscosity parameter (see Figure $4(\mathrm{~b})$ ), the creep compliance is [31]: 
$J(t)=\frac{1}{k_{1}+k_{2}} e^{-\left[\frac{k_{1} k_{2}}{k_{1}+k_{2}}\right] \frac{t}{c}}+\frac{1}{k_{1}}\left[1-e^{\left.-\left[\frac{k_{1} k_{2}}{k_{1}+k_{2}}\right] \frac{t}{c}\right]}\right.$

The ratio $\left[\frac{k_{1}+k_{2}}{k_{1} k_{2}}\right] c$ is known as the relaxation time. After substituting equation (7) into (2), the failure condition, and using the identities given in ( 1 ), the $\mu_{s}$ vs $\dot{\theta}$ curve has the form:

$$
-\frac{k_{1}}{p_{m}}+\left[\frac{k_{2}}{k_{1}+k_{2}}\right] \tau \dot{\theta}\left[1-e^{-\frac{\mu_{s}}{\dot{\theta} \tau}}\right]+\left[\frac{k_{1}}{T_{o}}-1\right] \mu_{s}=0 \ldots
$$

where:

$$
\tau=\left[\frac{k_{1}+k_{2}}{k_{1} k_{2}}\right] c
$$

This $\mu_{s}$ vs $\dot{\theta}$ curve also has an upper and lower asymptote for $\dot{\theta} \ll 1$ and $\dot{\theta} \gg 1$. Also, it has the same general shape as the $\mu_{s}$ vs $\dot{\theta}$ curve for the 2-parameter Kelvin-Voigt solid shown in Figure 5 . In this model, the upper asymptote is determined by $k_{1}, T_{0}$ and $\mathrm{p}_{\mathrm{m}}$ as follows:

$$
\begin{gathered}
\text { from (8) for } \dot{\theta} \ll 1: \\
\mu_{\mathrm{s} \max .}=\frac{\mathrm{T}_{\mathrm{o}}}{\mathrm{p}_{\mathrm{m}}}\left[\frac{\mathrm{k}_{1}}{\mathrm{k}_{1}-\mathrm{T}_{\mathrm{o}}}\right]
\end{gathered}
$$

The lower asymptote, $\mu_{\mathrm{s} \text { min. }}$ is also found from (8) for $\dot{\theta}>1$ :

$$
\mu_{\text {s min. }}=\frac{T_{o}}{p_{m}}\left[\frac{k_{1}+k_{2}}{k_{1}+k_{2}-T_{o}}\right]
$$

Note that if $k_{2} \gg T_{0}$, then $\mu_{s} \min . \simeq\left(T_{0} / p_{m}\right)$. 


\subsection{The Non-dimensional $\mu_{g}$ vs $\tau *$ Plot}

Consideration of the role of $c$ and $k_{1}, k_{2}$ in determining the $\mu_{s}-\dot{\theta}$ curve leads to the formation of a more general prediction of static friction results.

If the upper and lower asymptotes were fixed and $\mathrm{c}$ was varied independently, a family of $\mu_{s}$ vs $\dot{\theta}$ curves would result for both models. This is illustrated in Figure 6 . It is now obvious that by making the abscissa, $\dot{\theta}$, dimensionless the family of curves will collapse onto a single general curve, $\mu_{s}$ vs $\tau_{3}{ }^{*}$. If this reasoning is applied to the present study, it is obvious that if the test interfaces do follow one of the viscoelastic laws of deformation, and the $\mu_{s}-\dot{\theta}$ curves all have the same upper and lower asymptotes but different relaxation times, then the experimentally determined $\mu_{s}-\dot{\theta}$ values must fall on this general curve.

If the upper and lower asymptotes are set at the general values $\mathrm{x}$ and $\mathrm{y}$ respectively, then equation (6) becomes:

for the Kelvin-Voigt-Prandt1 solid:

$$
\mathrm{a}+\frac{\mathrm{c}}{\mathrm{k}} \dot{\theta}\left[1-\mathrm{e}^{-\frac{\mathrm{k}}{\mathrm{c}} \frac{\mu_{\mathrm{s}}}{\dot{\theta}}}\right]+\mathrm{b} \mu_{\mathrm{s}}=0
$$

and equation (8) becomes for the general linear solid-Prandt 1 model:

$$
\begin{gathered}
a+\dot{\theta} \tau\left[1-e^{-\frac{\mu_{s}}{\dot{\theta} \tau}}\right]+b \mu_{s}=0 \\
\tau=\left[\frac{k_{1}+k_{2}}{k_{1} k_{2}}\right] c
\end{gathered}
$$

where:

From (9) and (10), it is obvious that a family of $\mu_{s}$ vs $\dot{\theta}$ 
curves results given different $c$ values (and therefore different $\tau$ and $c / k$ ratios). Furthermore, this family of curves collapses to a single genera1 $\mu_{s}-\tau_{3} *$ curve by:

1) multiplying $\dot{\theta}$ by $c / k$ for the Kelvin-Voigt-Prandt 1 solid;

2) multiplying $\dot{\theta}$ in the general linear solid-Prandt 1 model case by $\tau$.

Then, for example, in the general linear solid case, all data for interfaces having the same asymptotes $\mathrm{x}$ and $\mathrm{y}$ but different $\tau$ values should collapse if the data are plotted, not on the usual $\mu_{s}, \dot{\theta}$ axes but on $\mu_{s}, \tau_{3}{ }^{*}$ axes where $\tau_{3}{ }^{*}=\tau \dot{\theta}$ as shown in Figure 7 .

\subsection{Changing the Relaxation Time of an Interface}

The question now arises as to whether or not the properties of an interface can be changed so as to change its relaxation or retardation time. Very little is known about how organic compounds affect the rheology of the air/solid interface. In contrast, the effect of these compounds on the surface viscosity of the air/water interface is well known. A great deal of experimental data has been published along with a limited amount of theoretical work [47]. Although the available data must be interpreted with care because of certain experimental variations in the surface viscosity measurements and because extrapolating information gained by studying air/water systems to air/ solid systems has limited validity, it is possible to draw several general conclusions from this work. Considering only carboxylic acids and their metallic soaps:

a) The surface viscosities of carboxylic acid monolayers 
such as stearic acid and oleic acid are only approximately Newtonian. They have been shown to exhibit a small amount of viscoelasticity at surface pressures greater than 20 dynes per cm [45]. Kimizuka [32] found that stearic acid spread on an acidic subphase $\left(\mathrm{T}=20^{\circ} \mathrm{C}\right.$, area per molecule $=$ $20.5 \AA^{2}$ ) behaved as a Voight solid having an apparent surface viscosity, $n_{s}$, of $0.13 \mathrm{gm}$ per second, and a surface shear modulus, $G$, of $8.4 \times 10^{-3}$ dynes per $\mathrm{cm}$.

The surface rheology is sensitive to surface pressure, temperature, $\mathrm{pH}$ and the cation content of the substrate as well as shear rate. If these variables are kept constant and the chain length of the organic species is increased, then the surface viscosity, (as one measure of film properties) would be expected to increase because of increased interchain cohesion. Experimental data from Gaines [45] supports this statement. Palmitic acid $\left(\mathrm{C}_{15} \mathrm{H}_{31} \mathrm{COOH}\right)$ has a surface viscosity of $1.8 \times 10^{-3} \mathrm{gm}$ per second, $\left(25^{\circ} \mathrm{C}, \pi=15\right.$ dyries per $\mathrm{cm}, 0.01 \mathrm{~N}$ acid) while its $\mathrm{C}_{20}$ homologue, $\mathrm{C}_{19} \mathrm{H}_{39} \mathrm{COOH}$ (arachidic acid), has a surface viscosity 15 times as large $\left(3 \times 10^{-2} \mathrm{gm}\right.$ per second) at the same temperature and surface pressure. The effect of the double $[-c=c-]$ bond or of side chains would be to decrease the surface viscosity. Oleic acid, for example $\left(\pi=15\right.$ dynes per $\mathrm{cm}, 17^{\circ} \mathrm{C}$, $\mathrm{pH}=2.0$ ) has $\eta_{\mathrm{s}}=1.43 \times 10^{-4}$ gm per second compared to $1.5 \times 10^{-3} \mathrm{gm}$ per second for stearic acid under similar conditions. The presence of the cis-double bond 
is responsible for the significantly decreased viscosity.

b) More interesting to this study is the effect of metal ions on surface rheology at the water/air interface. Depending on $\mathrm{pH}$ of the substrate and the metal ion content, the effect can be marked. Adding $\mathrm{Al}^{3+}$ to an acidic substrate at $\mathrm{pH}=5.5\left(\mathrm{~T}=35^{\circ} \mathrm{C}\right)$ causes stearic acid films to assume near-solid properties. Their response to shear stresses has been analyzed in terms of a 4-parameter viscoelastic model [40] by Motomura and Matuura. If the area per molecule is kept at approximately $33 \AA$, the measured values of the Burger's body are of the order of $\mathrm{n}_{0}, \mathrm{n}_{1}=5 \times 10^{5}$ gm per second, $G_{1}=500 \mathrm{gm}$ per second, $\mathrm{G}_{\ell}=100 \mathrm{gm}$ per second, where $\mathrm{n}_{1}, \mathrm{G}_{1}$ are the parameters of the Voigt element of this 4-parameter model. At appropriate $\mathrm{pH}$ values, other ions such as $\mathrm{Ca}^{++}, \mathrm{Ba}^{++}$give metal stearate films which are known to behave as KelvinVoight bodies while $\mathrm{Fe}^{3+}, \mathrm{Cu}^{++}, \mathrm{Ca}^{++}$give stearate films which have the characteristics of Maxwel1 bodies. Some ions, $\mathrm{Na}^{+}, \mathrm{K}^{+}, \mathrm{NH}_{4}^{+}$do not form solidified films with fatty acids under these conditions [47].

A further complication of soap formation in monolayers is that the ability. of metal ion to form a viscous solidified film with an organic acid is dependent on steric factors [35]. Oleic acid, for example, has nearly the same molecular weight and chain length as stearic acid but the presence of the double bond at the $\mathrm{C}_{9}$ position prevents $\mathrm{Ca}^{++}$ions from forming a complex network with the oleic acid molecules. Thus, it would be expected that, unlike stearic acid, 
which will form a highly structured solid-like soap film with $\mathrm{Ca}^{+}{ }^{+}$ions, the viscosity of oleic acid monolayers would be relatively unaffected by $\mathrm{Ca}^{++}$ions even though soap formation still takes place. The work of Deamer and Cornwell [36] confirms this expectation. Earlier work by Durham [35] shows that ethyl groups in the $\alpha$-positions of branched chain fatty acids may also provide enough steric hindrance to impair. film solidification by $\mathrm{Ca}^{++}$ions.

It is difficult to apply these observations directly to the present situation where monolayers of metallic soaps are deposited on the solid surface and then tested for friction properties. However, it is possible to draw some general conclusions since it is expected that the deposited monolayers will retain the same internal structure as they possessed at the air/water interface. Therefore, it is to be expected that the $\mu_{s}-\dot{\theta}$ curve for the less viscous ca-oleate film will lie to the right of the corresponding curves for Ca-stearate because the relaxation time for a Ca-oleate monolayer should be smaller than that of Ca-stearate.

Predicting the relative positions of the films of the stearic and oleic acid soaps deposited at pH 4 is more difficult as relevant rheological information is scarce. Spink and Sanders [41] have shown that at low $\mathrm{pH}$ values $(\mathrm{pH}=2.7)$ basic iron hydroxide ions in the aqueous substrata will form solidified films with fatty acids. In the present work, the source of iron contamination is the specimen itself as no $\mathrm{Fe}$ ions were deliberately added. Unfortunately, no detailed information on surface rheology for either of the basic iron soaps was available so that it was not possible to predict the static friction results. 


\subsection{The Effect of Temperature on $\tau$ Values}

From pressure-area $(\pi-A)$ curves and from the surface viscosity studies of numerous monolayers, it is well known that temperature changes dramatically affect the structure and the rheological properties of monolayers at the air/water interface. Furthermore, early work in the friction and wear area clearly indicated that increases in temperature seriously impair the effectiveness of monolayers as lubricants. At certain characteristic temperatures, lubrication breaks down completely [3].

Direct information on the structure of deposited films has been obtained by electron microscopy and electron diffraction studies [49]. Films of fatty acid soaps have a definite structure and the effect of raising the temperature is to destroy the order in the film. For example, electron diffraction patterns will fade as the temperature of the sample is raised because the molecules become disoriented (the monolayer "melts") and because some vaporization occurs.

More extensive studies of surface diffusion have shown that molecules of a deposited film are capable of moving over a solid substrata if the temperature is high enough. Molecules of stearic acid from stearic acid films deposited on mica sheets [48] can diffuse over the surface even at room temperature and at higher temperatures they will move with relative freedom across the surface. The activation energy for the surface diffusion has been measured at $8.6 \mathrm{~K}$ cal/gm atom compared to a value of $21 \mathrm{k} \mathrm{cal} / \mathrm{gm}$ atom for desorption of stearic acid from platinum.

One result of surface diffusion at higher temperatures is illustrated by an experiment in which a mica surface, covered with a 
stearic acid monolayer, was heated to $35^{\circ} \mathrm{C}$ and held at that temperature for 30 minutes [48]. The increased thermal agitation coupled with the elapsed time, enabled a significant number of molecules to leave their original positions in the film and to migrate across the surface and accumulate in shallow scratches in the surface.

How would small increases in surface temperature affect the $\mu_{\mathrm{s}}-\dot{\theta}$ curves for monolayer covered steel surfaces?

Considering equations (9) and $(10), \mathrm{p}_{\mathrm{m}}$, the mean yield pressure of the interface is established by the substratum and is approximately equal to $3 Y$, where $\mathrm{Y}$ is the yield point of the substratum. The hardness of mild steel is affected by high temperature but remains constant up to at least $200^{\circ} \mathrm{C}$, so that $\mathrm{p}_{\mathrm{m}}$ would be unaffected by small temperature changes. $T_{0}$, the shear strength of the interface, which is related to $\mathrm{p}_{\mathrm{m}}$, would also remain at approximately its room temperature value for small temperature increases.

The relaxation or retardation time, $\tau$, of a viscoelastic. material is, however, strongly influenced by temperature so that $\tau=\tau(T)$. Generally, $\tau$ decreases with increasing temperature. Experimental work [27] has shown that the relaxation time of viscoelastic materials obeys:

$$
\log \tau(T)=-\beta T+a
$$

so that,

$$
\tau(T)=a e^{\frac{1}{\beta T}}
$$

Further theoretical work [47] has indicated that:

$$
\tau(T)=A e^{\frac{E}{R T}}
$$


where $E_{a}$ is a characteristic activation energy and $R$ is the gas constant, approximately, 2 cal/mole. Therefore, equations (9) and (10) can be modified using (13) to give a general $\mu_{s}-\dot{\theta}-T$ relationship. This relationship will be valid only for a limited temperature range because of phase changes in the monolayer and desorption.

Unfortunately, most observations of the friction-temperature relationship yield very little quantitative information that can be extended to cover specific friction couples but some general effects are known:

(1) If the metallic substratum is sufficiently reactive, then a metallic soap will be formed when the monolayer is deposited. As the temperature is raised, the friction coefficient remains reasonably constant until the substratum reaches a temperature which is approximately equal to the bulk melting point of the metallic soap. At this point, the friction coefficient will increase by a factor of about 10 and there is a corresponding increase in surface damage. This indicates a phase change in the monolayer and thus would indicate that the viscoelastic model may no longer be valid.

(2) If the substratum is unreactive or a monolayer of a metallic soap is deposited without strong adhesion, then the friction coefficient shows a very large increase. when the temperatuxe of the substratum reaches the bulk melting point of the acid or the deposited metallic soap. Bowden [3] also reports that temperature effects in this temperature range are reversible. This indicates a phase change in 
the monolayer and not decomposition. At higher temperatures, though, desorption of the monolayer occurs and the friction coefficient will remain high even if the temperature is lowered.

Obviously then the $\mu_{s}-\dot{\theta}-T$ relationship developed is applicable only to temperature ranges below the melting point of the monolayer. 
IV. EXPERIMENTAL APPARATUS AND EXPERIMENTAL PROCEDURE

\subsection{Apparatus}

Three main pieces of equipment were required for the investigation. The first item is a device which measures the static friction over a range of $\dot{\theta}$ values, the second piece of equipment is the vacuum system and the third is the equipment needed for applying monolayers of organic acids to the test specimens by the abrasion technique and by the Langmuir-Blodgett technique. The vacuum system and friction measuring apparatus is shown in the photograph in Figure 8.

\subsubsection{Measuring the Static Friction as a Function of $\dot{\theta}$}

The apparatus for measuring $\mu_{s}$ and $\dot{\theta}$ is relatively simple. A unit was required which could apply, measure and record 3 parameters: $N$, the normal force; $F$, the shearing (lateral or tangential) force and $\dot{F}$ the rate of application of the shearing force. $N$ and $F$ were applied separately by Bimba hydraulic cylinders, and were measured by recording the displacement of calibrated strain rings on a dual channel Brush chart recorder.

The design of the complete unit was complicated by the restriction that some of the friction tests had to be conducted in vacuum. The final design is shown in Figure 9. This design was chosen partly because it requires only one bellows feedthrough unit, $B$, into the vacuum system. This bellows feedthrough, a 4" diameter, 6" displacement linear unit was specially constructed so that the feedthrough shaft moves freely through a $1-1 / 4$ " opening in the mounting flange. Unlike conventional feedthrough units, there was no frictional resistance due to rubbing of the shaft against the inner wall of the nounting flange or against a positioning sleeve. 
The samples are $A_{1}$ and $A_{2}$ (see Figure 9). $A_{2}$ is kept stationary throughout a test as it is fixed to a stationary support bar which is itself welded to the bell jar. $A_{2}$ has a restricted amount of movement in the $x, y$ direction for adjustment purposes. $A_{1}$, the upper sample, is mounted on the extension to the feedthrough shaft, $S$, and is the moving specimen. The rest of the assembly is mounted on a machine table which allows up to $10^{\prime \prime}$ of $\mathrm{x}$ and $\mathrm{y}$ movement for correctly positioning $A_{1}$ on $A_{2}$. The machine table is fixed to a rigid support table which is anchored to a concrete floor.

$A_{1}$ and $A_{2}$ are loaded together in the normal direction by applying an upward force $\mathrm{W}_{1}$ at $\mathrm{Y}$ with the hydraulic cylinder $\mathrm{H}_{2}$. Since the bar is pivoted at $x_{1}, A_{1}$ is forced onto $A_{2}$. The magnitude. of this normal force, $N$, is known as $W$, is measured by the calibrated strain ring $R_{2}$ and the dimensions of the bar are known. With this arrangement, it was possible to measure $N$ to less than $1 / 21 \mathrm{~b}$. Since $\mathrm{N}=50$ lbs., then $\mathrm{N}$ could be measured to $\pm 1 \%$.

The horizontal force $F$ was applied to the $A_{1}, A_{2}$ interface by the hydraulic cylinder $\mathrm{H}_{1}$. The magnitude of $\mathrm{F}$. was constantly monitored by recording the output of the strain ring $R_{1}$ against a time base using the Brush chart recorder. The rate of application of $F, \dot{F}$, is controlled by restricting the flow of fluid from the hydraulic cylinder with a Nupro microvalve. $\dot{\mathrm{F}}$ varied from .005 to 25 1bs. per sec. which was sufficient to cover $\dot{\theta}$ values from .0001 to $0.5 \mathrm{sec}^{-1}$. The static friction force, $F_{S}$, was found from the F-t chart by finding the force at which $F$ vs $t$ was no longer a straight line. When the $F-t$ curve is no longer a straight line, then $A_{1}$ is sliding over $A_{2}$. It is well known that even at very small values of $F$ - 
"microslip" - that is sliding movements of the order of 10 micro inches or so - are taking place but $\mathrm{F}_{\mathrm{S}}$ was defined as the force where sudden appreciable movement (of approximately 150 micro inches) of $A_{1}$ over $A_{2}$ occurs.

Since the minimum value of $F$ measured was 10 1bs. and $F$ could be measured to less than $1 / 4 \mathrm{lb}$., the maximum error in measuring $\mathrm{F}$ was $\pm 2.5 \%$.

The two strain rings used to measure $\mathrm{N}$ and $\mathrm{F}$ were used in conjunction with two E11is Associates Mode1 BAM-1 bridge amplifiers. The output from the amplifiers was fed to a dual channel Brush recorder so that $\mathrm{N}, \mathrm{F}, \dot{\mathrm{F}}$ could be constantly monitored during each test. The calibration of the ring-amplifier-recorder system was checked before, after, and at 1 hour intervals during each set of runs. This was necessary because the BAM units are subject to a certain amount of D.C. drift over long periods of time.

The hydraulic circuit used to control the two Bimba cylinders is shown schematically in Figure 10. The pump, accumulator, and reservoir section of the hydraulic system was identical to that used by Johannes [19]. The pressure was supplied by a tilted axis pistontype constant displacement pump driven by an electric motor. A pressure relief valve regulated the output pressure of the pump. The pump was used intermittently to pressurize the accumulator which was used on the blow-down principle thus providing a pulsation free source of constant pressure sufficient for several tests. Since the accumulator pressure could be varied from approximately 600 to 1500 psi, the range of flow rates through the micro valves was fairly extensive. 


\subsubsection{Vacuum System}

One essential part of this investigation involved separating the friction characteristics of the steel itself from those of adsorbed films on the steel. Basically, a unit suitable for this investigation would prevent oxidation and general contamination for the duration of several runs. The system selected provided such an environment. It also provided an analysis of the environment in the test chamber in terms of the concentration of gases remaining after the desired vacuum has been achieved.

Another primary consideration was the preparation of suitable test specimens. The investigation thus raised the inevitable questions about "what is a clean surface?" and "how can a clean surface be achieved?". These questions will be discussed further in the Procedures section during the description of sample preparations.

The ultra-high vacuum system used in this work was a bakeable, all metal unit capable of reaching $5 \times 10^{-11}$ torr in 15 hours with a 2. hour bake-out at $250^{\circ} \mathrm{C}$. Since the rough pumping (atmosphere to $10^{-3}$ torr) is produced by cryogenic pumping and the high and ultra high vacuum is produced by Titanium gettering and ion pumping, there is no possibility of organic contamination due to back streaming of pumping oils. This is an important consideration in lubrication-oriented research.

To determine which gases are present when the desired vacuum level is reached a residual gas analyzer (RGA) (a quadrupole-type mass spectrometer) was purchased. (Typically interest centres on the presence of any organic matter.) The probe section of the RGA was mounted on a $21 / 2^{\prime \prime}$ flange between the sample and the ion pump section. 
The RGA has a mass range of $1-250$ amu and a sensitivity of $1 \times 10^{-14}$ torr partial pressure for $\mathrm{N}_{2}$. It was also used as an accurate pressure gauge and as a very sensitive leak detector. The detailed specifications of the vacuum system and the RGA form Appendix I.

\subsubsection{Deposition of Monolayers}

Part of the study required that monolayers of organic acids or their soaps be deposited on the steel specimens. The two different methods of applying monolayers and the equipment required for each are described below. The first method used the Langmuir-Blodgett technique whereby a monolayer of an organic acid soap was first formed on an aqueous surface and then transferred to the solid substrate. The second technique employed was an adaptation of a machining method used by Smith and McGill [53]. The metal surface was machined under a dilute solution of organic acid in an inactive (non-polar) solvent. As the fresh metal was exposed by the cutting tool, the organic acid chemisorbed onto the newly machined surface to give a monolayer coverage.

(a) Langmuir-Blodgett Type Films

The best known method of applying organic films to a solid surface is the Langmuir-Blodgett technique. This technique was used extensively in early friction and wear research. Using this method, it is possible to deposit monolayers and multilayers of organic molecules onto solid surfaces in a controlled fashion. The structure of these films, their properties, and their reactions with metallic substrata have been studied intensively in the last 40 years [45] so that their characteristics are well known. The technique for monolayer 
deposition was described thoroughly by Blodgett in her 1935 paper [42]. Depositing monolayers by the Langmuir-Blodgett technique requires: (a) a shallow hydrophobic container for the liquid substratum (a "trough"); (b) hydrophobic barriers to sweep the surface of the liquid in the trough; (c) a hand-windlass or lead screw arrangement to withdraw the sample smoothly at constant speed; (d) a camera and a planimeter to determine the transfer ratio after deposition is complete; (e) waxed thread to contain the monolayer; (f) a piston oil to maintain a constant pressure on the monolayer during deposition; ( $g$ ) reagents: acids and bases to control the $\mathrm{pH}$ of the water bath, solvents; organic acids, soluble metal salts to provide metallic ions in solution; and (h) thermometer, $\mathrm{pH}$ indicator papers. The purity specifications of the reagents are given in Appendix 2. All reagents were used as received from the supplier. Attempts at further purification of small amounts of reagents often lead to greater contamination than originally existed.

The trough was a $6^{\prime \prime} \times 10^{\prime \prime} \times 2^{\prime \prime}$ deep pyrex container, coated, after a thorough cleaning with chromic acid and distilled water, with paraffin wax to make it hydrophobic. The sweep barriers were plexiglass ${ }^{R}$. The liquid substratum was distilled water. The pH of the water was controlled by adding suitable amounts of $\mathrm{HCl}$ or $\mathrm{NH}_{3} \mathrm{OH}$. Metallic ions (e.g., $\mathrm{Ca}^{++}$) were provided when necessary by adding the required amount of an appropriate metallic salt (e.g., $10^{-4} \mathrm{M} \mathrm{CaCO}_{3}$ ). Controlling the $\mathrm{pH}$ was necessary because the film composition is affected by $\mathrm{pH}$. According to Gaines [45], a stearic acid monolayer formed on an aqueous substratum containing $\mathrm{Ca}^{++}$ions is $100 \% \mathrm{Ca}$ stearate only when the pH exceeds 7.5. After the water surface was 
cleaned thoroughly by sweeping it with the barriers, the sample was placed in the trough below the water surface and the waxed cotton thread was carefully placed on the surface. A few drops of the $10^{-4} \mathrm{M}$ organic acid-n-hexane solution were then placed in the thread-enclosed area. The n-hexane-organic acid solution spread rapidly on the clean water surface and exerted a pressure against the confining thread. Since the hexane was volatile, it evaporated in a few minutes to leave a partial monolayer floating on the surface. The addition of a piston oil (such as oleic acid) placed outside the thread caused the film to contract as the oil compressed the thread enclosed area with a constant pressure characteristic of each piston oil (measured as 29.7 dynes per $\mathrm{cm}$ at $\mathrm{pH}=4.0$ for oleic acid). Each molecule in the monolayer then occupied a known area at a given temperature [45]. The waxed thread kept the piston oil separated from the monolayer which was confined within the thread barrier. The area of the monolayer was recorded and then the sample was slowly drawn upwards through the film. A lead screw device was used to withdraw the sample so that the film was evenly deposited as a monolayer film without "steps". Accidental stops or jerks give a discontinuous film thickness over the surface of the sample. It has been shown [45] that the monolayer deposits itself on the specimen so that the geometrical area of the specimen is covered. The film thus bridges the local topography of the surface. (The cohesive strength of most films is so great that Bikerman [51] was able to. deposit monolayers onto a fine wire grid.) During the withdrawal of the specimen, the area of the monolayer left on the surface proportionally decreased. However, as more water surface was exposed, part of the lens of the piston oil spread to cover the new area so that a constant 
pressure was maintained on the film. Because of the piston oil there was some assurance that the monolayer was iniform in properties across the sample. By measuring the area of the film remaining on the water surface after deposition was complete and by comparing the difference between the original area and final area to the geometrical area of the sample, it was possible to determine the extent of monolayer coverage. This figure is a rough guide to the success or failure of the deposition. Only those samples having transfer ratios of $1 \pm .05$ were accepted for friction tests. After transfer was complete, the sample was air dried for 15-20 minutes and it was then tested at atmospheric pressure and temperature.

(b) Monolayer Deposition by the Abrasion Technique A monolayer transferred from a water surface to a solid is an artifact and may be quite different from a monomolecular film adsorbed from solution or from the gas phase since the solid surface will always have a surface roughness on a scale larger than molecular dimensions. It is much more likely that the machining technique developed by Smith and Allen [52] and Smith and McGill [53] to study the adsorption mechanism of a long chain fatty acid (e.g., n-nonadecanoic acid) from a non-polar hydrocarbon (e.g., cyclohexane) more closely simulates actual film formation conditions during friction tests than the Langmuir-Blodgett transfer method.

A machining/abrasion technique requires equipment that will generate a fresh metal surface under the solution so that newlyexposed metal atoms are accessible to the polar component of the solution. While Smith and McGill used n-nonadecanoic acid in cyclohexane as the solution and a planing-type cutting machine for generating a 
fresh surface, in the present work stearic acid (n-octadecanoic acid) was used as the adsorbate, n-hexanes as the solvent and a rotating vire cup-brush was used to generate the fresh surface.

Prior to immersion in the stearic acid-n-hexanes solution, the samples were wire-brushed in air. Obviously, these surfaces were oxidized but this technique was used primarily to remove a layer of loosely adhering metal oxide scale, prior to an adsorption run.

The samples were immediately placed in the stearic acid-nhexane solution and were wire-brushed under the solution for 5 minutes, left for 2 minutes in the solution, rinsed in pure $n$-hexane, air-dried, and then tested at atmospheric pressure: The question arises as to the existence of a monolayer following this treatment. Smith and McGill [53] spend considerable time and effort determining if a monolayer was formed. They also showed that the organic acid was chemisorbed on "reactive" surfaces and that the net reaction was:

$$
\mathrm{Fe}+3 \mathrm{H}(\mathrm{St}) \rightarrow \mathrm{Fe}(\mathrm{St})_{3}+\frac{3}{2} \mathrm{H}_{2}
$$

where $(\mathrm{St})^{-}$represents the stearate ion $\left(\mathrm{C}_{17} \mathrm{H}_{35} \mathrm{COO}\right)^{-}$. They demonstrated that the mechanical activation energy which was supplied to the surface by cutting or brushing, assisted the reaction. Thus, although an evaluation of the free energy change during the proposed reaction might show that the reaction is not spontaneous, the reaction may proceed if the energy required can be supplied by the mechanical activation energy, (the Kramer effect energy). For metals more electropositive than silver, they found that the corresponding metallic soap was formed. Furthermore, based on the apparent area of metal substrate involved, the amount of soap formed was sufficient to give a monolayer of coverage. Even though this method more closely represents actual 
friction conditions, it had some shortcomings for the purposes of the present work since metallic soaps such as calcium or barium stearate could not be placed on the steel surface.

\subsection{Pretest Preparation of Samples}

The samples were all c 1020 steel, annealed at $1600^{\circ} \mathrm{F}$, then sand-blasted to remove the oxide scale formed during the anneal. The surfaces were then ground giving a surface roughness of $17 \mu$ ins. CLA. After grinding, the samples were vapor-degreased with Tricloroethylene to remove residual machining oil and loose dirt. After the degreasing treatment, the surfaces were wire-brushed. This procedure should have generated a new organic-free surface and the wire-brushing roughened the surface so that, according to the work of Greenwood and Williamson [7], the contact will be plastic. The roughness of the surfaces after wire-brushing was $50 \mu$ ins. CLA.

\subsubsection{Vacuum Friction Tests}

Following the wire-brushing, specimens to be tested in the vacuum were quickly transferred to the chamber and the pumpdown was commenced. A pressure of $10^{-3}$ torr was achieved in approximately 30 minutes; $10^{-6}$ torr after 1 hour. For the results given in Figure 12, the test pressure of $2 \times 10^{-8}$ torr was reached after approximately 12 hours. Very little bakeout was needed so that the temperature of the test surfaces never exceeded $100^{\circ} \mathrm{F}$. An analysis of the residual gas at this pressure showed that the principal residual gases were hydrogen, helium, water vapour, and nitrogen. The oxygen content was very low (a partial pressure of $5 \times 10^{-10}$ torr), as was the hydrocarbon content. The tell-tale sign of hydrocarbon contamination, the 43 amu 
peak, was visible only at very high amplifier gains so that the hydrocarbon content was less than $10^{-11}$ torr.

Since the vacuum friction tests were expected to yield information about the $\mu_{s}-\dot{\theta}$ properties of a steel-steel interface, free of significant amounts of contamination, the pretest surface preparation must yield a surface that is sufficiently "clean". The definition of surface cleanliness is an operational one and is tied to the measuring technique. Field ionization, for example, can reveal contaminates on the atomic level but adhesion and friction studies are only affected if the surface is $10 \%$ or more covered with contaminants [28]. There are two general methods for producing clean surfaces. In the first category are methods which synthesize a clean surface by depositing atoms of the desired surface material on a solid surface. Obviously, this deposited layer can differ from the substratum, in hardness and strength, so that in a friction test, it might act as a low shear-strength solid lubricant. In the second category are techniques which remove contaminants from the surface -- high temperature heating to desorb gases from the surface as well as crushing and cleaving to generate new surfaces. In addition, Hordon et al [28] successfully used a method of surface abrasion to prepare aluminium and copper samples for adhesion studies. After two minutes of abrasive cleaning with a rotating stainless steel wire brush, the adhesion coefficient of copper increased from 0 (negligible bonding) to a maximum constant value of 0.32 at $20^{\circ} \mathrm{C}$.

The method used in the present study was based, to a certain extent, on the work of Hordon, but also on the work of Bowden and Leben [16], who showed that repetitive sliding over areas deliberately covered 
with monolayers and multilayers of lubricants rapidly wore the layers from the surface and the coefficient of friction increased as did the amount of surface damage.

After the desired vacuum level was obtained, the slider was repeatedly rubbed across the test surface, immediately prior to testing. It was expected that the disruption of the surfaces would virtually destroy all of the original surface. It was not implied that the surfaces were contaminant-free during the test. At the pressures used, the fresh surface would be covered with a monolayer of adsorbed gas in about two minutes. The friction values, although higher than normally seen in boundary friction tests; also indicate that the surfaces were not "clean". However, the consistency in the friction values indicate that a certain constant level of surface preparation had been achieved. The $\mu_{s}-\dot{\theta}$ properties of surfaces treated in this way were very different from the $\mu_{s}-\dot{\theta}$ values obtained by other investigations [15], [19], [21] and both in terms of maximum $\mu_{s}$ values and the shape of the $\mu_{s}-\dot{\theta}$ curve. Since these investigators had used boundary lubricated surfaces, the difference in results suggested that the pre-test cleaning technique was adequate.

The $\mu_{s}-\theta$ values were obtained by running several tests at different $\dot{\theta}$ values across the same surface and measuring $\mu_{\mathrm{s}}$ at each $\dot{\theta}$ value. The $\mu_{s}-\dot{\theta}$ values were tested for "run-in". No effects were noticeable. The normal loads used in the set of results shown in Figure 12 were in the $50 \mathrm{lb}$. range, and the high $\dot{\theta}$ values were obtained by using higher tangential loading rates and not by decreasing $\mathrm{N}$.

\subsubsection{Air}

Those samples to be air-tested were left exposed to the atmos- 
phere for the allotted time, then tested both in air and under vacuum. In Figure 13, values of $\dot{\theta}>1.0$ were obtained by reducing $\mathrm{N}$ from 50 to approximately $25 \mathrm{lbs}$. That this would not change the $\mu_{\mathrm{s}}$ vs $\dot{\theta}$ values, was tested by extending the $N=251 \mathrm{~b} . \dot{\theta}$ values into the $N=50 \mathrm{lb}$. range of $\dot{\theta}$ values. The six points obtained in the range $.0001<\dot{\theta}<$ 1.0 by using $N=25$ 1bs. agreed very well with the values of $\mu_{s}$, obtained when $\mathrm{N}=50$ 1bs.

\subsubsection{Oxide Films}

i) furnace formed

After degreasing and wire-brushing the samples were heated at $250^{\circ} \mathrm{C}$ in the air for 2 hours and were then allowed to furnace cool. The result was a thick, blueblack oxide film. Films of this type were tested both in air and in vacuum $\left(2 \times 10^{-8}\right.$ torr $)$.

ii) water formed

Thinner oxide films were obtained by immersing the sample in $\mathrm{H}_{2} \mathrm{O}$ at $20^{\circ} \mathrm{C}$ and $\mathrm{pH}=5.0(\mathrm{HCl})$ for 15 minutes followed by air drying. These films were tested at room temperature and pressure immediately after drying in air.

\subsubsection{Monolayer Deposition}

i) abrasion

After the vapor degreasing and final wire-brushing procedure, samples undergoing monolayer deposition by abrasion were immediately placed in the stearic acid-nhexane solution and abraded, then rinsed in $\mathrm{n}$-hexane and 
tested immediately after drying. All the monolayer-covered samples were tested at atmospheric pressure because there can be up to a $50 \%$ loss in monolayer coverage under vacuum conditions [45].

ii) Langmuir-Blodgett films

The deposition technique has been described earlier in this chapter. After controlling the $\mathrm{pH}$ and metal ion concentration, the samples were immersed in the bath, the film was spread and the samples emerged "wet" from the trough. They were allowed to dry, then tested immediately at atmospheric pressure and temperature except in the temperature studies of the calcium stearate films. Four different Langmuir-Blodgett monolayers were formed with oleic acid as piston oil $\left(\pi_{A}=29.7\right.$ dynes $\left./ \mathrm{cm}\right)$ :

1) Stearic acid, $\mathrm{pH}=4.0$;

2) Oleic acid, $\mathrm{pH}=4.0$;

3) Stearic, $\mathrm{pH}=9.0-10.0 ; 10^{-4} \mathrm{M} \mathrm{Ca}{ }^{++}$;

4) Oleic acid, $\mathrm{pH}=9.0-10.0 ; 10^{-4} \mathrm{M} \mathrm{Ca}^{++}$.

\subsubsection{Temperature Studies of Calcium Stearate Monolayers}

For the temperature studies, calcium stearate monolayers

were deposited on the steel samples using the Langmuir-Blodgett technique. After drying, the film covered plates were tested at atmospheric pressure and at temperatures ranging from $22^{\circ} \mathrm{C}$ to $70^{\circ} \mathrm{C}$. A pair of quartz-iodide lamps $(2,000$ watts) were used as the heat source and a YSI Telethermometer equipped with a surface temperature probe was employed to monitor the temperature of the plate, see Figure 11. 
The temperature was regulated to within $\mathrm{T} \pm 2 .^{\circ} \mathrm{C}$ by manual operation of the controls for the heating lamps.

Besides the usual precaution of measuring deposition ratios to determine if film deposition was satisfactory, the samples to be. heated were tested for $\mu_{s}-\dot{\theta}$ characteristics prior to heating. The temperature tests lasted approximately 3 hours for each $\mu_{\mathbf{s}}-\dot{\theta}$ curve.

\subsection{General Experimental Procedure}

After each sample had received the appropriate pre-test preparation, the upper slider was wire-brushed then placed in contact with the sample and $N$, the normal load was applied. N varied slightly from one group of tests to another but was generally kept at approximately 50 1bs. In a few instances, $N$ had to be decreased so that $\mu_{s}$ at higher $\dot{\theta}$ values could be obtained; these cases are noted on the appropriate graphs in Chapter V. After $\mathrm{N}$ was applied, $\mathrm{F}$ was applied at a constant rate until gross slip occurred. $F$ and $N$ were released and the slider was moved to a new area (with the exception of the vacuum tests described earlier). The slider was always moved to a new test area because surface films are.disrupted during a test and the retesting of that area would have yielded higher $\mu_{\mathbf{s}}$ values.

A typical data run would consist of at least 25 data points covering the range of $\dot{\theta}$. Many separate data runs of monolayer-covered surfaces were carried out and the results given in the graphs are an accumulation of several separate runs: 


\section{RESULTS AND DISCUSSION}

\subsection{Introduction}

The first part of the experimental work was concerned with identifying the source of the observed rate-dependence of static friction. The possibility that the static friction force was ratedependent because the deformation of steel is strain-rate sensitive was checked experimentally by determining $\mu_{s}$ vs $\dot{\theta}$ values for steel/steel friction couples under high vacuum conditions. Testing a friction couple under these conditions was the most satisfactory method of minimizing the effects of oxidation or of hydrocarbon adsorption on friction characteristics.

Following the high vacuum work, static friction tests were also carried out on steel samples which had been deliberately oxidized and on samples which had been coated with a monolayer of metal-organic soap.

In the second half of the study, additional $\mu_{s}-\dot{\theta}$ data for several monolayer-covered steel surfaces were obtained as a check of the validity of the proposed theoretical model for static friction.

Finally, the experimental work was extended to cover the effect of small temperature increases on the $\mu_{s}-\dot{\theta}$ characteristics of monolayer-covered surfaces.

\subsection{Obtaining Static Friction Information for the Steel/steel System}

5.2.1 $\mu_{s}$ vs $\dot{\theta}$ curves at $2 \times 10^{-8}$ torr

Figure 12 summarizes two separate data runs of steel vs steel. at $2 \times 10^{-8}$ torr. The data points for this graph were obtained from more 
extensive data by averaging four $\mu_{s}$ values at a given $\dot{\theta}$. This graph is typical of $\mu_{s}-\dot{\theta}$ curves obtained at $2 \times 10^{-8}$ torr and at lower pressures. The effect on $\mu_{s}$ of lowering the vacuum pressure to $5 \times 10^{-9}$ torr was not noticeable. The most important feature of this curve is that it is independent of $\dot{\theta}$ through the range $.001<\dot{\theta}<5$. This means that some other component of the interface is responsible for the viscoelastic behaviour of the interface. The friction value of 0.75 , although higher than values obtained during other boundary lubrication studies, e.g., Johannes [19], Marion [21], is relatively low compared to values observed by some workers. Rittenhouse [28] for example, has observed values of 1.08 with "clean" steel. The low friction value can be explained by considering the pre-test preparation.

Before they were placed in the test chamber, the test surfaces were prepared by degreasing them over boiling trichloroethylene to remove residual machining oils and loose dirt, then wire-brushing them. The brushing disturbed the surface and exposed new steel which immediately oxidized in air. In a matter of seconds, the surface was covered with a thin layer of oxide about $20 \AA$ thick [55]. However, this procedure removed the majority of the scale and accumulated hydrocarbons from the surface. The specimens were placed in the vacuum chamber immediately after cleaning and the pumpdown procedure was commenced. A pressure of $10^{-6}$ torr was reached in approximately $1-1 / 2$ hours and $10^{-8}$ torr in about 12 hours.

What is the state of the surfaces at test time?

From the work of Kruger and Yolken [55] who studied the oxidation kinetics and the initiation of oxidation on iron surfaces; it is obvious that the initial oxidation rate of the freshly brushed surfaces 
is very high, but decreases exponentially with time. At the end of 17 hours in pure, dry oxygen at 760 torr, the film thickness would only have reached about $30 \mathrm{~A}$. Since the partial pressure of $\mathrm{O}_{2}$ in the vacuum chamber, as measured by the RGA, was very low (approximately $10^{-10}$ torr) during the major part of the 12 hour pumpdown time, it was doubtful if the film thickness exceeded $30 \AA$. Also, even when the bakeout heat was applied, the temperature of the specimen never exceeded $50^{\circ} \mathrm{C}$. Because of the low temperature, low $\mathrm{O}_{2}$ partial pressures and the high $\mathrm{H}_{2}$ content of the residual gas during bakeout (the hot ion pumps emit hydrogen during bakeout), it is unlikely that any further oxidation would have occurred in the chamber. Prior to the actual friction tests, the specimens were abraded together several times thus disrupting the oxide films. However, even if this procedure completely removed the oxide layer, the newly-exposed surfaces would not remain free of adsorbed gases indefinitely. At $10^{-8}$ torr and room temperature, the number of gas molecules remaining in the chamber was still so large than the cleaned area would have been covered with a monolayer of adsorbed gas in about 3 minutes. Thus, it was likely that during the friction tests, the test surfaces were covered with at least a monolayer of adsorbed gas, probably a mixture of $\mathrm{H}_{2}$ and $\mathrm{N}_{2}$. These findings assist in explaining why the observed friction coefficient was relatively low compared to values observed by other workers. The minimal effect of this adsorbed gas monolayer is interesting when compared to the effect of adsorbed. organic monolayers found in subsequent tests.

\subsubsection{Air Exposed}

A more interesting observation is that if the test surface used in vacuum was exposed to the atmosphere for 24 hours then 
retested, the maximum friction value fell to 0.55 , and the $\mu_{s}$ vs $\dot{\theta}$ behaviour is closer to that reported by Johannes [19] and Marion [21]. The 24-hour exposure results are compared with the vacuum results in Figure 13. What caused the shift in the friction value and the change in the shape of the $\mu$ vs $\dot{\theta}$ curve? The first thought was that the surface oxidized with further exposure to air. The second was that airborne hydrocarbons were adsorbed onto the surface. There is some independent evidence to suggest that hydrocarbon contamination could be present. When Coelho [60] was examining the infrared spectra of organic acids adsorbed on metal mirrors, he found that extraneous hydrocarbon bands appeared in the spectra before the acids had been deposited. These bands appeared when the mirrors had been exposed to the open atmosphere for approximately 18 hours. He concluded that this was the result of the adsorption of hydrocarbons from the atmosphere.

The possibility that oxide films could be contributing to the viscoelastic behaviour was checked by growing oxide films on the surfaces and testing their $\mu_{s}$ vs $\dot{\theta}$ characteristics. Subsequently, a study of deliberately deposited hydrocarbon monolayers was also performed.

\subsubsection{Oxide Films}

The first films tested were thick oxide films formed by heating the specimens to $250^{\circ} \mathrm{C}$. The friction coefficients were high, 0.79 , and appear to be independent of $\dot{\theta}$. They decreased very slightly at higher $\dot{\theta}$ (see Figure 15). When failure or slip occurred, the oxide film was torn from the base metal, exposing sections of steel. These friction values probably reflect the bond strength between oxide and parent metal rather than metal vs oxide friction. The friction values are slightly higher than those obtained for the 
vacuum tests and they are also higher than values of subsequent tests on the water formed oxide films shown in Figure 15. Other workers have observed this behaviour also [29]. When the oxide films are thin, the friction values are usually lower than values of the corresponding oxidefree surface, but increasing the film thickness can increase the friction coefficient. In Figure 16, the results of the friction tests on air formed and water formed films are plotted along with the results of Johannes [19] and Marion [21] for comparison. It is obvious that oxide films by themselves do not render the steel/steel interface viscoelastic over the ranges of $\dot{\theta}$ considered.

\subsubsection{Monolayers of Polar Organic Compounds}

a) Abraded

After the experiments showed that oxide-films were not responsible for the viscoelasticity observed by other workers, a monolayer of an organic metallic soap was deposited on the steel surface by abrading it under a hexane solution containing stearic acid. Unlike the oxide films just discussed, this film did give a $\mu_{s}-\theta$ curve similar to the one Johannes had reported (see Figure 17). It shows an upper and a lower asymptote for $\mu_{s}$. The values of these asymptotes compare favorably with those obtained by Johannes:

$\begin{array}{ccc} & \text { Johannes } & \text { Present Work } \\ \mu_{\max .} & 0.38 & 0.39 \\ \mu_{\min .} & 0.18 & 0.22\end{array}$

Another encouraging feature is that the general shape of 
the curves is quite similar. These results were the first clear indication that the $\mu_{s}-\dot{\theta}$ curves for steel were strongly influenced by hydrocarbons. The abrasion technique closely sinulates the film-formation process under ordinary friction conditions with one exception: the film formed by the abrasion technique was limited to a monolayer in thickness. Depending on surfactant concentration, the film formed during the "run-in" period of ordinary friction tests may be thicker. In either case, protection was obtained because the fatty acid reacted with newly exposed $\mathrm{Fe}$ atoms on the surface to form a metallic soap. This soap was relatively immobile because it is strongly bound to the surface and because it possesses an internal cohesiveness due to the lateral interactions of the chains of the oriented acid molecules.

Unfortunately; the abrasion technique was not very flexible and it was impossible to deposit soaps of other metals onto a steel surface. Consequently, it was felt that the Langmuir-Blodgett method offered more potential so in other tests, monolayers were deposited using that technique.

b) Langmuir-Blodgett Monolayers

After the results of the abrasion-formed monolayer were analyzed, further investigation of the results of the studies on the rheology of surface films at the air/. water interface indicated that it might be possible to 
provoke the steel/steel interface ințo giving different $\mu_{s}-\dot{\theta}$ curves by changing either the metal ion or the fatty acid in the monolayer. The results are as follows.

\subsubsection{Stearic Acid and Oleic Acid at $\mathrm{pH}=4.2$}

The first organic films to be deposited were formed by depositing stearic or oleic acid on a water surface. HCl had been added to reduce the $\mathrm{pH}$ to 4.2 . At this $\mathrm{pH}$, carboxylic acids are undissociated but Spink and Saunders [41], have shown that basic iron soaps can be formed if a ferric salt has been added to the aqueous solution.

Earlier work by Wolstenholme and Schulman [70] using myristic acid $\left(\mathrm{n}-\mathrm{C}_{13} \mathrm{H}_{25} \mathrm{COOH}\right)$ as the long chain polar compound is more explicit. They found that the $\mathrm{Fe}^{+H}$ ions themselves do not produce solid films but that when the $\mathrm{pH}$ value is greater than 2 , the film is condensed because basic iron ions $\left[\mathrm{Fe}(\mathrm{OH}){ }_{2}{ }^{+}\right.$or $\left.\mathrm{Fe}(\mathrm{OH})^{++}\right]$interact with the undissociated organic acid molecules. Wolstenholme and Schulman also proposed a mechanism of film condensation in which hydrogen bonding between the hydroxyl groups of the basic metal ions was responsible for condensing the film. The basic metal ions form a complex network situated just beneath the monolayer. At" $\mathrm{pH}>5.5$, no solid films could be detected. Above $\mathrm{pH}$ 5, the basic metal ions form colloidal aggregates in the solution and network formation under the monolayer will no longer take place.

In the present study, the steel sample was the source of the basic metal ions. Prior to depositing the monolayer on its surface, the sample was submerged in the water filled ( $\mathrm{pH} 4$ ) trough and held there for approximately 20-30 minutes. Thus, it is expected that the deposited films are not stearic or oleic acid monolayers but monolayers of the 
appropriate basic iron soap.

The mechanical properties of these films have not been studied in detail, but from their performance during friction tests, they are likely to be less viscous than calcium stearate films. The $\mu_{\mathbf{s}}$ vs $\dot{\theta}$ curves for both films are shown in. Figure 18. Both curves show a pronounced variation of $\mu_{s}$ with $\dot{\theta}$. The upper and lower asymptotes are 0.70 and 0.47 respectively. The $\mu_{s_{\max }}$ value of 0.70 is close to values obtained for the water formed oxide. The curves are similar in shape to the $\mu_{s}-\dot{\theta}$ curves obtained by Johannes but are displaced upwards and to the right.

\subsubsection{Ca-stearate and Ca-oleate at $\mathrm{pH}=9.5$}

As noted earlier [36], [38], $\mathrm{Ca}^{++}$ions cause stearic and monolayers to become highly viscous with an activation energy for flow of approximately $11 \mathrm{Kcal} / \mathrm{mole}$ over certain ranges of $\mathrm{pH}$. On the other hand, $\mathrm{Ca}^{++}$ions have very little effect on oleic acid monolayers because $\mathrm{Ca}^{++}$is sterically hindered from forming the same highly structured polymer-1ike film with oleic acid as it does with stearic acid.

Deamer and Cornwell [36] found that the viscosity of an oleic acid monolayer on water (at $\mathrm{pH} 2.0)$ was not significantly increased by the addition of $\mathrm{Ca}^{+}$ions at $\mathrm{pH} 10$ even though a calcium oleate di-soap was formed. However, stearic acid monolayer became so solid-1ike that its viscosity increased from $4 \times 10^{-4}$ to greater than 0.2 dyne-sec. per $\mathrm{cm}$ which was the upper limit of their viscometer.

The effect of this solidification on static friction is shown in the $\mu_{s}-\dot{\theta}$ curves given in Figures 19 and 20. The Ca-stearate film shifts the $\mu_{s}-\dot{\theta}$ curve to the left so that $\mu_{s}$ is lower for a given $\dot{\theta}$, while Ca-oleate leaves the curve in approximately the same position as 
it had at $\mathrm{pH}=4.0$. The upper and lower asymptotes remain close to 0.70 and 0.47 in each case.

It is obvious that the properties of the deposited monolayer can affect the $\mu_{s}-\dot{\theta}$ curve dramatically. These results will now be interpreted in terms of the model proposed in Chapter III.

\subsection{Discussion of $\mu_{s}-\dot{\theta}$ Results}

5.3.1 Applying the Viscoelastic Model to $\mu_{s}-\dot{\theta}$ Results

Consider the composition of a typical interface and its response to the applied forces. Both surfaces consist of a soft steel substratum covered by a layer of deformed metal about 0.1 microns deep which is, in turn, covered with an oxide layer at least $30 \stackrel{\circ}{\mathrm{A}}$ thick. In addition, the stationary half of the friction couple is covered by a deliberately deposited monolayer of organic material. The application of $\mathrm{N}$ causes plastic yielding in the substrata immediately beneath the highest points of each surface so that small discrete areas of contact are formed. Independent work by Courtney-Pratt and Eisner [14] and Green [15] has shown that these contact areas are at least partially metallic, probably because the oxide film cracks and new metal is exposed. Any oxide or organic material trapped in a contact zone will experience reasonably high compressive stresses as the yield pressure, $p_{m}$, for steel is about $200 \mathrm{Kg} / \mathrm{mm}$. When the tangential stress is applied, the shear stress: 1) will be transmitted to the substratum causing the total contact area to grow; 2) may squeeze a portion of the oxidemonolayer material out of the contact zone thus increasing the metallic area of contact.' During this time, the surfaces will show small amounts of vertical as well as horizontal movement as the interface adjusts to 
the stresses. At some point, however, the applied tangential force will cause gross slip of one surface over the other.

a) What is $T_{0}$, to the shear strength/unit area of the interface, when slip occurs?

In the most extreme case, the majority of the contact area would be metallic and the average shear strength per unit area would approach the shear strength of the metal substrata, $S_{M^{*}} S_{M^{\prime}}$ is approximately $0.2 p_{m} \cdot[3]$ : (Note that $S_{M}$ may vary from junction to junction as the substratum is anisotropic but only average values are considered.) A more usual circumstance is that only a a fraction, $\alpha$, of the total contact area is metallic, the rest, $(1-\alpha)$, consists of an oxide-monolayer mixture with shear strength per unit area, $\mathrm{S}_{\mathrm{nm}}$, which is less than $\mathrm{S}_{\mathrm{M}^{*}}$ (If $\mathrm{S}_{\mathrm{nm}}>\mathrm{S}_{\mathrm{M}}$, shearing would take place in the underlying weaker metal.) Therefore, at fracture. $\mathrm{F}_{\mathrm{f}}=\mathrm{A}_{\mathrm{f}}\left[(1-\alpha) \mathrm{S}_{\mathrm{nm}}+\alpha \mathrm{S}_{\mathrm{M}}\right]=\mathrm{T}_{\mathrm{o}} \mathrm{A}_{\mathrm{f}}$. Thus, the shear strength per unit area of the interface, $T_{0}$, has a maximum value of $\mathrm{S}_{\mathrm{M}^{*}}$ Therefore, $\left[\mathrm{T}_{\mathrm{o}} / \mathrm{p}_{\mathrm{m}}\right] \leq 0.2$ approximately.

b) When will the area growth end?

Measurements of the electrical resistance of the interface show that the final amount of contact area at a given normal load is a function of the rate at which the tangential force was applied.

Because of the complex nature of the interface, predicting the amount of area growth by considering the 
deformation of each component is difficult. In Chapter III, a more general approach was taken and it was assumed that the contact area growth shows a viscoelastic type of behaviour so that at fracture:

$$
\begin{aligned}
F_{f} & =A_{f} T_{o} \\
& =A_{i}\left[1+\varepsilon\left(t_{f}\right)\right] T_{0}=\frac{N}{p_{m}} T_{o}\left[1+\varepsilon\left(t_{f}\right)\right]
\end{aligned}
$$

and

$$
\mu_{s}=\frac{F_{f}}{N}=\frac{T_{O}}{P_{m}}\left[1+\varepsilon\left(t_{f}\right)\right]
$$

Also, in Chapter III, two possible types of viscoelastic models were used to predict $\mu_{s}$. From the experimental data obtained from static friction tests of surfaces covered with Langmuir-Blodgett monolayers, the two models will be evaluated.

\subsubsection{Kelvin-Voigt-Prandt1 Mode1}

In the simplest case, the interface is assigned one elastic parameter, $k$, and one viscous parameter, $c$, and treated as if its deformation behaviour was that of a Kelvin-Voigt body. S1ip occurs when a fracture stress, $T_{0}$, is reached. Using this approach, equation (6) was derived earlier. It is interesting to evaluate $c$, $k$ and $T_{0} / p_{m}$ for each of the four cases.

$$
\text { Considering equation (6) in Chapter III: the upper }
$$

asymptote is

$$
\mu_{\max .}=\frac{\mathrm{T}_{\mathrm{o}}}{\mathrm{p}_{\mathrm{m}}}\left[\frac{\mathrm{k}}{\mathrm{k}-\mathrm{T}_{\mathrm{o}}}\right]
$$


the lower asymptote is $\mu_{\mathrm{min}}=\mathrm{T}_{\mathrm{o}} / \mathrm{p}_{\mathrm{m}}$.

0.47 in all four cases so that:

$$
\text { From the data for the monolayers } \mu_{\mathrm{s}_{\max }}=0.70 \text { and } \mu_{\mathrm{s}_{\min }}=
$$

$$
0.47=\frac{\mathrm{T}_{\mathrm{o}}}{\mathrm{p}_{\mathrm{m}}}
$$

and

$$
0.70=\frac{\mathrm{T}_{\mathrm{o}}}{\mathrm{p}_{\mathrm{m}}}\left[\frac{1}{1-\frac{\mathrm{T}_{\mathrm{o}}}{\mathrm{k}}}\right]
$$

From (6) with $\mu_{s_{\max }}=0.70, \mu_{s_{\min }}=0.47$, the $\mu_{s}-\dot{\theta}$ curve is:

$$
-1.46+\frac{c}{k} \dot{\theta}\left[1-e^{-\frac{k}{c} \mu_{s}}\right]+2.08 \mu_{s}=0
$$

and

$$
\frac{\mathrm{k}}{\mathrm{p}_{\mathrm{m}}}=1.46, \quad \frac{\mathrm{T}_{\mathrm{o}}}{\mathrm{p}_{\mathrm{m}}}=0.47, \quad \frac{\mathrm{c}}{\mathrm{k}}=\alpha
$$

The value for $\alpha$ the "retardation time" is different for each monolayer. It is obtained by solving (1I) given a data point $\left(\mu_{s j}, \dot{\theta}_{j}\right)$ from the experimental curves. Given that $\mathrm{P}_{\mathrm{m}}=200 \mathrm{Kg} / \mathrm{mm}^{2}$ is a reasonable yield value for steel (published values range from 100 to $300 \mathrm{Kg} / \mathrm{mm}^{2}$ ), then $c, k, T_{0}$ are calculated from the set of equations (12) for each film (see Table. I).

The value of $c$ gives a bulk effective viscosity for each interface. As expected from the relative positions of the $\mu_{\mathbf{s}}-\dot{\theta}$ curves, the interface with calcium stearate as the monolayer shows the highest bulk viscosity, value.

At this point, it is obvious that one difficulty with using the simple model to describe static friction is that it predicts an 


\begin{tabular}{|l|c|c|c|c|}
\hline \multicolumn{1}{|c|}{$\begin{array}{c}\text { MONOLAYER } \\
\text { DEPOSITED }\end{array}$} & $\mathrm{c} / \mathrm{k}$ & $\mathrm{T}_{\mathrm{O}}$ & $\mathrm{k}^{*}$ & $\mathrm{c}$ \\
\cline { 2 - 5 } & $(\mathrm{sec})$ & $\left(\mathrm{kg} / \mathrm{mm}^{2}\right)$ & $\left(\mathrm{kg} / \mathrm{mm}^{2}\right)$ & $(\mathrm{poise})$ \\
\hline Ca-oleate & .69 & 94 & 292 & $1.97 \times 10^{10}$ \\
$\mathrm{Ca}-$ stearate & 40 & 94 & 292 & $111.4 \times 10^{10}$ \\
$\mathrm{Fe}(\mathrm{OH})_{2}$ Oleate & .92 & 94 & 292 & $2.63 \times 10^{10}$ \\
$\mathrm{Fe}(\mathrm{OH})_{2}$ Stearate & .34 & 94 & 292 & $.96 \times 10^{10}$ \\
\hline
\end{tabular}

$*_{k}=2.86 \times 10^{10}$ dyne $/ \mathrm{cm}^{2}$.

TABLE I, Calculated Values of Relaxation Time, Viscosity, Elastic Modules and Shear Strength for the 2-Parameter Model. 
unreasonably large value for the fracture stress, $\mathrm{T}_{\mathrm{o}} \cdot\left[\mathrm{T}_{\mathrm{o}} / \mathrm{p}_{\mathrm{m}}\right]$ is expected to have a maximum value in the 0.20 range and this model predicts a value $\left[\mathrm{T}_{0} / \mathrm{P}_{\mathrm{m}}\right]=0.47$ which is almost $2-1 / 2$ times the maximum value.

\subsubsection{3-Parameter (Standard Linear Solid) - Prandtl Model}

In developing the 3-parameter model, two elastic modulii $k_{1}$ and $k_{2}$ were used to describe the elasticity of the interface while $c$ described its viscous properties. The failure condition is that slip occurs when $\mathrm{T}_{\mathrm{o}}$ is reached. From (8):

$$
-\frac{k_{1}}{p_{m}}+\left[\frac{k_{2}}{k_{1}+k_{2}}\right] \tau \dot{\theta}\left[1-e^{-\frac{\mu_{s}}{\dot{\theta} \tau}}\right]+\left[\frac{k_{1}}{T_{0}}-1\right] \mu_{s}=0
$$

where: $\quad \tau=\left[\frac{k_{1}+k_{2}}{k_{1} k_{2}}\right] c$

The asymptotes are:

$$
\begin{array}{r}
\mu_{\text {max. }}=\frac{T_{0}}{p_{m}} \cdot\left[\frac{k_{1}}{k_{1}-T_{0}}\right] \\
\mu_{\text {min. }}=\frac{T_{0}}{p_{m}}\left[\frac{k_{1}+k_{2}}{k_{1}+k_{2}-T_{0}}\right]
\end{array}
$$

For all four interfaces, $\mu_{s_{\max }}=0.70, \mu_{s_{\min }}=0.47$.

Using these values, (13) becomes:

$$
-1.46+\tau \dot{\theta}\left[1-e^{-\frac{\mu_{s}}{\dot{\theta} \tau}}\right]+2.08 \mu_{s}=0
$$

The ratio $\left[\frac{k_{1}+k_{2}}{k_{1} k_{2}}\right] c=\tau$ is the relaxation time for a particular 
interface. Values of $\tau$ for each interface are different and are determined from the experimental data by substituting $\left(\mu_{\mathrm{si}}, \dot{\theta}_{i}\right)$ into $(16)$. As can be seen from the graphs in Figures 21 to 24 , the theoretical $\mu_{\mathrm{s}}-\dot{\theta}$ relationship fits the data reasonably well.

It is interesting to determine the magnitudes of $c$, and $k_{1}, k_{2}$ for each interface. To do this, the value $T_{o} / p_{m}$ is needed. In the development of this model, it was assumed that $\mathrm{T}_{0}$ is known for each interface. Unfortunately, this is not the case. By rearranging (15), it is obvious that (15) has solutions only when $\left[\mathrm{T}_{\mathrm{o}} / \mathrm{p}_{\mathrm{m}}\right]<\mu_{\mathrm{min}}$; since $k_{1}$ and $k_{2}$ are positive quantities.

$$
k_{1}+k_{2}=\left[\frac{T_{o}}{1-\frac{1}{\mu_{\text {min }}}\left[\frac{T_{o}}{p_{m}}\right]}\right]
$$

Thus, $\mathrm{T}_{\mathrm{o}} / \mathrm{p}_{\mathrm{m}}$ has an upper limit of 0.47 . The $\mathrm{c}, \mathrm{k}_{1} \mathrm{k}_{2}$ parameters for each interface were calculated for a range of $\left[\mathrm{T}_{0} / \mathrm{p}_{\mathrm{m}}\right]<\mu_{\mathrm{min} .}$. In Table II, these parameters are given for several $\mathrm{T}_{\mathrm{o}} / \mathrm{p}_{\mathrm{m}}$ values up to 0.47 which represents the largest possible $\mathrm{T}_{\mathrm{o}} / \mathrm{p}_{\mathrm{m}}$ ratio. However, as discussed earlier, a more reasonable value of $\mathrm{T}_{\mathrm{o}} / \mathrm{p}_{\mathrm{m}}$ would be about 0.20 or less. If $\mathrm{T}_{\mathrm{o}} / \mathrm{p}_{\mathrm{m}}=0.15$, then the bulk viscosity of the interface is $2 \times 10^{10}$ poise for calcium stearate, for example.

The bulk viscosities for the interfaces may be compared to published values of the viscosities of some common materials given in Table ITI.

If the interface viscosity values are compared to published values for the viscosities of monolayers at the air-water interface, then they seem unusually large. The surface viscosity of calcium oleate for example, was measured by Deamer and Cornwell as $3 \times 10^{-4}$ surface 


\begin{tabular}{|c|c|c|c|c|c|c|c|c|}
\hline$\frac{T_{0}}{P_{m}}$ & $\mathrm{k}_{1}\left[\frac{\mathrm{kg}}{\mathrm{mm}^{2}}\right]$ & {$\left[k_{1}+k_{2}\right]\left[\frac{\mathrm{kg}}{\mathrm{mm}^{2}}\right]$} & $\mathrm{k}_{2}\left[\frac{\mathrm{kg}}{\mathrm{mm}^{2}}\right]$ & $\frac{k_{1}+k_{2}}{k_{1} k_{2}}$ & $\mathrm{Ca} \stackrel{\mathrm{c}}{\mathrm{St}} \mathrm{t}_{2}$ & $\mathrm{Ca} \mathrm{Ol}_{2}$ & $\mathrm{Fe}\left(\stackrel{\mathrm{C}}{(\mathrm{OH})_{2} \mathrm{St}}\right.$ & $\mathrm{Fe} \stackrel{\mathrm{C}}{(\mathrm{OH})}{ }_{2} \mathrm{Ol}$ \\
\hline & & & & & (poise) & (poise) & (poise) & (poise) \\
\hline 0.05 & 10.8 & 11.20 & .4 & 2.59 & $21.5 \times 10^{10}$ & $4.7 \times 10^{8}$ & $2.3 \times 10^{8}$ & $6.26 \times 10^{8}$ \\
\hline 0.1 & 23.3 & 25.4 & 2.1 & 0.52 & $4.3 \times 10^{10}$ & $.9 \times 10^{8}$ & $.45 \times 10^{8}$ & $1.2 \times 110^{8}$ \\
\hline 0.15 & 38 & 44 & 6 & 0.19 & $2 \times 10^{10}$ & $.3 \times 10^{8}$ & $.15 \times 10^{8}$ & $.4 \times 10^{8}$ \\
\hline 0.20 & 56 & 69.6 & 13.6 & 0.09 & $.747 \times 10^{10}$ & $.16 \times 10^{8}$ & $.08 \times 10^{8}$ & $.2 \times 10^{8}$ \\
\hline 0.30 & 105 & 165 & 60 & 0.026 & $.216 \times 10^{10}$ & $.04 \times 10^{8}$ & $.02 \times 10^{8}$ & $.05 \times 10^{8}$ \\
\hline 0.40 & 187 & 537 & 350 & 0.008 & $0.66 \times 10^{10}$ & $.015 \times 10^{8}$ & $.007 \times 10^{8}$ & $.02 \times 10^{8}$ \\
\hline 0.46 & 268 & 4324 & 405.6 & 0.004 & $.03 \times 10^{10}$ & $.007 \times 10^{8}$ & $.003 \times 10^{8}$ & $.009 \times 10^{8}$ \\
\hline 0.47 & 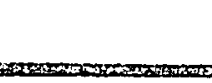 & $\infty$ & $\infty$ & & & & & \\
\hline
\end{tabular}

TABLE II, Elastic Modulii and Viscosity Values as a Function of $\mathrm{T}_{\mathrm{o}} / \mathrm{p}_{\mathrm{m}}$ for the 3-Parameter Model. 


\begin{tabular}{|l|l|}
\hline \multicolumn{1}{|c|}{ MATERIAL } & \multicolumn{1}{|c|}{ BULK VISCOSITY } \\
\hline glycerine $\left(0^{\circ} \mathrm{C}\right)$ & $5 \times 10^{2}$ poise \\
butter $\left(20^{\circ} \mathrm{C}\right)$ & $5 \times 10^{2}$ poise \\
pitch $\left(0^{\circ} \mathrm{C}\right)$ & $5 \times 10^{11}$ poise \\
pitch $\left(15^{\circ} \mathrm{C}\right)$ & $1.3 \times 10^{10}$ poise \\
greases $\left(20^{\circ} \mathrm{C}\right)$ & ranges from 10 to $10^{11}$ poise \\
glacier $i \mathrm{Ce}$ & $1.2 \times 10^{14}$ poise \\
glass $\left(20^{\circ} \mathrm{C}\right)$ & $10^{22}$ poise \\
\hline
\end{tabular}

TABLE III. Viscosities of Some Materials. 
poise. The corresponding bulk viscosity (using $20 \AA$ as the monolayer thickness) is $1.2 \times 10^{3}$ poise, which is much smaller than the viscosity value just obtained for the calcium-oleate covered interface. This apparent discrepancy in viscosity values indicates that the substratum strongly influences the rheology of the interface. This is not surprising when one considers that the apparent viscosities of monolayers at the air/water interface are known to be strongly influenced by the liquid substratum. When the surface viscosity values for the monolayers are converted to 3 -dimensional bulk viscosities, the apparent bulk viscosities are much higher than those obtained for the actual materials. However, if the measured viscosity is considered to be the sum of two components, the viscosity of the monolayer itself plus a viscosity contribution due to the substratum, then when the substratum's contribution is estimated and subtracted from the apparent viscosity, the monolayer viscosity values are much closer to the bulk values. In view of these observations, it is reasonable to expect that the measured interface viscosity may be much higher than the viscosity of the monolayer itself or the bulk soap.

\subsection{Dimensionless $\mu_{s}-\dot{\theta}$ Curves}

After examining the $\mu_{s}-\dot{\theta}$ data, it is apparent that the $\mu_{s}-\dot{\theta}$ relationship fits each set of data reasonably well. The $\mu_{s}-\dot{\theta}$ curves for each interface have the same asymptotes and are separated on the $\dot{\theta}$ axis because their relaxation times are different. It is also apparent that a more general form of friction curve could be obtained by making $\dot{\theta}$ dimensionless and that all the experimental $\mu_{s}, \dot{\theta}$ data should collapse onto this curve. Multiplying $\dot{\theta}$ by the relaxation time 
will give a dimensionless parameter, $\tau^{*}$, as the abscissa and the general friction curve will be in the form of $\mu_{\mathrm{S}}$ vs $\tau *$.

The relaxation time $\tau_{i}$ for each of the four interfaces was determined earlier. The data for all four interfaces were plotted as $\mu_{s}$ vs $\tau_{i} \dot{\theta}$. The results are given in Figure 25 . It is apparent that the experimental data will collapse onto a single curve which has the form:

$$
-1.46+\tau^{*}\left[1-e^{-\frac{\mu_{s}}{\tau^{*}}}\right]+2.08 \mu_{s}=0
$$

What use is this? For the four interfaces already tested, the use is obvious -- knowing $\tau_{i}$ allows one to predict $\mu_{s}$ at any $\dot{\theta}$. Unfortunately, for other metal soaps $\tau_{i}$, and $k_{1}, k_{2}$ must be determined by experimentation.

\subsection{Effect of Temperature on Static Friction.}

The temperature studies were not meant to be an exhaustive examination of the effects of heat on the friction characteristics of monolayer-covered surfaces. They were carried out as a supplementary check of the postulated viscoelasticity of the interface since it is well known that the relaxation times of viscoelastic materials are affected by temperature.

The calcium stearate film was selected for the temperature study because its room-temperature $\mu_{s}-\dot{\theta}$ curve is situated so that if temperature effects do alter the relaxation time, the position of the new $\mu_{s}-\dot{\theta}$ curve should still be within the experimental range of $\dot{\theta}$ values. Also, the melting point of bulk calcium stearate is reasonabiy high $\left(180^{\circ} \mathrm{C}\right.$ as compared to $84^{\circ} \mathrm{C}$ for calcium oleate) so that higher test 
temperatures are possible before film melting effects might interfere.

Heating the monolayer-covered steel surface to $35^{\circ} \mathrm{C}$, Figure 26, shifted the $\mu_{s}-\dot{\theta}$ curve slightly to the right so that $\tau_{35^{\circ} \mathrm{C}}$ is reduced to $10 \mathrm{sec}$. Similarly, heating to $50^{\circ} \mathrm{C}$ shifted the $\mu_{s}-\dot{\theta}$ further to the right, Figure 25 , and $\tau_{50^{\circ} \mathrm{C}}$ is further reduced to .5

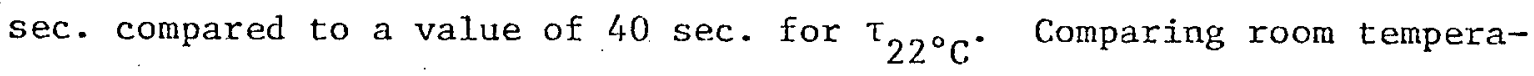
ture curves for Ca-stearate, Figure 21, with these two higher temperature curves, Figures 26, and 27 , it is obvious that the effect of temperature increase is to decrease the relaxation time of the interface. There is also some indication that the increase in temperature has caused the upper asymptote to shift upwards slightly. The maximum value of $\mu_{s}$ previously obtained for $\mathrm{Ca}$-stearate films at room temperature is 0.705 compared to $\mu_{s_{\max }}=0.73$ for the higher temperature tests. However, if the data for these curves is compared to the data plotted on the general curve of Figure 25, then it appears that 0.73 is well within the experimental scatter shown by all the friction data. Therefore, $\mu_{s_{\text {max. }}}, \mu_{s_{\text {min. }}}$ are considered to be unaffected by temperature increases for the limited temperature range investigated.

\subsubsection{Discussion of Temperature Results}

In light of this information and by further examination of equations (6) and (8), which show that the upper and lower asymptotes for $\mu_{s}$ are determined by $p_{m}, T_{0}$ and $k_{1}, k_{2}$, the elastic modulii, it appears that temperature has very little effect on the elastic modulii of the interface. It has however a significant effect on $c$, the viscosity parameter.

Quantitatively then, over a limited range of temperature, the $\mu_{s}-\dot{\theta}$ equations would be modified by substituting $c(T)$ for 
c as follows:

$$
c=c(T)=p e^{(\Delta E / B T)} \quad[47]
$$

using the viscosity-temperature relationship derived for monolayers. $\Delta \mathrm{E}$ is the activation energy for flow, $\mathrm{B}$ is Boltzman's constant and $\mathrm{p}$ is a suitable constant.

It is interesting to estimate $\Delta \mathrm{E}$ as Matijevic [47] has given a value of $11 \mathrm{Kcal} / \mathrm{mole}$ for the activation energy for flow in calcium stearate monolayers. From (19):

$$
\text { In } c=p+\frac{\Delta E}{B T}
$$

Given the relaxation times, $\tau_{i T}$, for $22^{\circ} \mathrm{C}, 35^{\circ} \mathrm{C}$ and $50^{\circ} \mathrm{C}, \Delta \mathrm{E}$ is determined from a semilog plot, Figure 28 to be 28.5 (Kcal/gm-mole).

Over a limited range of temperatures, the $\mu_{\mathbf{s}}-\dot{\theta}$ equations would be modified as follows:

$$
\left.-1.46+\frac{c(T)}{k} \dot{\theta}\left[1-e^{-\left[\frac{k}{c(T)} \frac{\mu_{s}}{\dot{\theta}}\right.}\right]\right]+2.08 \mu_{s}=0
$$

or

$$
-1.46+\frac{\tau(T) k_{2}}{k_{1}+k_{2}} \dot{\theta}\left[1-e^{\left.-\left[\frac{\mu_{s}}{\dot{\theta} \tau(T)}\right]\right]+2.08 \mu_{s}=0 \ldots \ldots}\right.
$$

If the surface, temperatures are kept within a limited range (certainly below the decomposition or desorption temperatures of the film), then $\dot{\theta}$ and temperature effects on static friction would give the $\mu_{s}-\dot{\theta}-\mathrm{T}$ curve shown in Figure 29(a). The upper and lower asymptotes are not functions of $\mathrm{T}$.

If temperature increases affect the asymptotes ( $k$ values as well as c values are temperature dependent but as discussed earlier 
$\mathrm{T}_{\mathrm{o}}$ and $\mathrm{p}_{\mathrm{m}}$ are unaffected) then the $\mu_{\mathrm{s}}-\dot{\theta}-\mathrm{T}$ surface of Figure 29(b) would be expected.

One single cross-sectional curve of the "friction surface" described by $\mu_{s}, \dot{\theta}$ and $\mathrm{T}$ was obtained and it is shown in Figure 30. $\dot{\theta}$ was kept constant at $0.345 \mathrm{sec}^{-1}$ while the temperature of the calcium stearate covered surface was raised to $60^{\circ} \mathrm{C}$ in $5^{\circ} \mathrm{C}$ increments. The friction coefficient gradually climbed from 0.50 at $22^{\circ} \mathrm{C}$ to 0.68 as the temperature was raised to $60^{\circ} \mathrm{C}$. Since changing the temperature changes the relaxation time, $\tau$, and not the asymptotes, the $\mu_{s}-\dot{\theta}-\mathrm{T}$ data should also collapse on the general $\mu_{s}-\tau^{*}$ curve obtained earlier. : The relaxation times at each temperature, $\tau_{i T}$, were determined from the appropriate $\mu_{s}-\dot{\theta}$ data. Using $\tau^{*}=\tau_{i T} \dot{\theta}$, the experimental data was replotted in Figure 31. The agreement is good. The significance of this finding is that, once $\Delta \mathrm{E}$ has been determined, then the relaxation time at any other temperature, $\mathrm{T}_{j}$, can be calculated using equation (15). Knowing the relaxation time means that the $\mu_{s}-\dot{\theta}$ curve at $T_{j}$ can be predicted. Of course for this approach to be valid, $T_{j}$ must not exceed the limits set earlier.

More extensive theoretical and experimental studies of the $\mu_{S}=\dot{\theta}-T$ relationship may yield a general method for normalizing friction curves for both static and kinetic friction. Excellent results have already been obtained in developing a "master curve" which gives temperature and sliding velocity effects on the friction of rubber on glass [27]. 
VI. SUMMARY AND GENERAI DISCUSSION OF RESULTS

\subsection{Summary}

The experimental part of this investigation showed that a monolayer of an organic compound will cause the static friction coefficient, $\mu_{s}$, of a steel/steel friction couple to exhibit a rate dependency.

Four organo-metallic soap monolayers, deposited on mild steel samples by the Langmuir Blodgett technique were intensively studied. Over certain ranges of $\dot{\theta}$, the static friction values were relatively low, 0.47 . When $\dot{\theta}$.dropped below a critical value, however, the $\mu_{s}$ values rose until a maximum of $\mu_{s}=0.70$ was reached. The $\mu_{s}-\dot{\theta}$ data for all four monolayer-covered surfaces were adequately described by a modified version of the theoretical model for $\mu_{s}-\dot{\theta}$ introduced by Johannes [19]. The model is based on the premise that the real area of contact between the surfaces determines $\mu_{s}$ and that the amount of this contact area is determined by $\dot{\theta}$ and the physical properties of the interfacial region. In the theoretical prediction of $\mu_{S}-\dot{\theta}$ values, the contact area at any rate $\dot{\theta}$ was derived by assuming that the deformation of the "interface" could be represented by a mechanical model made up of elastic and viscous elements. The failure condition was that slip occurred when $T_{0}$ was exceeded. Unfortunately, the exact value for $T_{0}$ is not available but it should be less than $0.2 \mathrm{p}_{\mathrm{m}}$ which represents the shear strength/unit area of the metal substratum. Two mechanical model representations of the deformation were examined. For the simplest model, the actual value of $\left(\mathrm{T}_{\mathrm{o}} / \mathrm{p}_{\mathrm{m}}\right)$ was too high. This model was rejected in favor of the more general 3-parameter linear solid-Prandtl model for area growth. 


\subsection{The Contact Area at Slip}

Initially, the area of contact is $A_{0}=\left(N / p_{m}\right)$. It is composed of regions of metal - nonmetal contact as well as metal - metal contact. 'When slip occurs:

$$
\mu_{S}=\frac{T_{O} A_{O}}{N}\left(1+\varepsilon\left(t_{f}\right)\right) .
$$

The contact area at slip can be calculated if $\mathrm{T}_{\mathrm{o}}$, the shear strength/per unit area of the interface is known. If $\left(\mathrm{T}_{\mathrm{o}} / \mathrm{p}_{\mathrm{m}}\right) \simeq 0.2$, then the contact area at slip has a value of $A_{O}\left(1+\varepsilon\left(t_{f}\right)\right)=3.5 A_{O}$ at $\mu_{S}=\mu_{\max }=$ 0.70. This is the maximum contact area (for $\left(\mathrm{T}_{\mathrm{o}} / \mathrm{p}_{\mathrm{m}}\right) \simeq 0.2$ ) for all $\dot{\theta}$. It is the contact area at very low loading rates, $\dot{\theta} \ll 1$. The corresponding minimum value is $A_{0}\left(1+\varepsilon\left(t_{f}\right)\right)=2.35 \mathrm{~A}_{\mathrm{o}}$ when $\mu_{\mathrm{s}}=\mu_{\min }=0.47$ for $\dot{\theta}>1$.

From the theoretical prediction for the upper and lower asymptotes, $\mu_{\max }, \mu_{\min }$ and the preceeding discussion of contact area, it is obvious that both the maximum and the minimum extent of area growth responds to the interface $\mathrm{T}_{\mathrm{o}} / \mathrm{p}_{\mathrm{m}}, \mathrm{k}_{1}, \mathrm{k}_{2}$ values and not to the interface viscosity term:

$$
\mu_{\mathrm{s} \max .}=\frac{\mathrm{T}_{\mathrm{o}}}{\mathrm{P}_{\mathrm{m}}}\left[\frac{1}{1-\frac{\mathrm{T}_{\mathrm{o}}}{\mathrm{k}_{1}}}\right]
$$

and

$$
\mu_{\mathrm{s} \min .}=\frac{\mathrm{T}_{\mathrm{o}}}{\mathrm{p}_{\mathrm{m}}}\left[\frac{1}{1-\mathrm{T}_{\mathrm{o}}\left[\frac{1}{\mathrm{k}_{1}+\mathrm{k}_{2}}\right]}\right]
$$

At this point, it is useful to consider the conditions under which a rate-dependency will be observed. 
a) Since $\left[\mu_{s} \max .-\mu_{s}\right.$ min. $]$ represents the "spread" in static friction values, it is obvious that if $k_{2} \ll k_{1}$ for a given interface, then $\left[\mu_{s} \max .-\mu_{s}\right.$ min. $] \rightarrow 0$ and no rate-dependency will be discernible. In these cases, $\mu_{s}(\dot{\theta}) \simeq \mu_{s} \max$. for all $\dot{\theta}$. For most friction experiments, the scatter is at least $5 \%$ so that small $\mu_{s} \max$. $\mu_{s}$ min. values will not be noticed.

b) Even though the asymptotes are not sensitive to the viscosity term, the ratio $\left[\frac{c}{k_{1}+k_{2}}\right]$, the relaxation time is still an important property of an interface. It determines where the $\mu_{s}-\dot{\theta}$ curve will lie on the $\dot{\theta}$ axis. Since small $\left[\frac{c}{k_{1}+k_{2}}\right]$ ratios shift the $\mu_{s}-\dot{\theta}$ curve to the right side of the $\dot{\theta}$ axis, $i t$ is possible that the full shape of the curve will only be visible if $\dot{\theta}$ is relatively' large. If this is the case for a particular interface, then over the rest of the range of $\dot{\theta}$ values, $\mu_{s}$ may appear constant at $\mu_{s}=\mu_{s \max } \cdot$ Similarly, if $\left[\frac{c}{k_{1}+k_{2}}\right]$ is large, the $\mu_{s}-\dot{\theta}$ curve is shifted to the left and $\mu_{s}$ may appear constant at $\mu_{s}=\mu_{s \min .}$

Because of these two factors, a given interface may appear to show no rate-sensitivity over a particular $\dot{\theta}$ range.

\subsection{Applicability of Results to Lubricant Selection}

Although low static friction values are not the sole criterion of boundary lubricant performance, the $\mu_{s}-\dot{\theta}$ curve should be of value in lubricant selection. Certainly in some applications, such as switching gear, static friction values are important. Unfortunately, relevant design data are scarce and poorly tabulated. Individual $\mu_{s}-\dot{\theta}$ curves are useful because finding $\mu_{s}$ is a simple matter: given any normal load at any tangential loading speed, $\dot{\theta}$ is readily calculated. 
More generally, for a series of lubricants which have known upper and lower asymptotes, only their individual relaxation times are required before a particular $\mu_{s}-\dot{\theta}$ curve or a $\left(\mu_{s_{i}}, \dot{\theta}_{i}\right)$ value is fully defined.

Although the majority of the preceeding discussion concerns the friction behaviour of Langmuir-Blodgett monolayers, an examination of the friction behaviour of the ferric stearate monolayer deposited by the abrasion technique shows that this film has bettex lubricating qualities than any of the other soap monolayers. This observation is not surprising when one considers that monolayers formed in this way are strongly bound to the substratum through chemisorption while the Langmuir-Blodgett soap monolayers are only physically adsorbed in the present case and thus more easily disrupted by the applied forces.

Further consideration of the effects of abrading a metallic surface in contact with a surfactant may explain the frequently observed phenomenon of run-in during friction studies. Generally, one observes that with repeated traversals of the same track, the friction coefficient will decrease until it reaches a constant value. Since the sliding process itself generates "clean" areas which are ideal sites for chemisorption, repeated traversals cause the formation of an absorbed. metallic soap and a subsequent decrease in friction. In addition, one must consider that certain metals are capable of catalyzing the oxidation of organic compounds [3]. The formation of these new surfactants, which are also capable of forming friction reducing surface films, may be another factor in run-in.

The temperature work has shown that relaxation times are strongly influenced by temperature increases. If the relaxation time 
for each of two temperatures is experimentally determined, the activation energy'can be calculated. Then, it is possible to construct the appropriate $\mu_{s}-\dot{\theta}$ curve for any other temperature within the given range.

Unfortunately, it is not yet possible to predict quantitatively the $\mu_{s}-\dot{\theta}$ behaviour of an interface from a simple study of monolayer and substrata properties. Additional work along these lines is necessary.

\subsection{A Note on the Time-dependence of Static Friction}

Early investigators of static friction observed that the static friction values were not constant and proposed that the static friction coefficient was a function of "stationary contact time", meaning the time elapsed between the first application of the shearing force and the time at which macroscopic sliding occurred.

Johannes tested their hypothesis by applying a tangential load at a given rate, holding the load constant for time periods up to 100 seconds, then applying further tangential force (at the initial rate) until macroscopic sliding occurred. He found that $\mu_{s}$ for the "delayed stick" test was not significantly larger than the $\mu_{s}$ value for corresponding tests in which the tangentia1 loading by uninterrupted by a delay period. In examining the viscoelastic models for static friction (Equations 6, 10), it is obvious that time is involved in static friction. However, it is probable that no increase in static friction was observed during Johannes creep tests because the amount of area growth during the "delayed stick" time was very small, and the resulting small increase in $\mu_{s}$ was not considered significant.

Given the viscoelastic parameters of the interface, its stress 
history and appropriate creep compliance $J(t)$, it is possible to calculate the increased area growth due to the delay time. Consider an interface with calcium stearate as the monolayer and steel as the substratum: at $22^{\circ} \mathrm{C}$, if the interface behaves as a Kelvin-Voigt substance up to the fracture point, then $c / k=40 \mathrm{sec}, \mathrm{p}_{\mathrm{m}} / \mathrm{k}=1 / 1.46$. Given $\dot{\theta}=.005, t_{2}=50$ secs., and the loading history shown in Figure 32, the amount of area growth for delayed stick times of 1 second to $\infty$, was calculated as follows:

$$
A_{0} \text {, the initial contact area is } N / P_{m} \text {. At time } t_{2} \text {, } A_{0} \text { has }
$$
grown to $A_{0}\left(1+\varepsilon\left(t_{2}\right)\right)$. The value of $\varepsilon\left(t_{2}\right)$ is found from the hereditary integral given in equation (3), for a loading time of $t_{2}$. Therefore:

$$
A_{0}\left(1+\varepsilon\left(t_{2}\right)\right)=A_{0}\left[1+\frac{\sigma_{2}}{t_{2} k^{2}}\left(k t_{2}-c\right)+\frac{\sigma_{2}}{t_{2}} \frac{c}{k} e^{-\frac{k}{c} t_{2}}\right]
$$

At $t=t_{3}$, evaluating the same integral for the loading history given by line 2 of Figure 32 which includes the delay period $\left(t_{3}-t_{2}\right)$, the area will be [31]:

$$
A_{0}\left(1+\varepsilon\left(t_{3}\right)=A_{0} \cdot\left[1+\frac{\sigma_{2}}{k}+\frac{\sigma_{2}}{k} \frac{c}{t_{3}}\left[1-e^{\frac{k}{c} t_{2}}\right] e^{-\frac{k}{c} t_{3}}\right]\right.
$$

Therefore, the present area increase due to area growth during the delay is:

$$
D=\frac{A_{0}\left(1+\varepsilon\left(t_{3}\right)\right)-A_{0}\left(1+\varepsilon\left(t_{2}\right)\right)}{A_{0}\left(1+\varepsilon\left(t_{2}\right)\right)} \times 100 \%=\left[\frac{1+\varepsilon\left(t_{3}\right)}{1+\varepsilon\left(t_{2}\right)}-1\right] \times 100 \%
$$

where:

$$
\sigma_{2}=\frac{\dot{\mathrm{F}} \mathrm{t}_{2}}{\mathrm{~A}_{\mathrm{o}}}=\dot{\theta} \mathrm{p}_{\mathrm{m}} \mathrm{t}_{2}
$$




$$
\frac{c}{k}=40 \mathrm{sec} \cdot \frac{\mathrm{k}}{\mathrm{p}_{\mathrm{m}}}=1.46 \quad \mathrm{t}_{2}=50 \mathrm{sec}
$$

Using these values, the area at $t_{2}$, immediately when the delay time begins, is $1.07 \mathrm{~A}_{0}$. The area at $t_{3}$ is $A_{0}\left[1.171-.34 e^{-t_{3} / 40}\right]$. The \% increase in area due to delay time is plotted in Figure 33. For a delay time of 1 second, the area is increased by $0.5 \%$, an insignificant amount. The maximum area growth occurs when the delay time is infinite; even then the area increase in only $9.5 \%$. For $\dot{\theta}=.005$, $\mu_{s}$ for no delay tangential loading is 0.60 . Therefore:

$$
\mu_{S}=\frac{F_{\text {final }}}{N}=T_{0} A_{\text {final }}=.60 .
$$

If, due to the delay time, the final area increases by the maximum amount, $10 \%$, then $\mu_{s}$ would increase to approximately 0.66 from 0.60 , and increase which might be considered significant, depending on the amount of scatter in the data. Certainly considering the results obtained for calcium stearate, Figure 21 , the scatter band is such that area increases less than $5 \%$ would not be considered significant. Therefore, in this case, for delay times less than 50 seconds, no time effects would be noticeable. This calculation indicates why Johannes [19] did not observe significantly increased $\mu_{s}$ values and why the electrical resistance measurements of Green [16] did not indicate appreciable area growth during the delayed static contact period even though static friction is time dependent.

The experimental results of: Seireg and Weiter [57] provide additional information on a viscoelastic model of static friction. They conducted creep tests in much the same manner as Johannes with the exception that they were able to measure the very small amounts of micro- 
slip (of the order of .00005 inches) which took place during the creep test. They also consiclered using a viscoelastic model to explain their results and found that the 3-parameter model adequately approximated the observed creep. It is interesting to examine their results further. Based on their values for creep displacement, the relaxation time for the three parameter model has been calculated as $0.13 \mathrm{sec}$. This compares very favourably with the results of the present study. Unfortunately, Seireg and Weiter did not include sufficient data on loading rates so that calculating a $\mu_{s}-\dot{\theta}$ curve for their system was impossible. 


\section{CONCLUSIONS}

Previous investigations of static friction have shown that the static friction coefficient of a steel/steel friction couple largely

depends on the magnitude of the rate parameter, $\dot{\theta}$, for the range $.0001<\theta<10$.

The first part of the present experimental work was concerned with finding the cause of this observed rate dependence. Static friction vs $\dot{\theta}$ studies under high vacuum conditions showed no rate effect over the range $.0001<\dot{\theta}<2$ for steel surfaces. The static friction value $\mu_{S}$, was somewhat lower than initially expected but when the effect of residual surface contamination was considered, 0.70 was thought to be a reasonable value.

No rate effects were observed in this range of $\dot{\theta}$ values when oxide films were deliberately grown on the steel surfaces. The friction coefficients were high $(0.80$ and 0.70$)$ for oxide films formed by two methods: heating at $250^{\circ} \mathrm{C}$ in air and by immersing the samples in $\mathrm{H}_{2} \mathrm{O}$ of $\mathrm{pH} 4.0$.

When monolayers of organometallic soaps were deposited on the surface, however, the static friction coefficient did show the expected rate dependency. One conclusion arising from this work was that, since the static friction of reasonably clean steel samples was independent of $\dot{\theta}$, the rheology of surface films was a large factor in determining the static friction characteristics. The exact shape of the $\mu_{s}-\dot{\theta}$ curve depended on the metallic soap deposited on the surface as well as on the method of deposition. Five soap monolayers were investigated. Four monolayers, calcium oleate, calcium stearate, and the basic iron soaps of stearic acid were deposited using the Langmuir- 
Blodgett technique. The fifth monolayer, ferric stearate was grown in situ by abrading the steel surface under a solution of stearic acid in n-hexanes. For the stearic acid soap monolayer deposited by the abrasion technique, $\mu_{s}$ max. was 0.39 and $\mu_{s}$ min. was 0.22 . For the four soap monolayers deposited by the Langmuir-Blodgett method, $\mu_{s_{\max } \text {. was }}$ 0.70 and $\mu_{s_{\min }}$ was 0.47 . Although the upper and lower asymptotes were the same for each curve, the curves were displaced from one another on the $\dot{\theta}$ axis. An examination of possible theoretical models showed that the static friction behaviour for steel surfaces covered with any of these four Langmuir-Blodgett monolayers is adequately described by:

$$
-1.46+\tau \dot{\theta}\left[1-\mathrm{e}^{-\frac{\mu_{s}}{\tau \dot{\theta}}}\right]+2.08 \mu_{s}=0
$$

where $\tau$ is the relaxation time for the interface.

The theoretical model for static fxiction implicitly assumes that the origin of frictional resistance. lies in the breaking of the short-range metal-metal bonds formed at areas of contact. A further assumption is that the final contact area between the surfaces is a function of $\dot{\theta}$ because the interface has the deformation characteristics of a viscoelastic solid. It is also assumed that slip will occur only when the tangential shearing stress exceeds a certain value, $T_{0} \cdot$ Using (23), it was possible to calculate relaxation times for each of the monolayer-covered surfaces from the experimental $\mu_{s}-\dot{\theta}$ data. These relaxation times provide some indication of a particular monolayer's effectiveness as a boundary lubricant. Monolayers which had high relaxation times gave low static friction coefficients over the largest part of the $\dot{\theta}$ range. Conversely low relaxation times mean $\mu_{s}=\mu_{s} s_{\max }$. for most $\dot{\theta}$ values. 
The relaxation time of the calcium stearate-covered interface decreased as the substratum temperature was increased. This effect is important because it shows how $\mu_{s}$ is affected by temperature -- a particular monolayer may be adequate at room temperature but at $50^{\circ} \mathrm{C}$, the static friction coefficient may be as high as $\mu_{s_{\max }}$

In the discussion section, the prerequisites for observing rate dependence were briefly discussed. They are:

1. the numerical values of $k_{1}$ and $k_{2}$ for an interface must be such that the difference between $\mu_{s_{\max }}$ and $\mu_{s_{\min }}$ is detectable;

2. the relaxation time, $\left[\frac{c}{k_{1}+k_{2}}\right]$, must be large enough, or the range of $\dot{\theta}$ must be wide enough to show the expected $\mu_{s}-\dot{\theta}$ curve.

One of the inadequacies of friction research from the designer's point of view is that it is still very difficult to find the appropriate friction data in a concise, useable form. Thus, the possibilities of the general $\mu_{s}-\tau *$ curve look promising. If 3 values for an interface, 1) the asymptotes, 2) the relaxation time, and 3 ) the temperature coefficient were published, then the $\mu_{s}$ value at a given $\dot{\theta}$ for a given temperature could be calculated from the general $\mu_{s}-\tau$ * curve.

In the preceeding work, the source of the viscoelasticity was identified and some advances in modelling static friction were made. This method of modelling static friction is essentially a study of macroscopic behaviour but it also provides some insight into friction phenomena at the microscopic level. 
Bibliography

1. Johnson, K.L.; "Deformation of a Plastic Wedge by a Rigid Flat Die Under the Action of a Tangential Force", Journal of Mechanics and Physics of Solids, Vol. 16, p. 395 (1968).

2. Simkins, T.E.; "The Mutuality of Static and Kinetic Friction", Lubrication Engineering, p. 26, January (1967).

3. Bowden, F.P., Tabor, D.; The Friction and Lubrication of Solids, Volume II, Clarendon Press, Oxford (1965).

4. Archard, J.F.; "Elastic Deformation and the Laws of Friction", Proceedings of the Royal Society (London), Series A, Vol. 243, p. $190(1957)$.

5. Archard, J.F.; "Single Contact and Multiple Encounters"; Journal of Applied Physics, Vol. 32, No. 8, p. 1420 (1961).

6. O'Connor, J.J., Johnson, K.L.; "The Role of Surface Asperities in Transmitting Tangential Forces Between Metals", Wear, Vol: 6, p. 118 (1963).

7. Greenwood, J.A., Williamson, J.B.P.; "Contact of Nominally Flat Surfaces", Proceedings of the Royal Society (London), Series A, Vol. 295, p. 300 (1966).

8. Greenwood, J.A.; "The Area of Contact Between Rough Surfaces and F1ats", Journal of Lubrication Technology, p. 81 (January 1967).

9. Rabinowicz, E.; Friction and Wear of Materials, John Wiley and Sons, New York (1965).

10. Ko, P.L.; "Autonomous Quasi-harmonic and Forced Vibration of Frictional Systems", Department of Mechanical Engineering, The University of British Columbia (1965).

11. Potter, A.F.; "A Study of Friction Induced Vibration", M.A. Sc. Thesis, Department of Mechanical Engineering, The University of British Columbia (1962).

12. Davis, H.R.; "The Dependence of the Static Coefficient of Friction on the Time of Stationary Contact", M.A. Sc. Thesis, Department of Mechanical Fngineering, The University of British Columbia (1966).

13. Cameron, R.; "Friction Induced Vibration", M.A. Sc. Thesis in Nechanical Engineering, The University of British Columbia (1963).

14. Courtney-Pratt, J.S., Eisner, E.; "The Effect of a Tangential Force on the Contact of Metallic Bodies", Proceedings of the Royal Society (London), Series A, 233, p. 529 (1957). 
15. Green, M.A.; "Some Fundamental Aspects of Static Friction", M.A. Sc. Thesis, Department of Mechanical Engineering, The University of British Columbia (1971).

16. Bowden, F.P., Leben, L.; "The Friction of Lubricated Metals", Phil. Trans., A239, p. 1 (1946).

17. Akhniatov, A.S.; Molecular Physics of Boundary Friction, Israel Program for Scientific Translations, Jerusalem (1966). 18. Metal Deformation Processes - - Friction and Lubrication, Schey, J.A.,

19. Johannes, V.I.; "Friction Induced Vibrations in a Hydraulically Driven System", Ph.D. Thesis, Department of Mechanical Engineering, The University of British Columbia (1969).

20. Bowden, F.P., Tabor, D.; "The Friction and Lubrication of Solids", Volume I, Clarendon Press, Oxford (1954).

21. Marion, T.L.; "Transitory Static and Kinetic Boundary Friction Mechanisms", Ph.D. Thesis, Department of Mechanical Engineering, The University of British Columbia (1972).

22. Bowden, F.P., Tabor, D.; "Friction, Lubrication and Wear: A Survey of Work During the Last Decade", Journal of Applied Physics, Vol. 17, p. 1521 (1966).

23. Hardy, Sir W.B.; Collected Works (1936).

24. Schulman, J.H., Waterhouse, R.B., Spink, J.A.; "Adhesion of Amphipathic Molecules to Solid Surfaces", Kolloid Zeitschriff, Pand 146,
p. 78 (1955). 25. Tschoegl, N.W.; "Elastic Moduli in Monolayers", J. Colloid Sci.,
13, p. 500 (1958).

26. Bowden, F.P., Moore, A.C.; "Physical and Chemical Adsorption of Long Chain Compounds on Metals", Research 2, p. 585 (1949). 27. Moore, D.F.; The Friction and Lubrication of Elastomers, Pergamon
Press, Toronto (1972).

28. Adhesion or Cold Welding of Materials in Space Environments, ASTM, stp 431, ANERICAN SOCTETY FOR TESTING AND NATERIALS, Philadelphia,

29. Kragelskii, I.V.; "Friction and Wear", Butterworths, Toronto (1965).

30. Shchedrov, V.; "On Preliminary Displacenent", Proc. Conf. on Lubrication and Wear, Inst. Mech. Eng. London (1957). 3.1. Viscoelasticity, H. Flugge, Blaisdell Publishing Company, Toronto, 
32. Kinizuka, H.; "The State of Metal Ion in Aqueous Solutions and its Surface Chemical Effects. III. Rheological Study for the Effect of Metal Ions on the Monolayer of Stearic Acid", Bu11. Chem. Soc. Japan, 29, p. 123 (1956).

33. Sasaki, T., Kimizuka, H.; "Physiochemical Properties of the Surface of Aqueous Solutions. III. Mechanical. Behaviour of Surface of: Micellar and Macromolecular Solution", Bull. Chem. Soc. Japan, 25, p. 318 (1952).

34. Wolstenholme, G.A., Schulman, J.H.; "Metal-Monolayer Interactions in Aqqueous Systems", Trans. Faraday Soc., 47:2, p. 788 .(1951).

35. Durham, K.; "The Interaction of Monolayers of Branched Chain Fatty Acids with Calcium Ions in the Underlying Solution", J.App1. Chem., 5, p. 686 (1955).

36. Deamer, D.W., Cornwe11, D.G.; "Calcium Action on Fatty Acid and Phospholipid Monolayers and its Relation to the Cell Membrane", Eiochim. Biophys. Acta, 116, p. 555 (1966).

37. Sasaki, T., Matuura, R.; "Studies on Monomolecular Films. VII. The Effect of Metallic Ions on the Monomolecular Film of Stearic Acid", Bul1. Chem. Soc. Japan, 24, p. 274 (1951).

38. Matuura, R.; "Studies on Monomolecular Films. VIII. Rigidity of the Monolayer of Stearic Acid on the Surface of Salt Solutions", Bu11. Chem. Soc. Japan, 24, p. 278 (1951).

39. Inaba, A.; "Wettability of Solid Surface. VI. The Effects of Metallic Cations on Stearic Acid Built-up Film", Bul1. Chem. Soc. Japan, 26, p. 43 (1953).

40. Motomura, K., Matuura, R.; "Physiochemical Studies of Stearic Acid Monolayer - Aluminum Ion Interactions. II. The Surface viscoelasticity", Bul1. Chem. Soc. Japan, 35, p. 289 (1962).

41. Spink, J.A., Sanders, V.; "Soap Formation in Monomolecular Films on Aqueous Solutions"; Trans. Far. Soc., 51, p. 1154 (1955).

42. Blodgett, K.B.; "Films Built by Depositing Successive Monomolecular Layers on a Solid Surface", J. Am. Chem. Soc., 57, P. 1007 (1935).

43. Handy; R.M., Scala, L.C.; "Electrical and Structural Properties of Langmuir Films", J. Electrochem. Soc., 113, p. 109 (1966).

44. Gaines, G.L., Jr.; "Some Observations on Monolayers of Carbon-14 Labelled Stearic Acid", J. Colloid Sc., 15, p. 321 (1960).

45. Gaines, G.L., Jr.; Insoluble Monolayers at Liquid-Gas Interfaces, Interscience Publishers, New York (1966).

46. Greenhill, E.B.; "The Lubrication of Metal Surfaces by Mono- and Multi-monolayers", TRANS. FARADAY SOC., 45, p. 631 (1949). 
47. Surface and Colloid Science, Vo1. 5, E. Matijevic, ed., WileyInterscience, New York (1972).

48. Monomolecular Layers, H. Sobotka, ed., American Association for the Advancement of Science, Washington, D.C. (1954).

49. Germer, L.H., Storks, K.H.; "Arrangement of Molecules in a Single Layer and in Multiple Layers":, J. Chem. Phys., 6, p. 280 (1938).

50. Moore, W.J., Eyring, H.; "Theory of the Viscosity of Unimolecular Films", J. Chem. Phys., 6, p. 391 (1938).

51. Bikerman, J.J.; "On the Formation and Structure of Multilayers", Proc. Roy. Soc. (London), A170, p. 130 (1939).

52. Smith, H.A., Allan, K.A.; "The Adsorption of n-Nonadecanoic Acid on Metal Surfaces", J. Phys. Chem,, 58, p. 449 (1954).

53. Smith, H.A., McGil1, R.M.; "The Adsorption of n-Nonadecanoic Acid on Mechanically Activated Surfaces", J. Phys. Chem, 61, p. 1025 (1957).

54. Nelson, H.R.; "The Low Temperature Oxidation of Iron", J. Chem. Phys.,
6, p. 606 (I938).

55. Kruger, J., Yolken, H.T.; "Room Temperature Oxidation of Iron", Corrosion, 20, p. 99t (1963).

56. Langmuir, I.; "The Mechanism of the Surface Phenomena of Flotation", Trans. Faraday Soc., 15, Part 3, p. 62 (1920).

57. Seireg, A., Weiter, E.J.; "Viscoelastic Behaviour of Frictional Hertzian Contacts Under Ramp-type Loads", Proc. Instn. Mech. Engs., Vol. 181, Pt. 3:0, p. $200(1966-1967)$.

58. Bailey, A.I., Courtney-Pratt, J.S.; "The Area of Real Contact and the Shear Strength of Monomolecular Layers of a Boundary Lubricant", Proc. Roy. Soc. A, 227, p. 500 (1955).

59. Tolstoi, D.M., Kaplan, R.L., Lin Fu-sheng and P'an.Pin-yao; "New Experimental Data on External Friction", p. 99, Research in Surface Forces, B.V. Deryagin, ed., Consultant's Bureau, New York (1961)

60. Coelho, E.M.; "FJotation of Oxidized Copper Minerals: An Infrared Spectroscopic Study", Ph.D. Thesis, Department of Mineral Engineering, The University of British Columbia (1972).

61. Derjaguin, B.V., Push, V.E., Tolstoi, D.M.; "A Theory of Stickslip Sliding of Solids", Proceedings of the Conference on Lubrication and Wear, p. 257, Octobex (1957).

62. Howe, P.G., Benton, D.P., Puddington, I.E.; "London-Van der Waals Attractive Forces Between Glass Surfaces", Canadian Journal of Chemistry, 33, p. 1375 (1955). 
63. Kosterin, J.I., Kragelskii, I.V.; "Rheological Phenomena in Dry Friction", Wear, 5, 190-197 (1962).

64. Rabinowicz, E.; "The Nature of the Static and Kinetic Coefficients of Friction": Journal of Applied Physics, Vol. 22, No. 11, pp. 13731379 (1951).

65. Spurr, R.T.; "Creep and Static Friction", British Journal of Applied Physics, Vol. 6, pp. 402-3 (1955).

66. Moore, A.C., Tabor, D.; British Journal of Applied Physics, Vol. 3, p. 299 (1952).

67. Atkins, A.G., Silverio, A., Tabor, D.; "Indentation Hardness and the Creep of Solids", Journal of the Institute of Metals, Vo1, 94 , pp. 369-378 (1966).

68. Mulhearn, T.0., Tabor, D.; "Creep and the Hardness of Metals: A Physical Study", Journal of the Institute of Metals, Vo1. 89, pp. 7-12 (1966).

69. Rosenfield, A.R., Hahn, G.T.; "Numerical Descriptions of the Ambient Low Temperature, and High Strain Rate Flow and Fracture Behaviour of Plain Carbon Steel", TRANS. ASM, 59, p. 962 (1966).

70. Wolstenholme, G.A., Schulman, J.H.; "Metal Monolayer Interactions in Aqueous Systems -- Part. I", Trans. Faraday Soc., 46, p. 475 (1950). 


\section{APPENDIX I}

\section{THE VACUUM SYSTEM}

The ultra-high vacuum system used in this work was purchased from Ion Equipment Corporation of Santa Clara, California. The basic TTSB-200 system is a bakeable, all metal unit, capable of reaching a total pressure of $5 \times 10^{-11}$ torr in 15 hours, including a two-hour bake-out at $250^{\circ} \mathrm{C}$. The vacuum chamber consists of 2 major items -1) a basewell assembly which houses two of the three gas pumping units plus ten 1-1/2" I.D. feedthrough ports, and 2) a metal bell jar which was custom built to our specifications.

A quadrupole type mass spectrometer, also purchased from IEC was added to the vacuum system. It was used as a total pressure gauge and a leak detector as well as a residual gas analyzer.

\section{a) The Pumping System}

A rough vacuum is produced by cryogenic pumping. The dual soxption-pump unit uses $\mathrm{LN}_{2}$ as a coolant and highly porous synthetic (calcium or sodium aluminophosphate) zeolite molecular sieve as the sorbant. These pumps are rated at 110 litres per second $\mathrm{N}_{2}$ and will produce a vacuum in the $10^{-3}$ torr range which is the starting pressure for the ion pumps. Although cryogenic pumping units handle relatively small volumes of gas when compared with mechanical or diffusion pumps, they are vibration free. One other important advantage of using cryogenic pumping in tribological research is that the possibility of contamination due to the backstreaming of pumping oils is eliminated. 
If diffusion pumps are poorly baffled, then the vacuum atmosphere will be contaminated by small amounts of the heavy oils used as the pumping fluid. Molecules of these oils can condense on the test surfaces and thus provide a lubricating film.

The ultra high vacuum is produced using titanium getter pumping and ion pumping. The titaniun getter pump is a four filament titanium sublimator, capable of pumping 4300 1itres per second $\mathrm{N}_{2}$. The titanium is sublimed over $370 \mathrm{sq}$. in. of the $\mathrm{LN}_{2}$ - cooled stainless steel cryoshroud. The work area is shielded from the titaniun sublimation pump. This type of pumping effectively pumps large volumes of gas at high pressures. The ion pump consists of an array of eight $25 \mathrm{l} / \mathrm{sec} . \mathrm{N}_{2}$ magnetic diode units. These units are an integral part of the vacuum chamber. The ion pump assembly is capable of pumping $200 \mathrm{l} / \mathrm{sec}$. air; $60 \mathrm{l} / \mathrm{sec}$. helium or $40 \mathrm{l} / \mathrm{sec}$. argon.

The pumping section of the basewell assembly can be isolated from the upper part of the chamber by a poppet valve. This allows the pumps to maintain a vacuum level of $10^{-8}$ torr or lower in the basewell assembly while the work area is at atmospheric pressure. The basewell assembly also contains 10 feedthrough ports of $1-1 / 2$ inch I.D.

\section{b) Custom Bell Jar}

The custom bell jar unit is shown in situ in Figure 8 . It is 8" high and 12" in diameter. It contains 6 feedthrough ports: 1) 4 ports with $1-1 / 2$ " I.D. of which 2 ports are optical ports, 1 port is used for mounting a standard 3" Iinear motion mechanical feedthrough and the fourth port is used for an electrical feedthrough; 2) 1 large (2-1/2" I.D.) port used for a custom-made 6" 1inear motion mechanical. feedthrough, and 
3) 1 large (2-1/2" I.D.) optical port on the bell jar cover. The bell jar unit also contains a 4" wide by 1 "thick work support platform. I.t is positioned at the base of the chamber and is welded to the inner flange at the chamber base.

c) Measuring the System Pressure

In friction and adhesion work, both system pressures and residual gas composition are important. From a calibration curve of ion pump current vs Nitrogen-equivalent pressure supplied by the manufacturer, it was possible to monitor the pressure in the system down to $10^{-10}$ torr by measuring the ion pump current. However, ion pumps and ionization gauges (a type of ion pump) are sensitive to the type of gas being pumped. Therefore, in order to find the true total pressure of the system, it is necessary to know the composition of the gases being pumped. To accomplish this, a quadrupole-type residual gas analyzer was purchased from IEC. This instrument has a sensitivity of $1 \times 10^{-14}$ torr partial pressure for Nitrogen, a mass range of $I-250$ amu and is capable of resolving adjacent mass peaks to mass 250 . (10\% valley definition of resolution). The residual gas analyzer formed an integral part of the vacuuin system. It could be used in the total pressure mode to give the Nitrogen-equivalent pressure in the chamber and it was used as a sensitive leak detector as well as a mass spectrometer. This instrument was invaluable in detecting small amounts of contamination inadvertently left in the chamber. At the test pressures, $10^{-9}$ torr, a typical analysis would show that the residual gases were primarily $\mathrm{H}_{2}$, He, and Ar (after bake-out). 
APPENDIX II

PROPERTIES OF REAGENTS USED

a) Stearic Acid (Octadecanoic Acid)

$$
\begin{gathered}
\mathrm{CH}_{3}\left(\mathrm{OH}_{2}\right)_{16} \mathrm{COOH} \\
\mathrm{Mol} . \mathrm{Wt} .=284.49 \\
\text { m.p. }=67-69^{\circ} \mathrm{C}
\end{gathered}
$$

This acid was obtained as laboratory grade from Fisher

Scientific.

b) Hexanes

$$
\begin{gathered}
\mathrm{C}_{6}{ }_{14}^{\mathrm{H}_{14}} \\
\text { F.W. }=86.18
\end{gathered}
$$

A mixture of isomers. In the as received condition, it has

a $\mathrm{pH}$ of 0.00 .

$$
\begin{aligned}
& \text { Actual Lot Analysis } \\
& \text { Boiling Range: } 66.1^{\circ}-68.1^{\circ} \mathrm{C} \\
& \text { Density: } \mathrm{g} \cdot / \mathrm{ml} \cdot-0.668 \\
& \text { Residue After Evap.: } 0.0004 \% \\
& \text { Acidity as } \mathrm{CH}_{3} \mathrm{COOH} \mathrm{P} . \mathrm{T} . \\
& \text { Sulphur Cmpds. (as S): } 0.004 \% \\
& \text { Thiophene: } \mathrm{P} \cdot \mathrm{T} . \\
& \text { Reagent grade. }
\end{aligned}
$$$$
\text { c) } \mathrm{HCl}, \mathrm{Ca} \mathrm{CO}_{3}
$$ 
d) $\mathrm{H}_{2} \mathrm{O}$

Double distilled.

e) Oleic Acid Films

Oleic acid: (9-octadecenoic acid)

Mol. Wt. $=282.46$

$\mathrm{C}_{8} \mathrm{H}_{17} \mathrm{CH}: \quad \mathrm{CH}\left(\mathrm{OH}_{2}\right)_{7} \mathrm{COOH}$

Insoluble in $\mathrm{H}_{2} \mathrm{O}$.

Approximate surface pressure on $\mathrm{H}_{2} \mathrm{O}$ at $25^{\circ} \mathrm{C}, 30$ dynes $/ \mathrm{cm}$. 
1. Estimating the activation energy $\Delta \mathrm{E}$ from the shift relaxation time, $\tau$, due to temperature:

$$
\begin{gathered}
\frac{\tau_{1}}{\tau_{2}}=e^{\frac{\Delta E}{k}}\left[\frac{1}{T_{1}}-\frac{1}{\mathrm{~T}_{2}}\right] \\
\ln \frac{\tau_{1}}{\tau_{2}}=\frac{\Delta E}{k}\left[\frac{1}{T_{1}}-\frac{1}{T_{2}}\right] \\
\ln \left[\frac{40}{.5}\right]=\frac{\Delta E}{1.98 \mathrm{cal} / \mathrm{mole}}\left[\frac{1}{295}-\frac{1}{323}\right] \\
\because \Delta \mathrm{E}=28.7 \mathrm{Kcals} / \mathrm{mole} .
\end{gathered}
$$


FIGURES

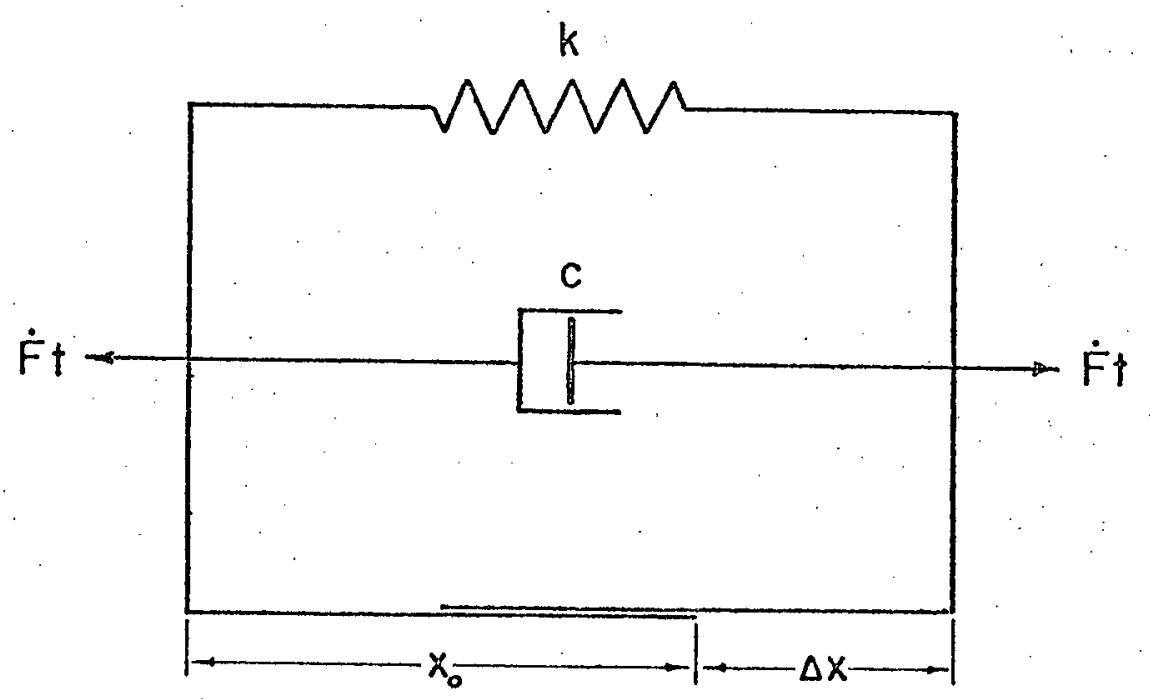

FIGURE 1. Viscoelastic Model of Static Friction Developed by Johannes [19]. 


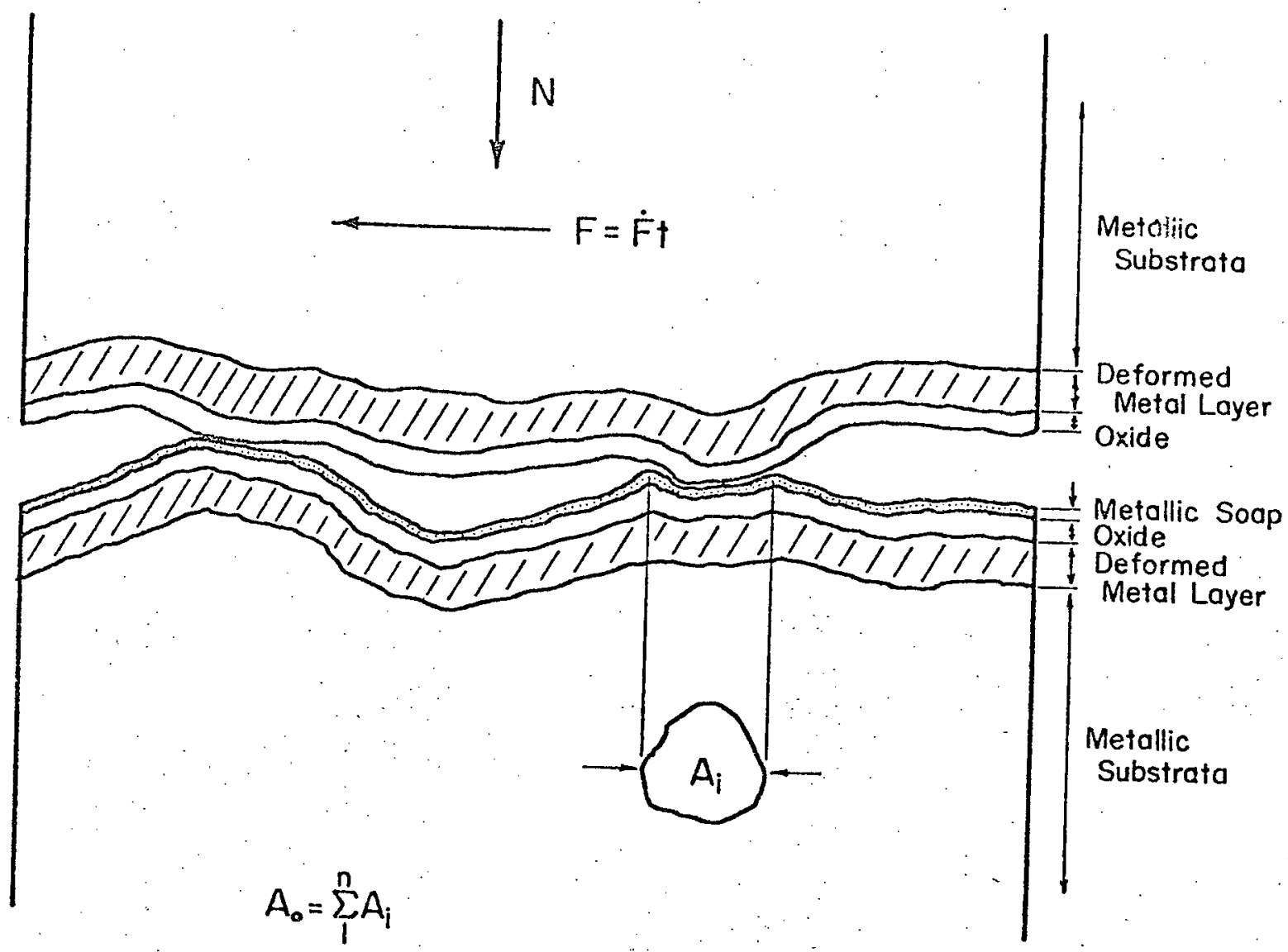

FIGURE 2a. The Contact Area Between Two Solid Surfaces is the Sum of the Smal1 Discrete Areas of Contact Formed Where Opposing Asperities Meet. 


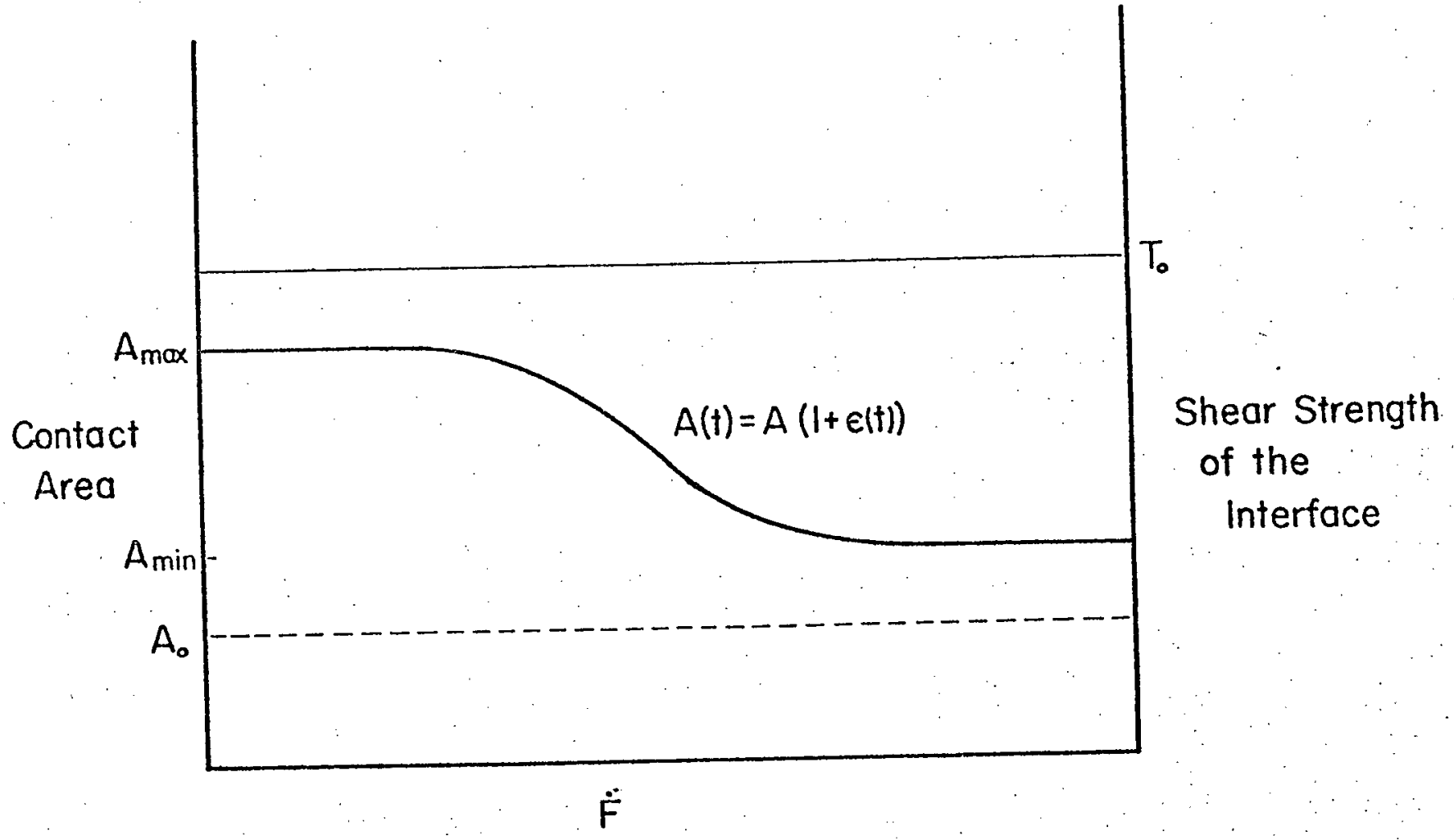

FIGURE 2b. The Area of Contact and the Shear Strength as Functions of the Rate of Application of the Tangential Shearing Force. 


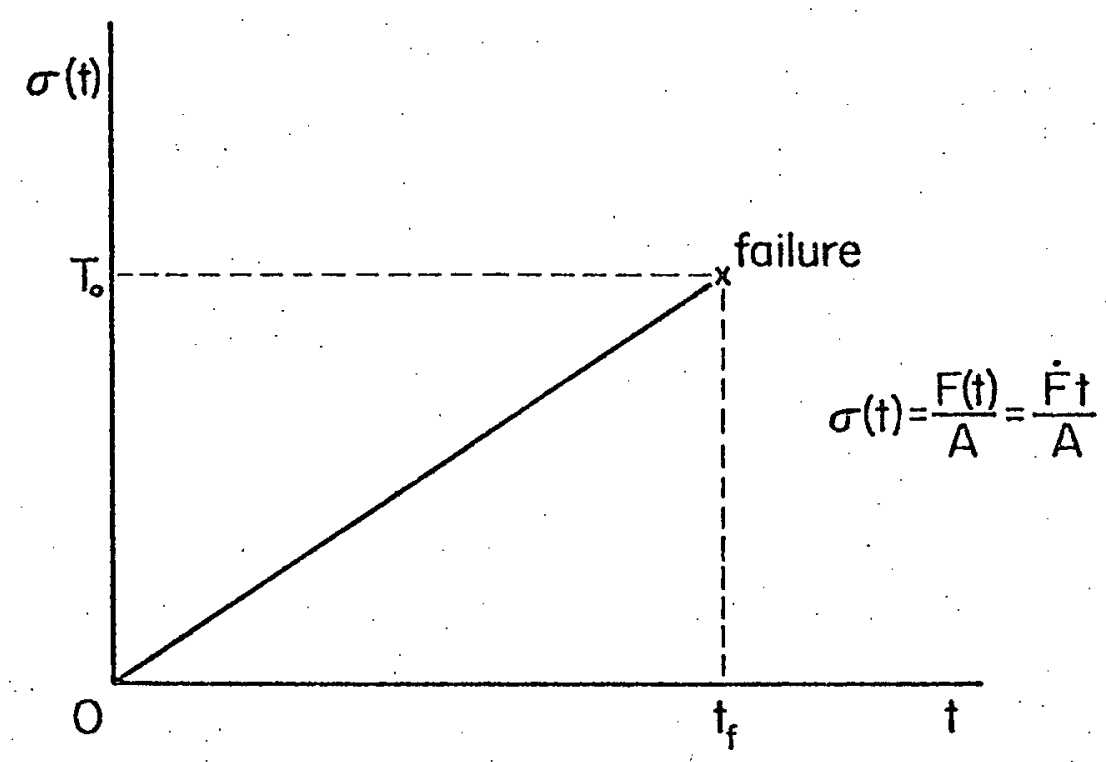

FIGURE 3. Tangential. Loading During a Static Friction Test. 


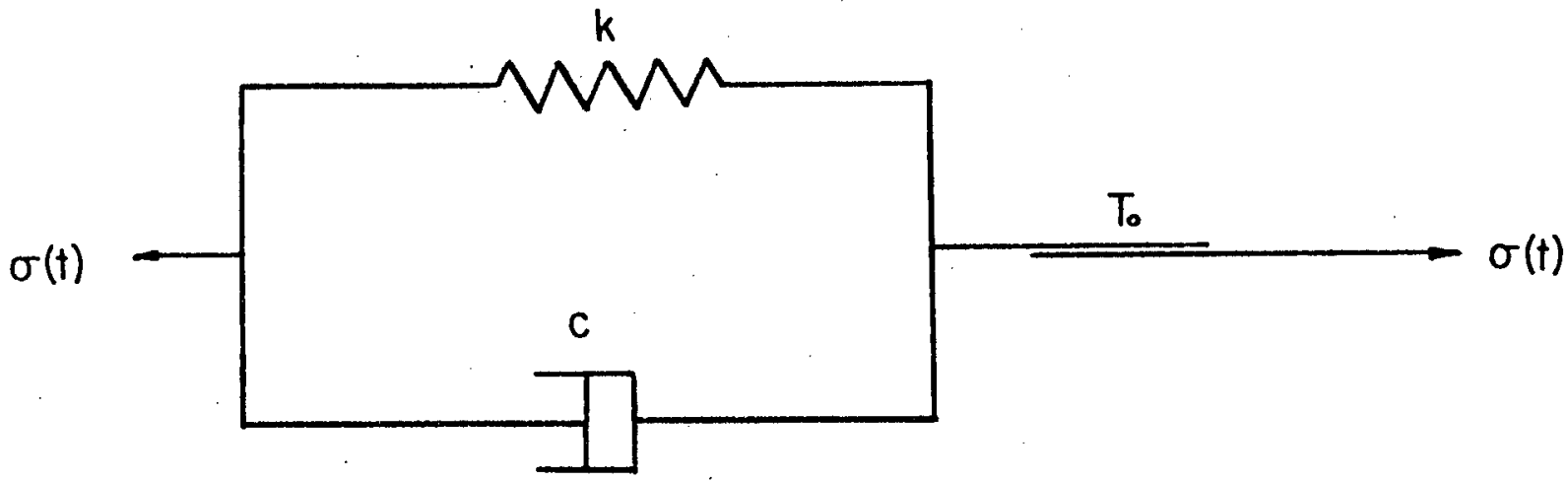

a) The Simplest Mathematical Model for Static Friction Involves a Kelvin-Voigt Element Coupled with a Prandt1-Type Element.

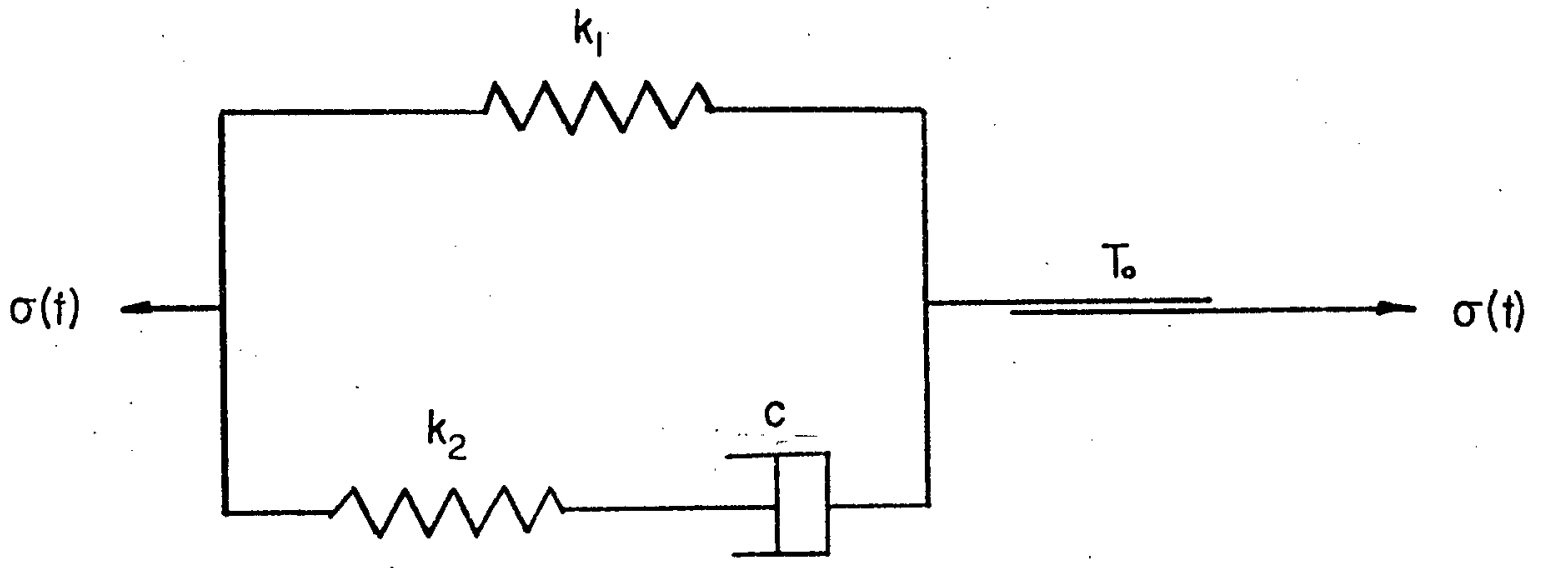

b) More Complicated Model. The Interface Deforms as a General Linear Solid Having a Failure Strength per Unit Area of $\mathrm{T}_{\mathrm{o}}$.

FIGURE 4. Models for Static Friction. 


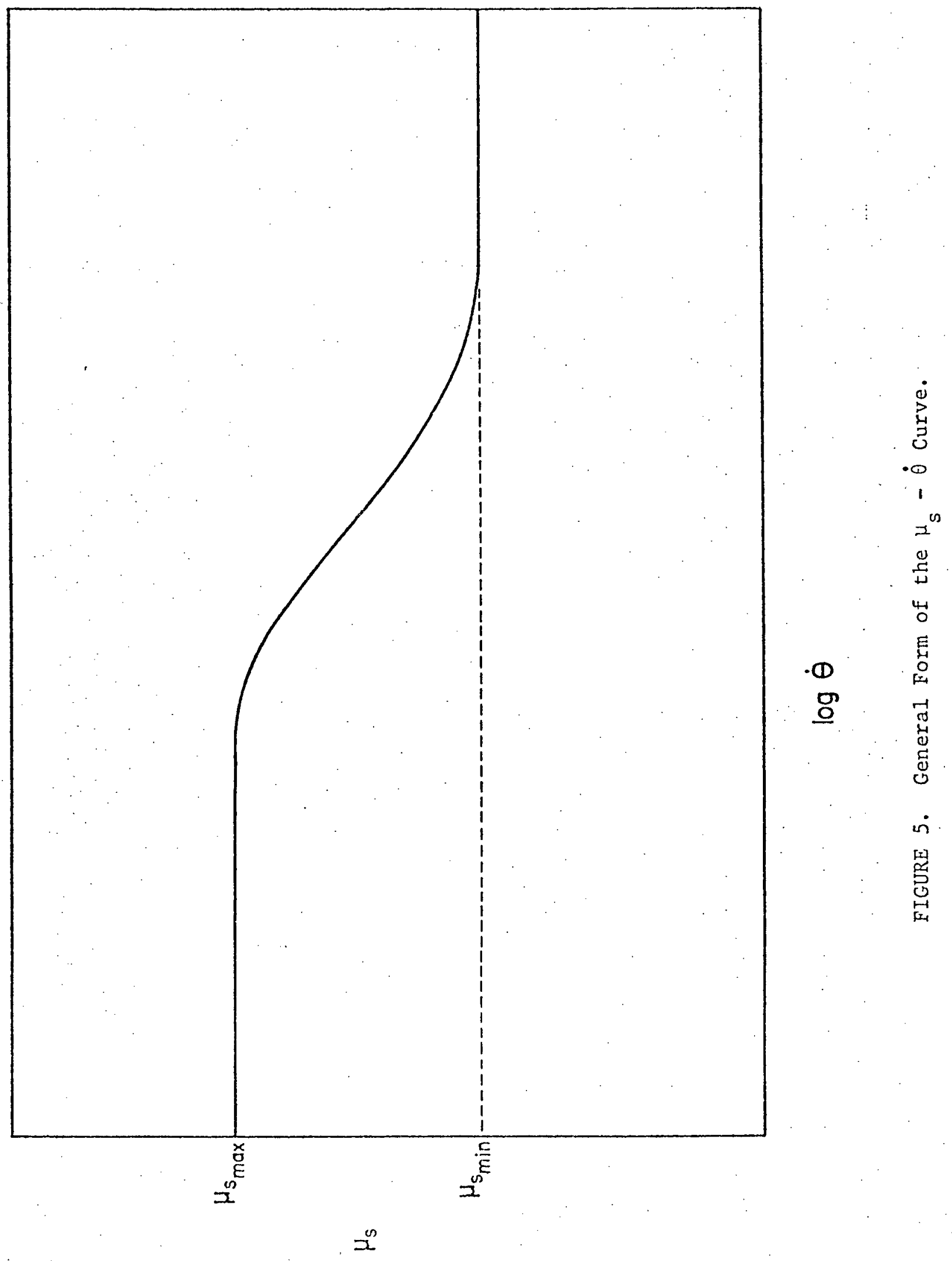




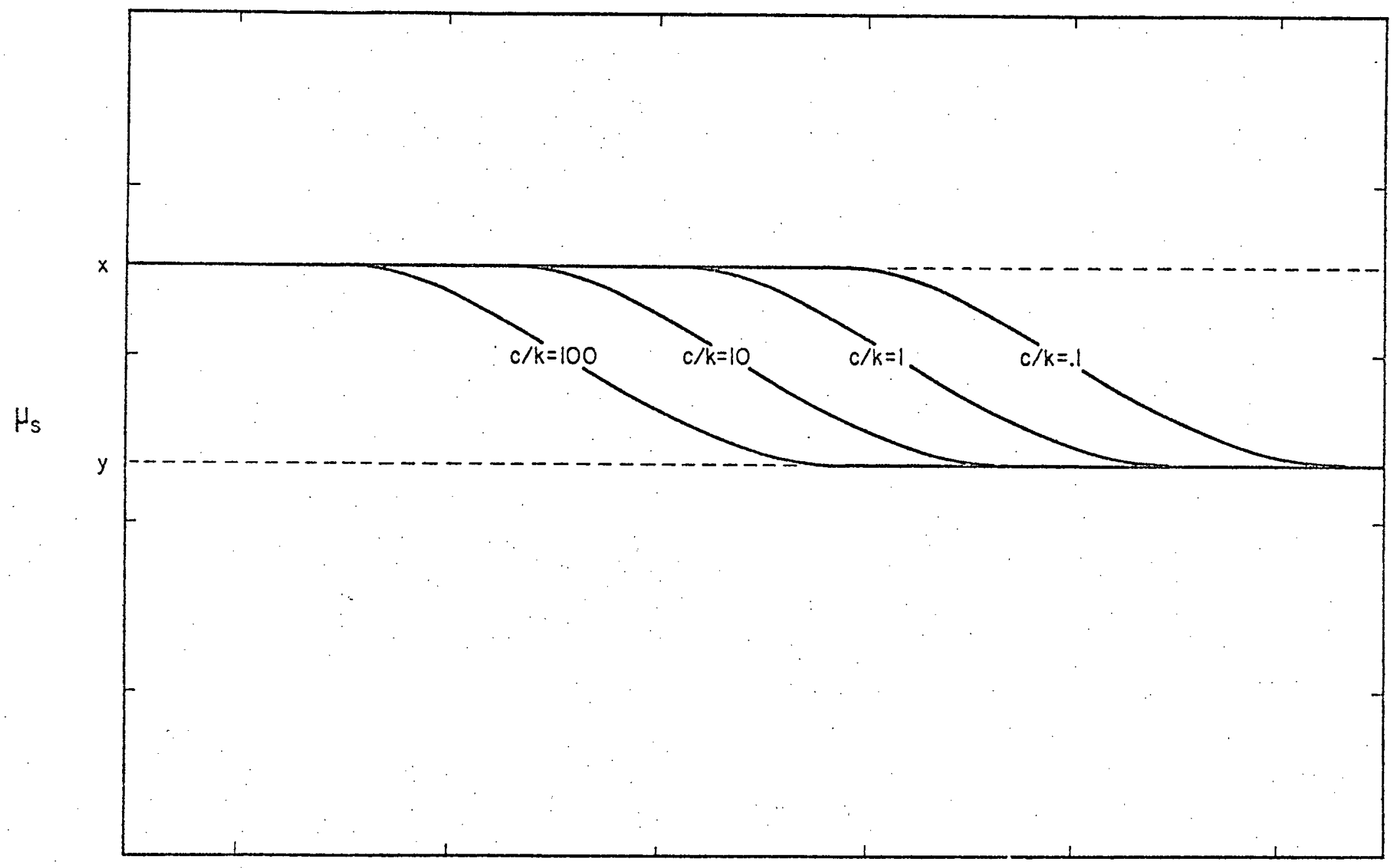

$\log _{10} \dot{\theta}$

FIGURE 6. Changing $c$ Results in a Family of $\mu_{s}-\dot{\theta}$ Curves: 


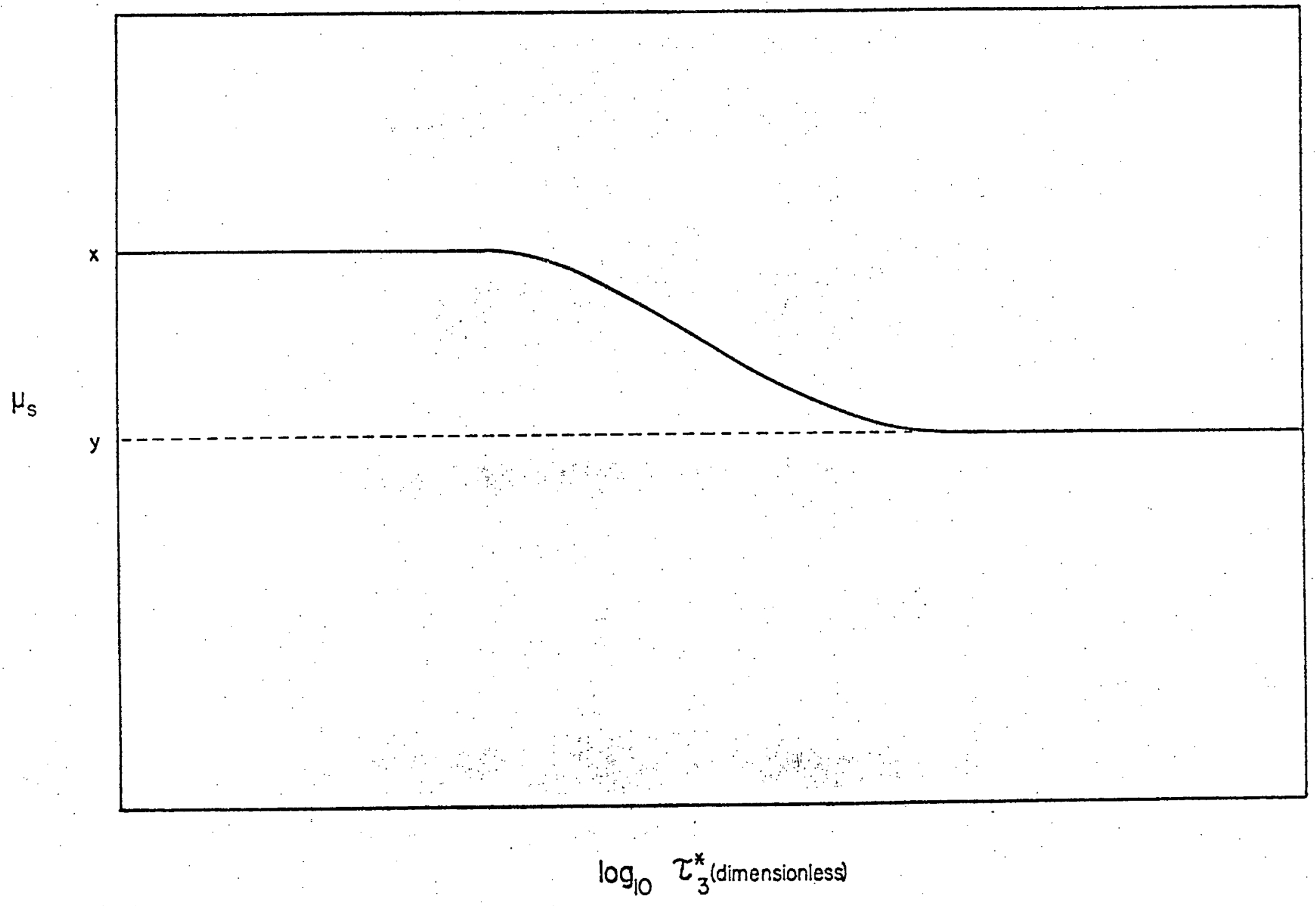

FIGURE 7. The General Static Friction Curve. 


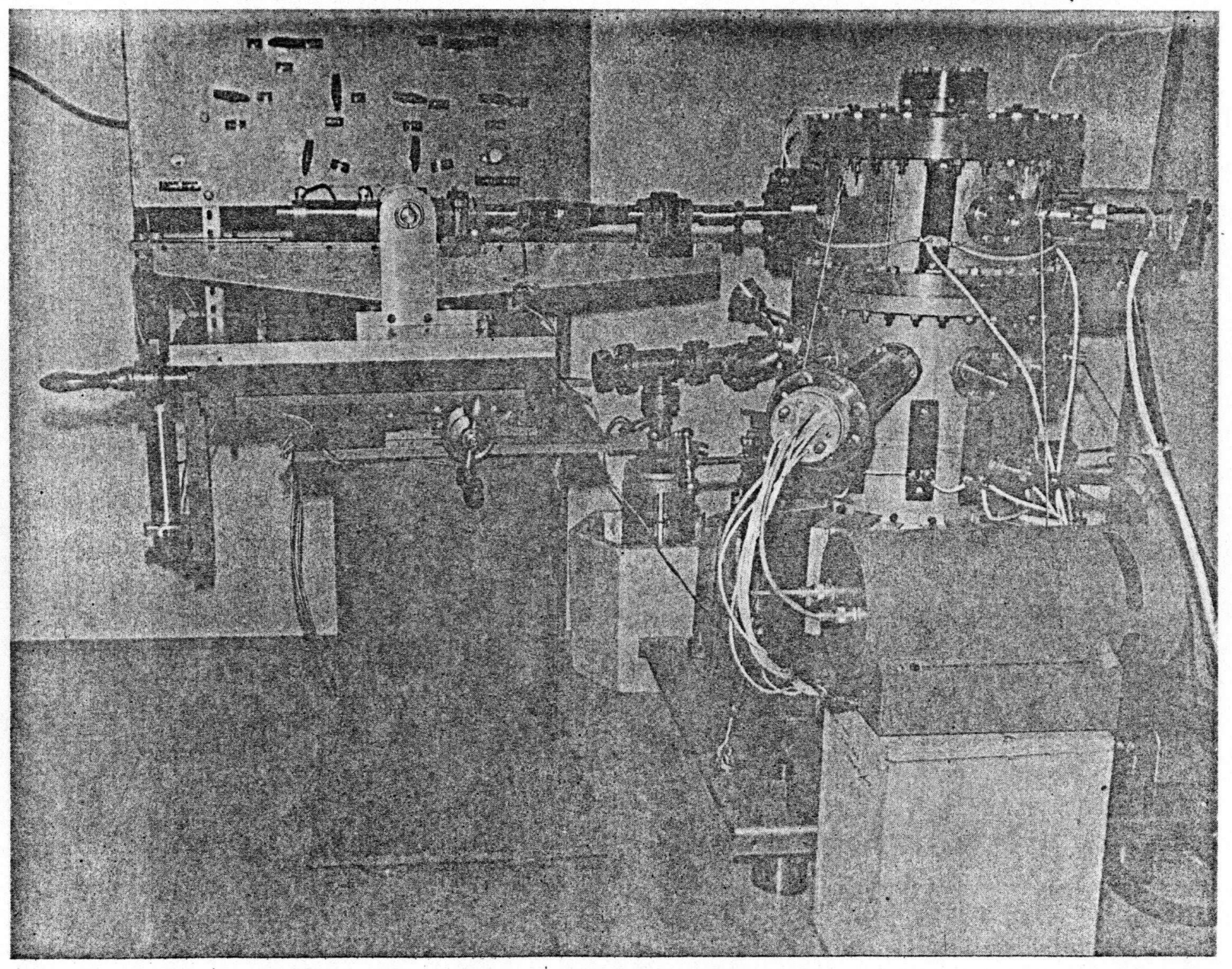

FIGURE 8. General Arrangement of Vacuum System and Experimental Apparatus. 


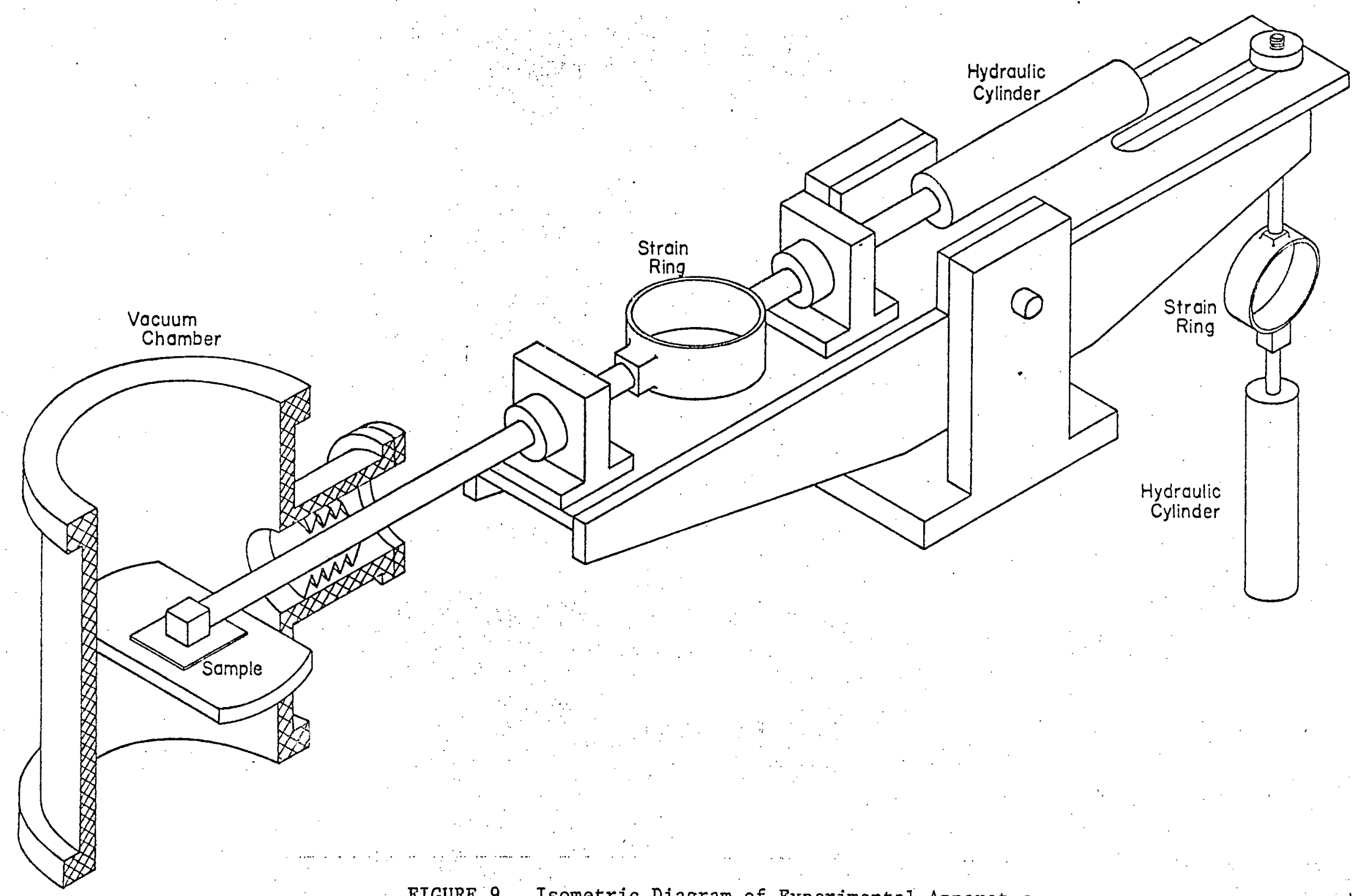

FIGURE 9. Isometric Diagram of Experimental Apparatus. 


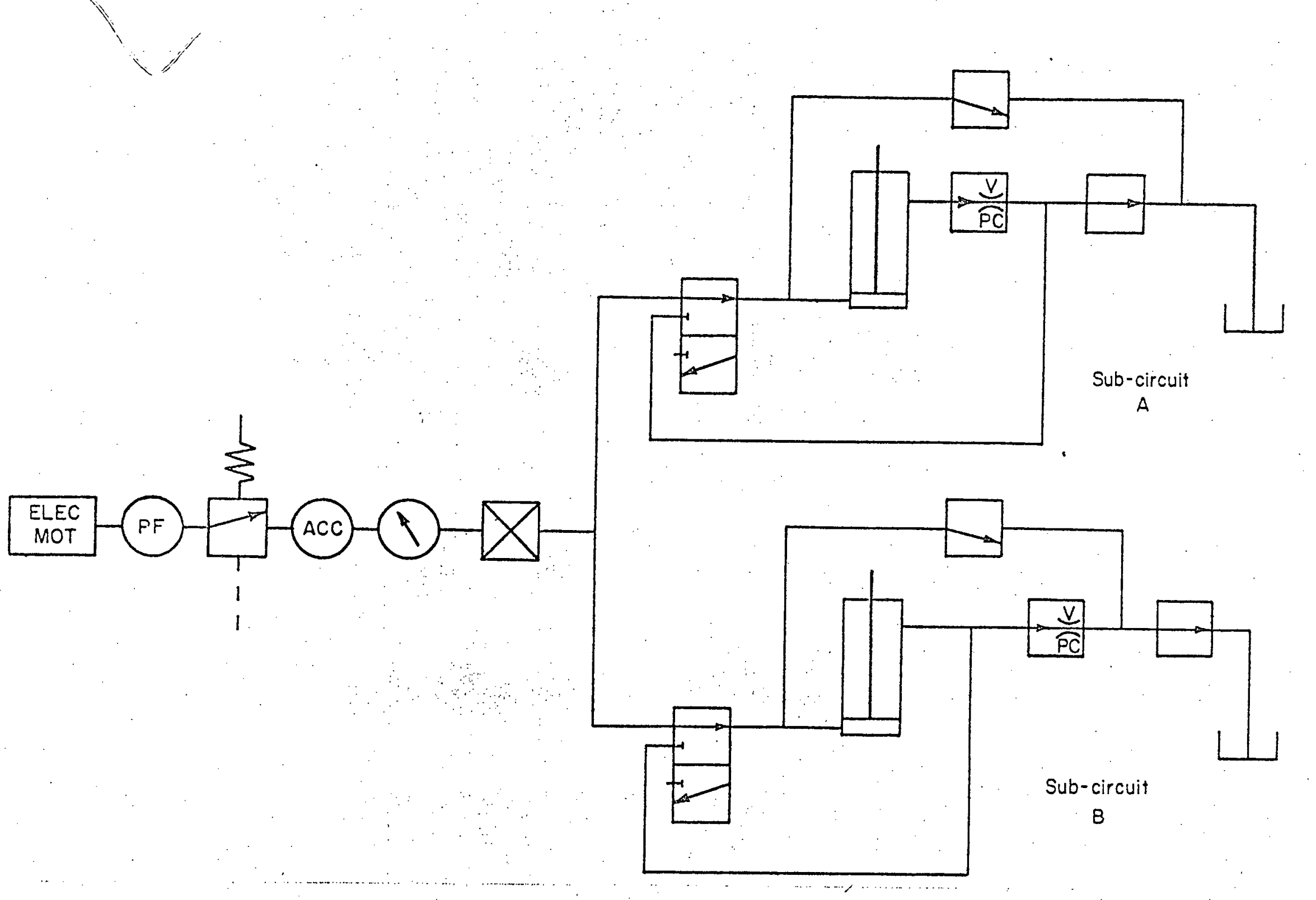

FIGURE 10. Schematic of the Hydraulic Control System.

Sub-circuit A controls the application and the release of the normal load. Sub-circuit $B$ controls the tangential force $F$ and the tangential loading rate $F$. 


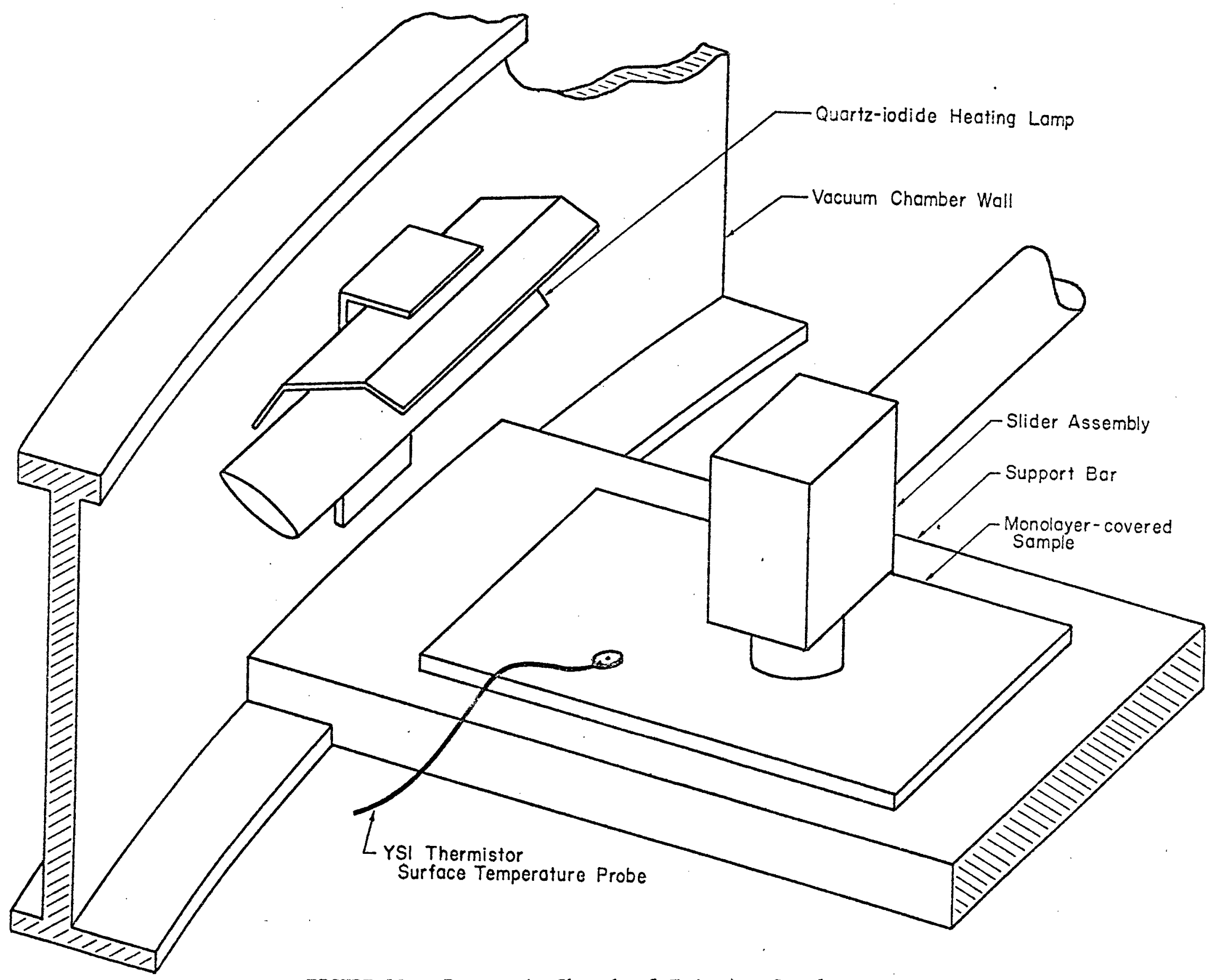

FIGURE 11. Isometric Sketch of Friction Couple. 


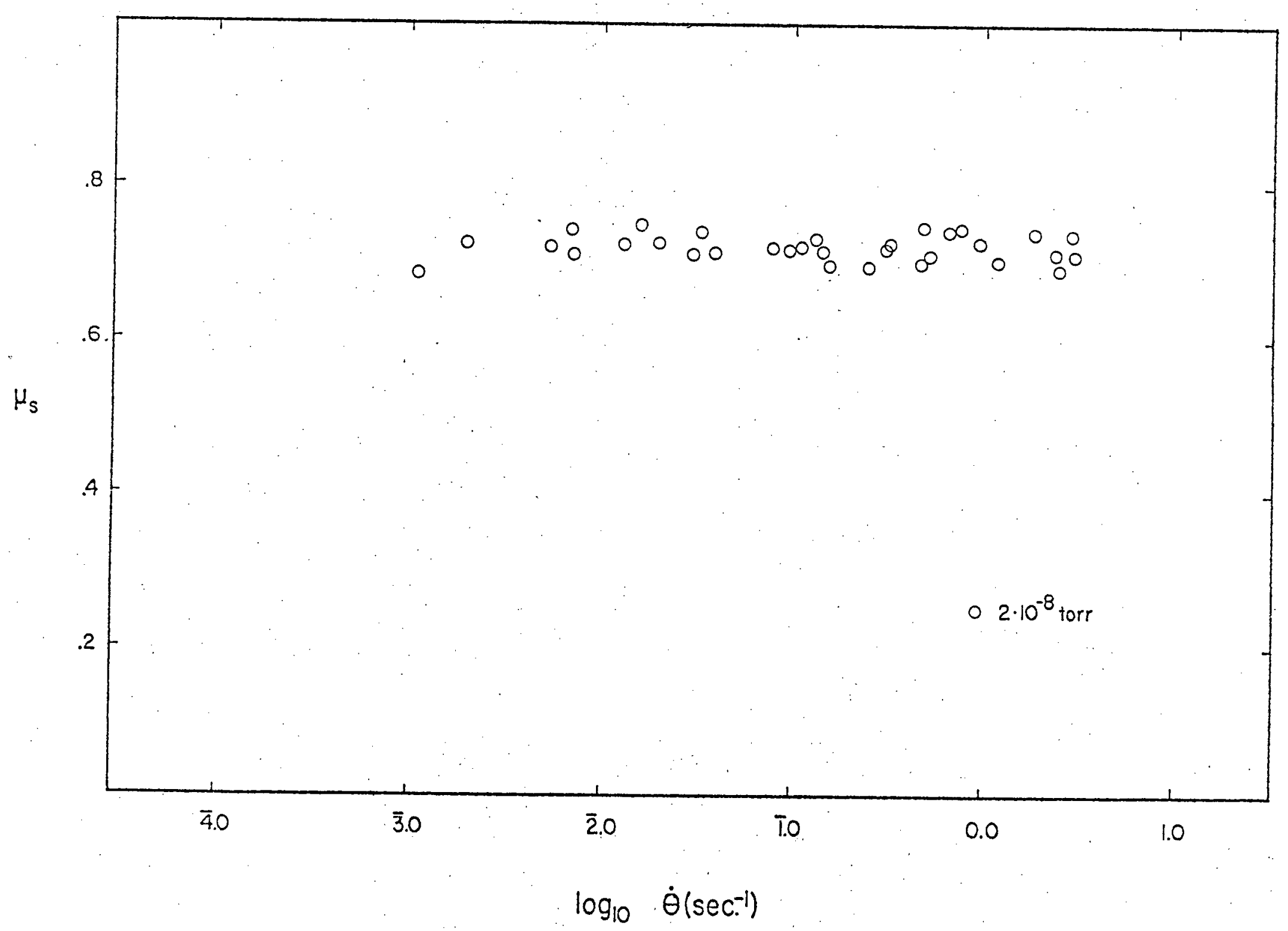

FIGURE 12. Static Friction of C1020 steel in Vacuum of $2 \times 10^{-8}$ torr at $20^{\circ} \mathrm{C}$.

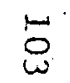




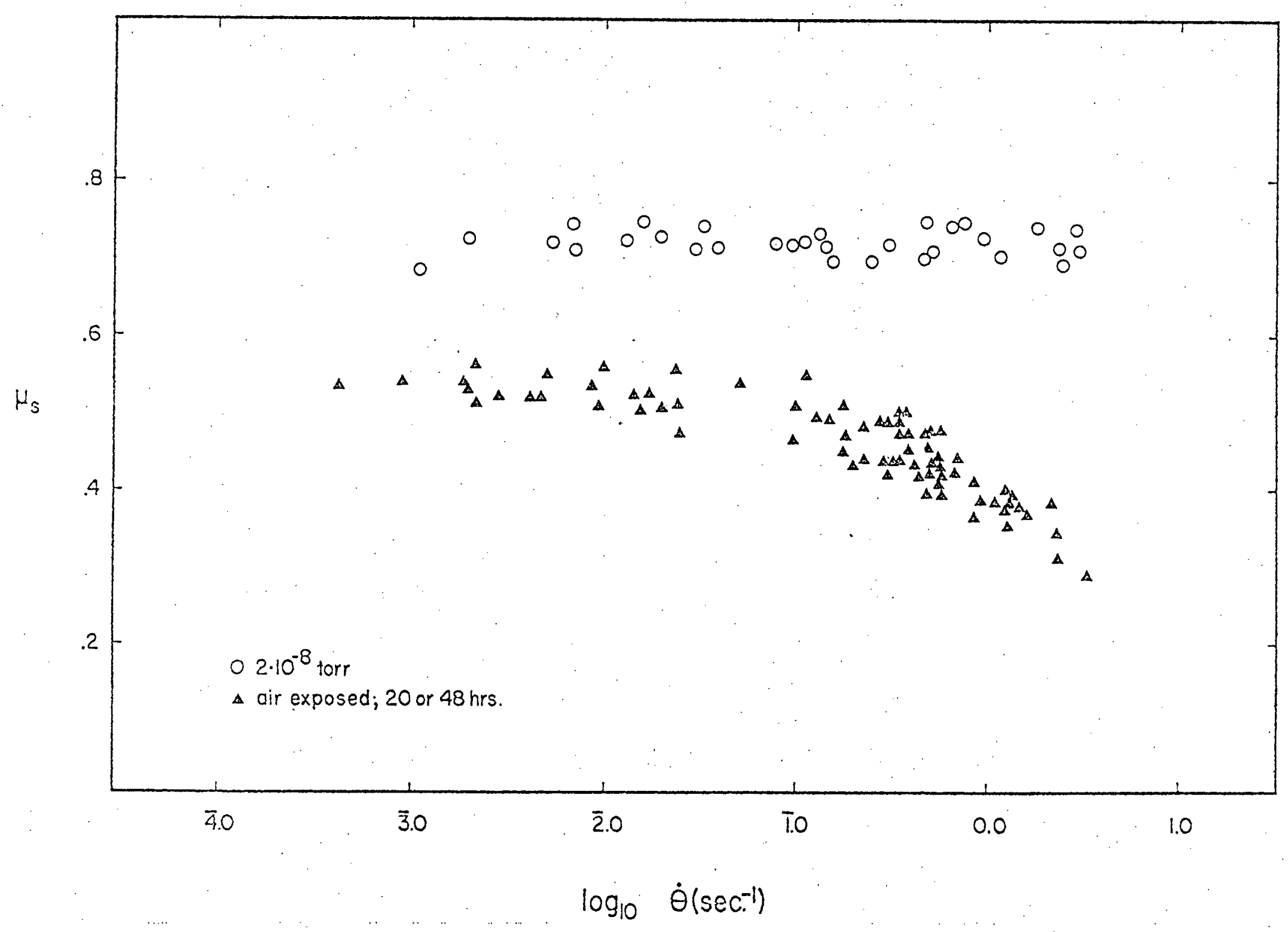

FIGURE 13. Static Friction of C1020 Steel in Vacuum and After Exposure to Atmosphere. 


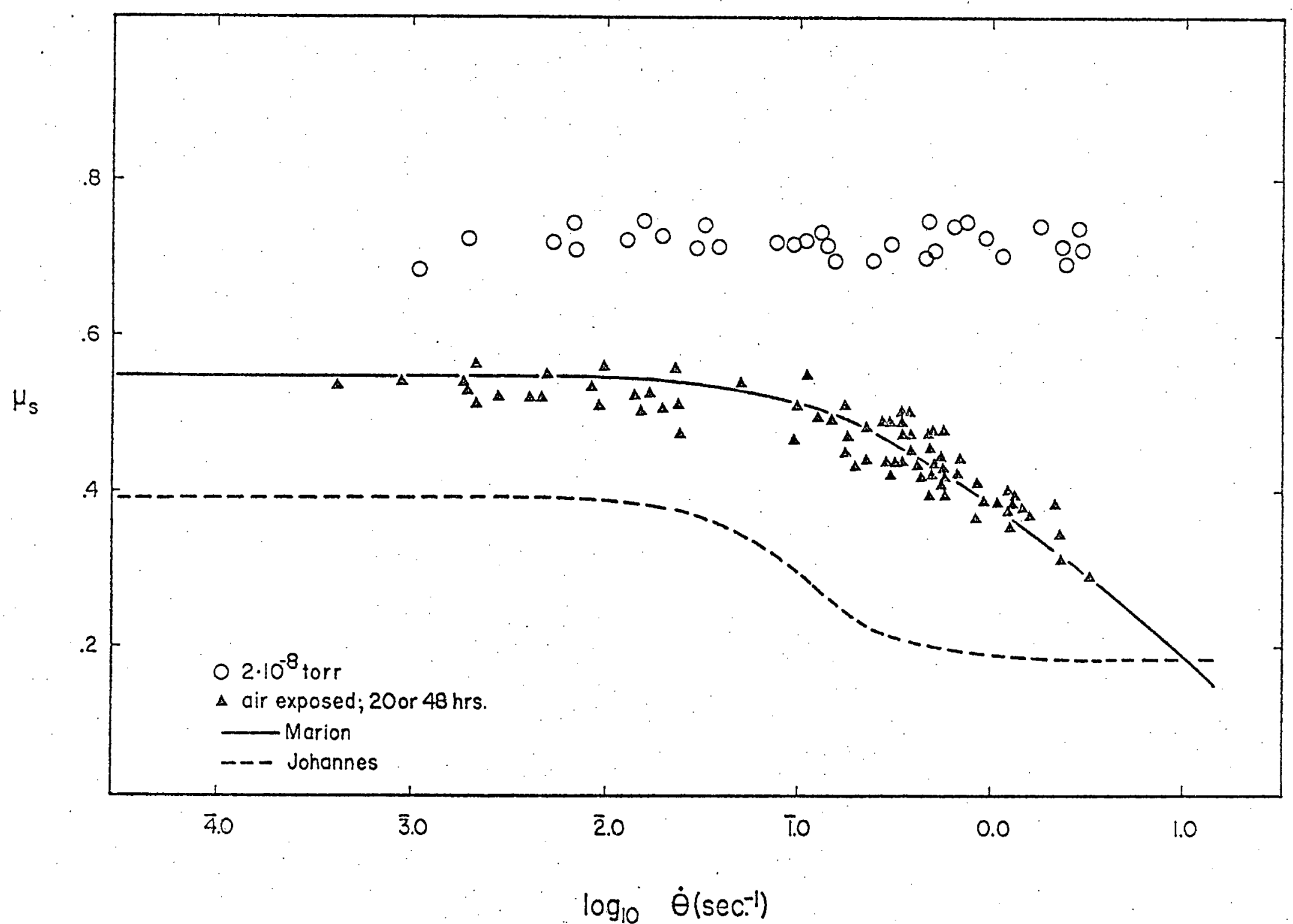

FIGURE 14. Comparison of Static Friction of C1020 Steel in Vacuum and After Exposure to Atmosphere to Static Friction Values Obtained by Johannes [19] and Marion [21].

莫 


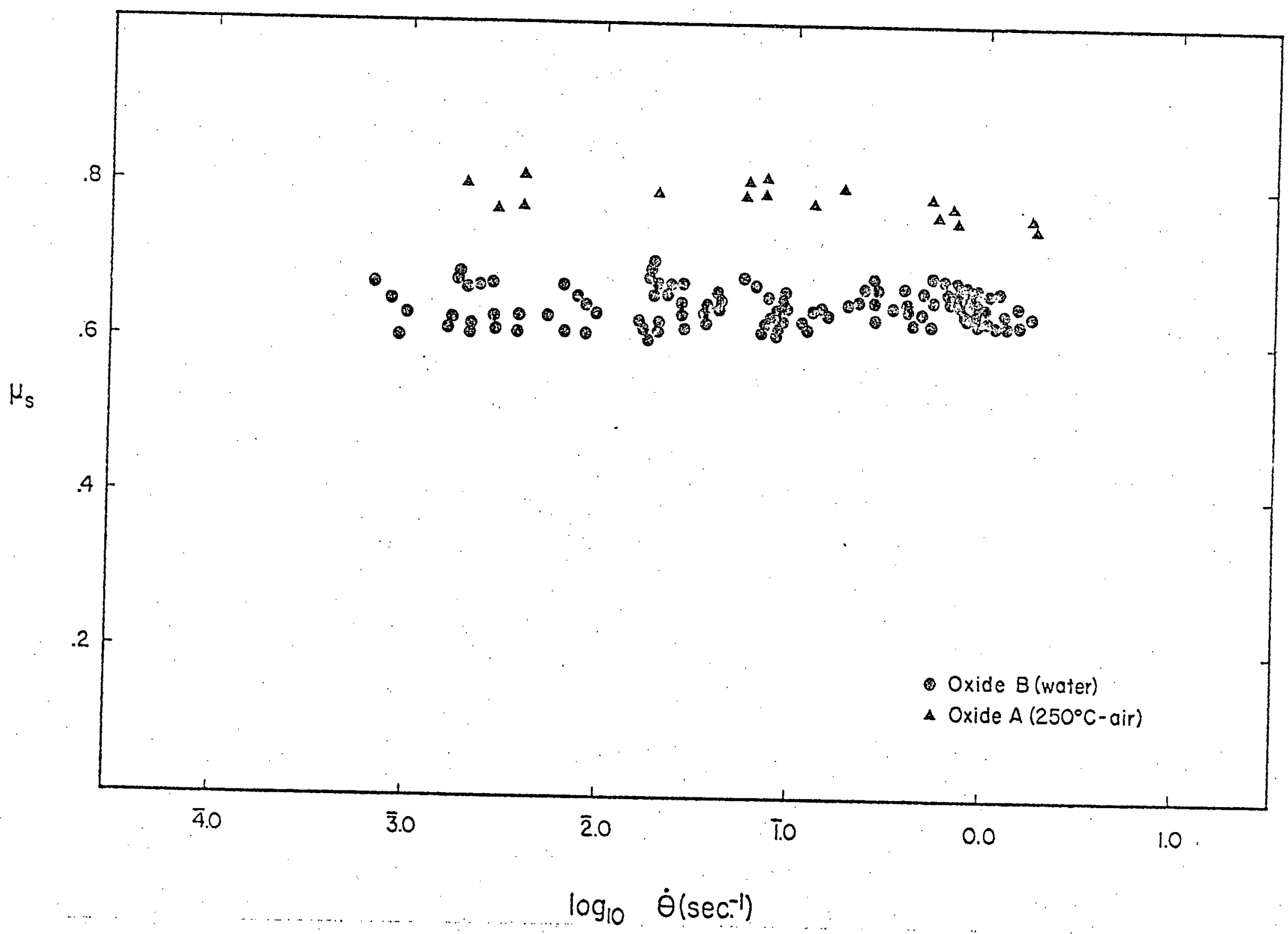

FIGURE 15. Static Friction of C 1020 Steel Covered with Oxide Films. 


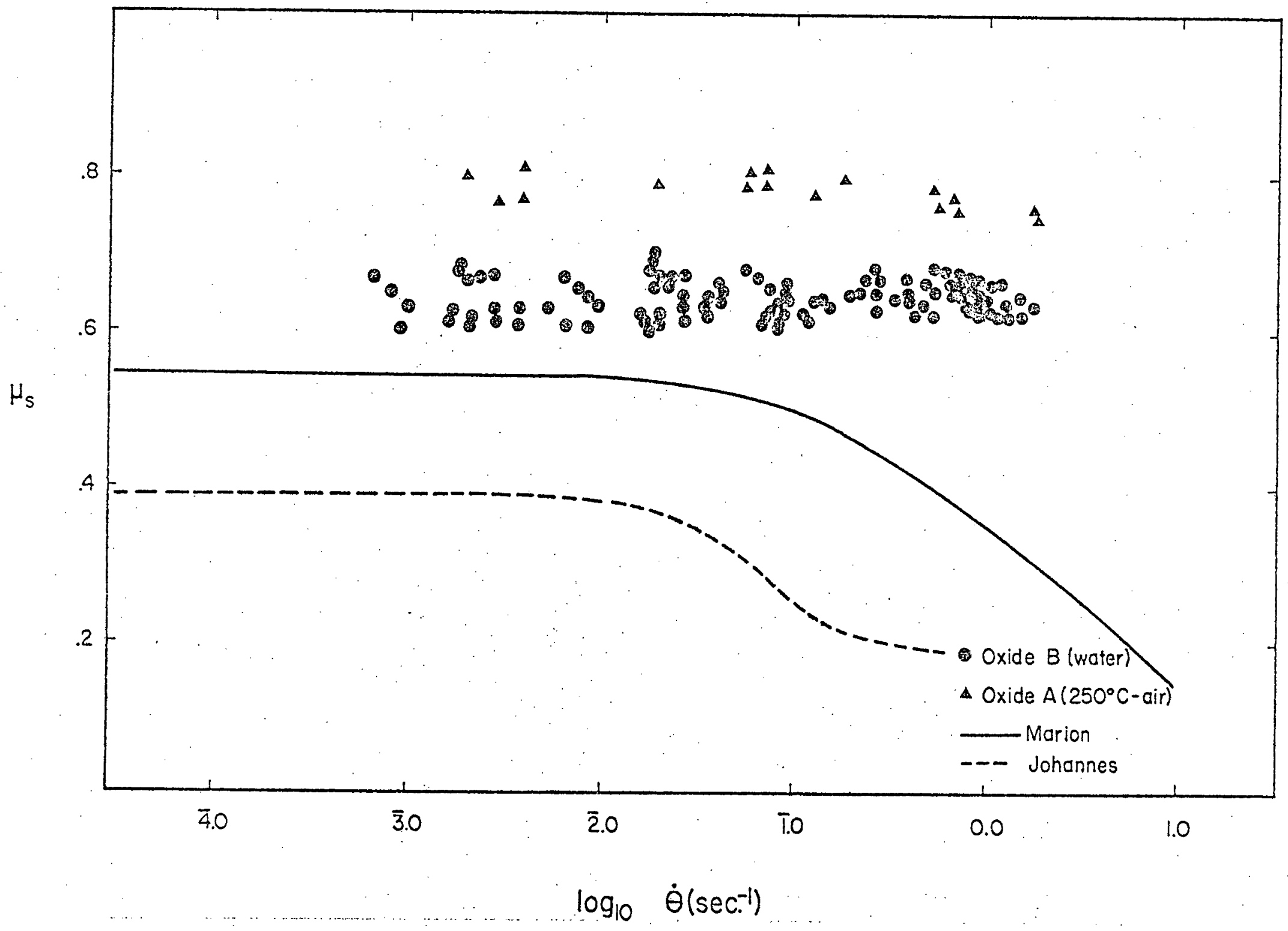

FIGURE 16. Comparison of Static Friction of Oxide-covered C1020 Steel to Static Friction Values Obtained by Johannes and Marion. 


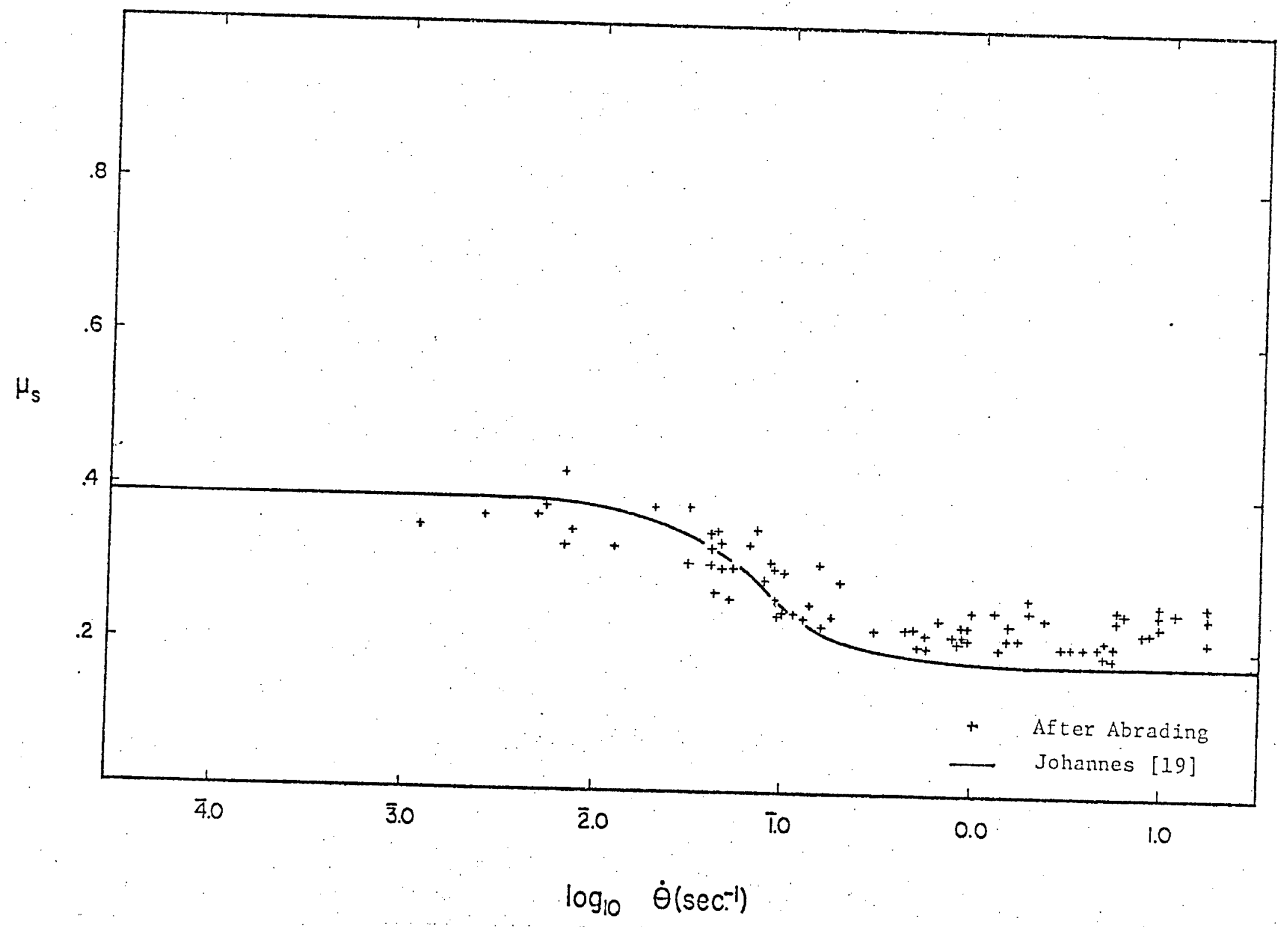

FIGURE 17. Static Friction of C1020 Steel After Abrading Surface Under Stearic Acid-Hexane Solution. 


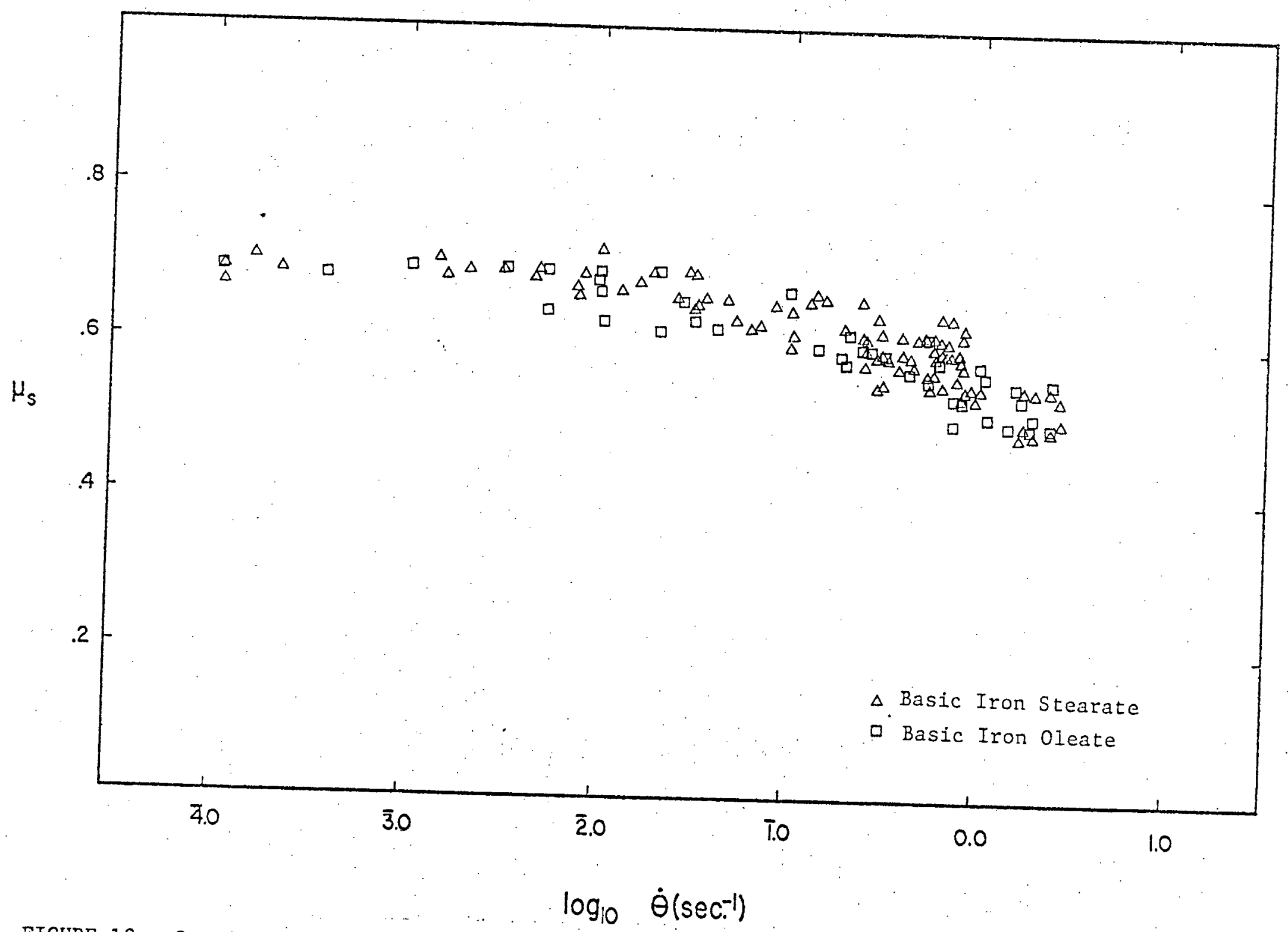
FIGURE 18. Static Friction of C1020 Steel Covered with a Monolayer of Either a Basic Iron Stearate or a
Basic Iron Oleate. $\mathrm{pH}$ of Substrata is $4 . \mathrm{T}=20^{\circ} \mathrm{C}$. 


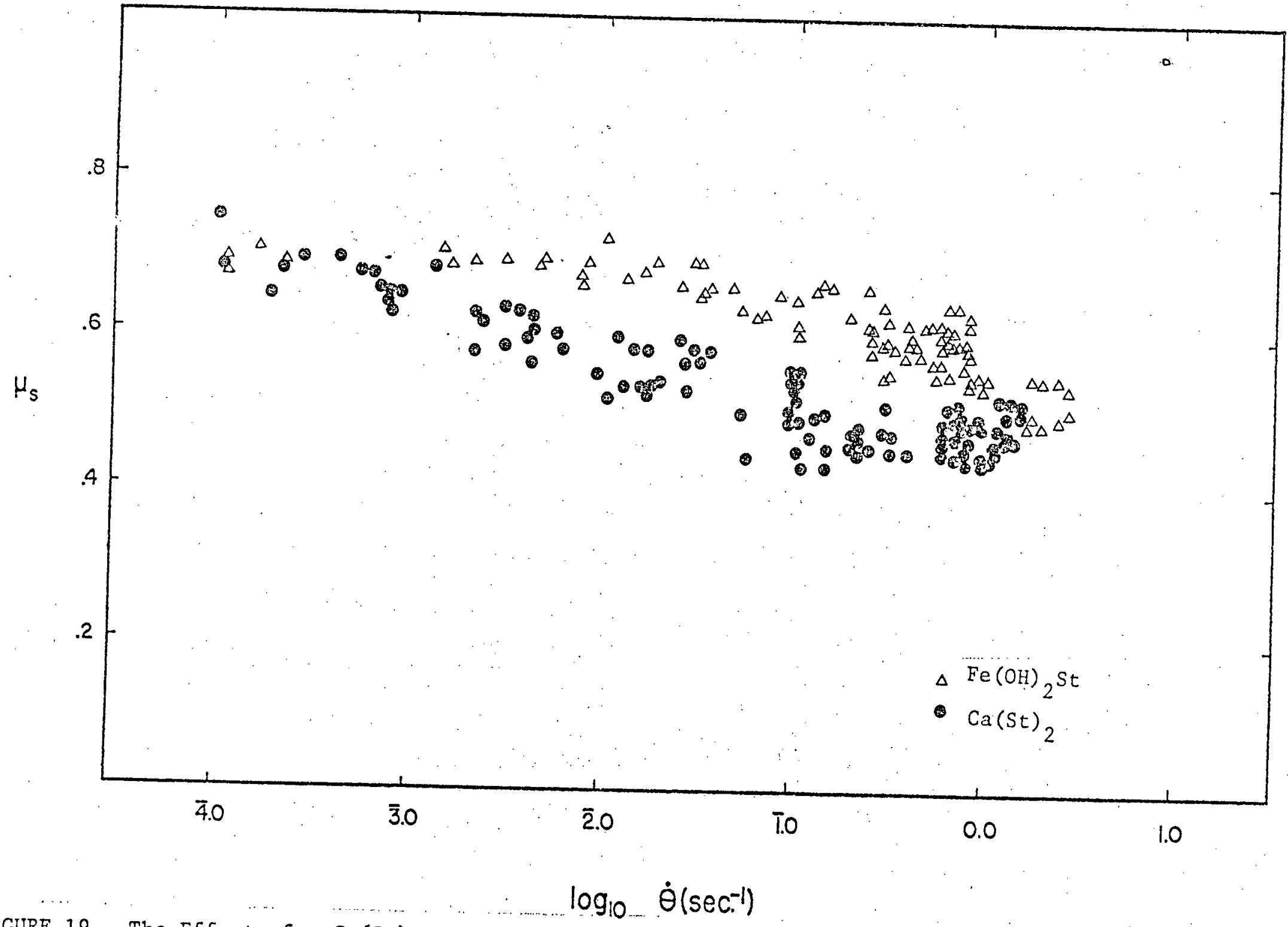

FIGURE 19. The Effect of a $\mathrm{Ca}(\mathrm{St})_{2}$ Monolayer on Static Friction as Compared to the Effect of an Fe(OH) ${ }_{2} \mathrm{St}$ Monolayer. $\mathrm{pH}$ of Substrata is 4 for Iron-stearate Soap, 9 for Calcium-stearate Soap. $\mathrm{T}=20^{\circ} \mathrm{C}$. 


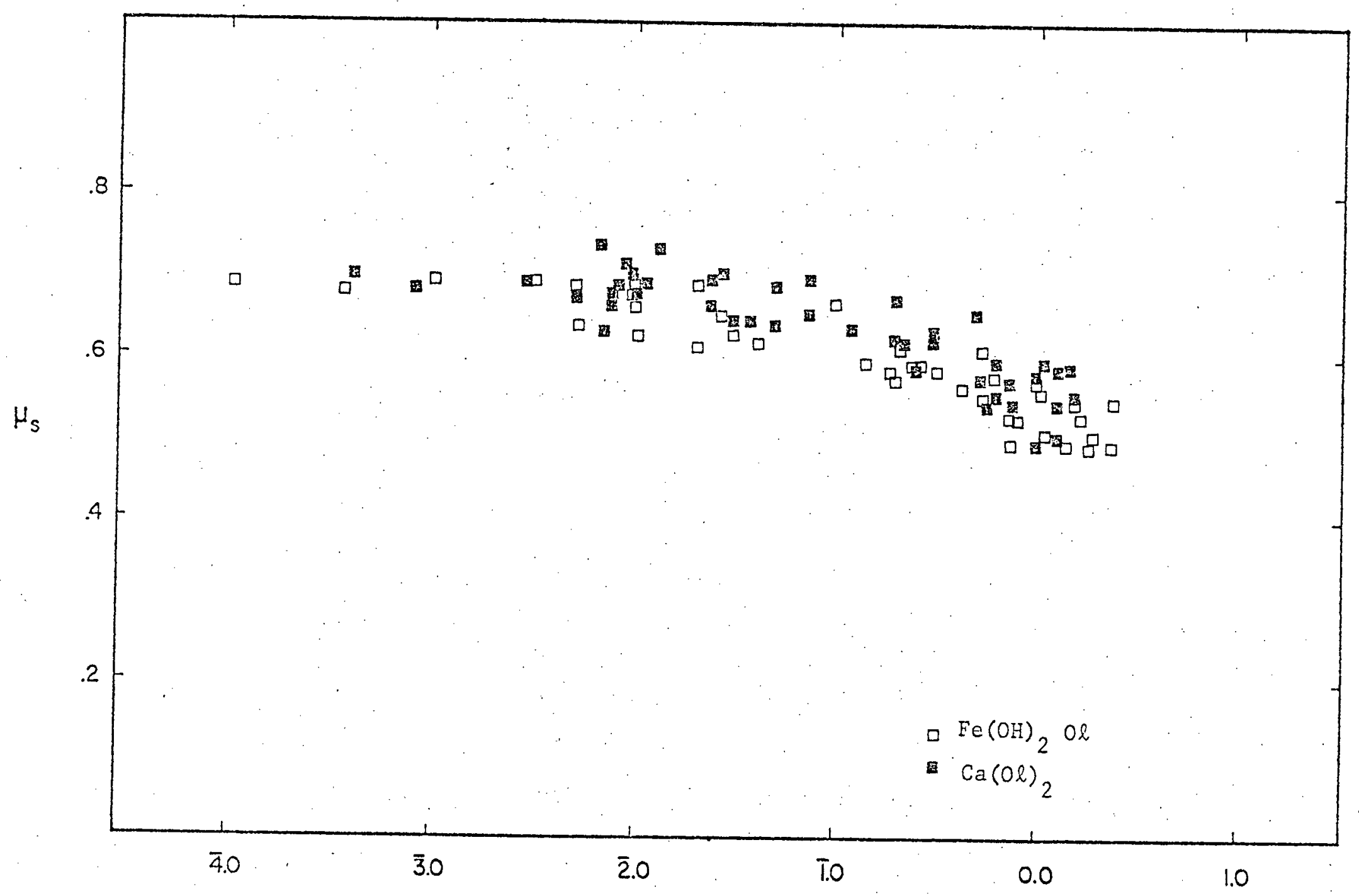

$\log _{10} \dot{\theta}\left(\sec ^{-1}\right)$

EIGURE 20. The Effect of a $\mathrm{Ca}(\mathrm{Ol})_{2}$ Monolayer on Static Friction Compared to the Effect of an $\mathrm{Fe}(\mathrm{OH})_{2} \mathrm{Ol}$ Monolayer. $\mathrm{pH}$ of Substrate is 4 for Iron-oleate Soap, 9 for Calcium-oleate Soap. $\mathrm{T}=20^{\circ} \mathrm{C}$. 


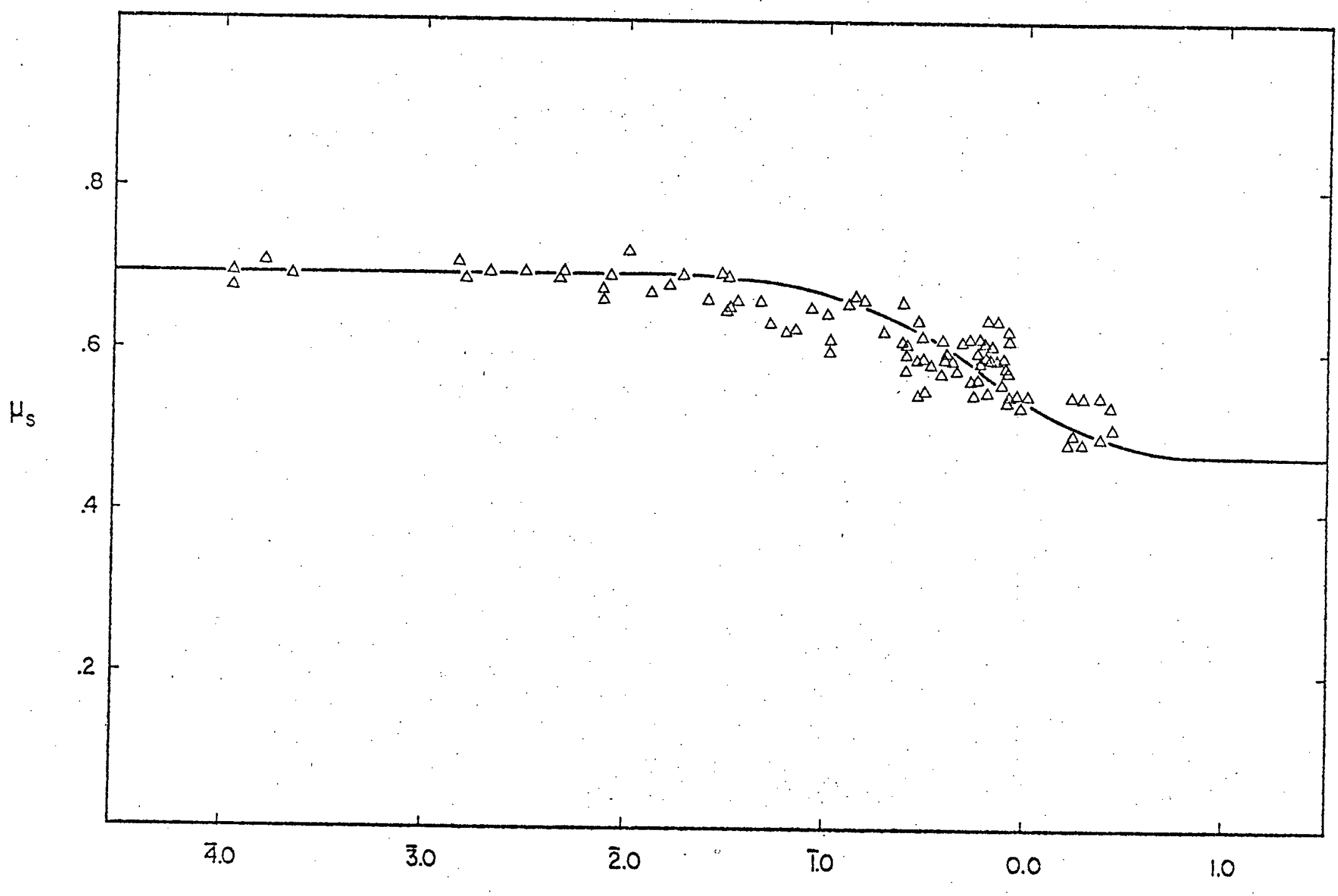

$\log _{10} \dot{\theta}\left(\sec ^{-1}\right)$

FIGURE 21. Experimental Data and Theoretical $\mu_{s}-\dot{\theta}$ Curve for Static Friction when steel Surface is Covered with $\mathrm{Fe}(\mathrm{OH})_{2}$ St Monolayer. $\mathrm{pH} 4, \mathrm{~T}=20^{\circ} \mathrm{C}$. 


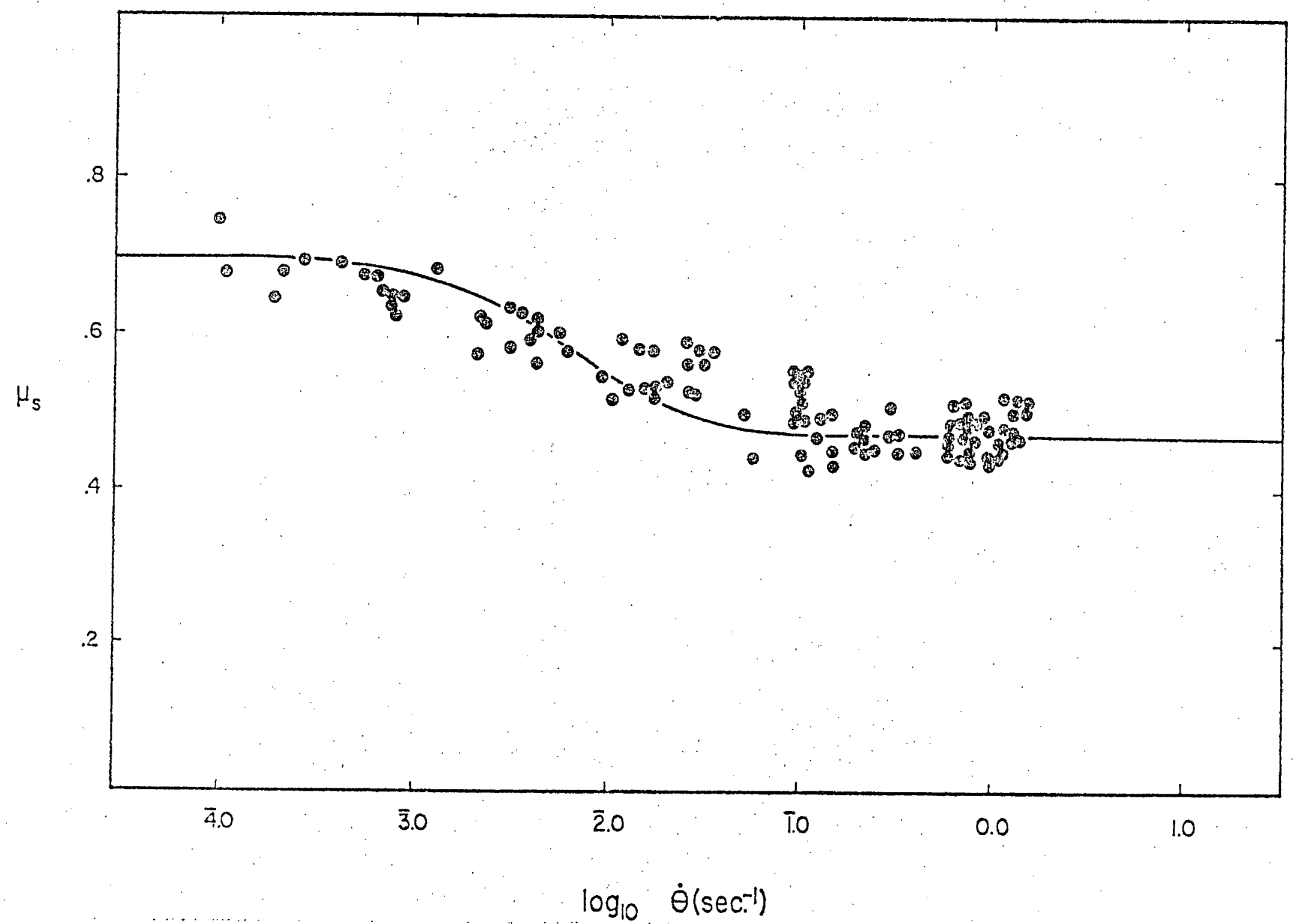

FIGURE 22. Experimental Data and Theoretical $\mu_{s}-\dot{\theta}$ Curve for Static Friction when Steel Surface is Covered with $\mathrm{Ca}(\mathrm{St}) 2$ Monolayer. $\mathrm{pH} 9, \mathrm{~T}=20^{\circ} \mathrm{C}$. 


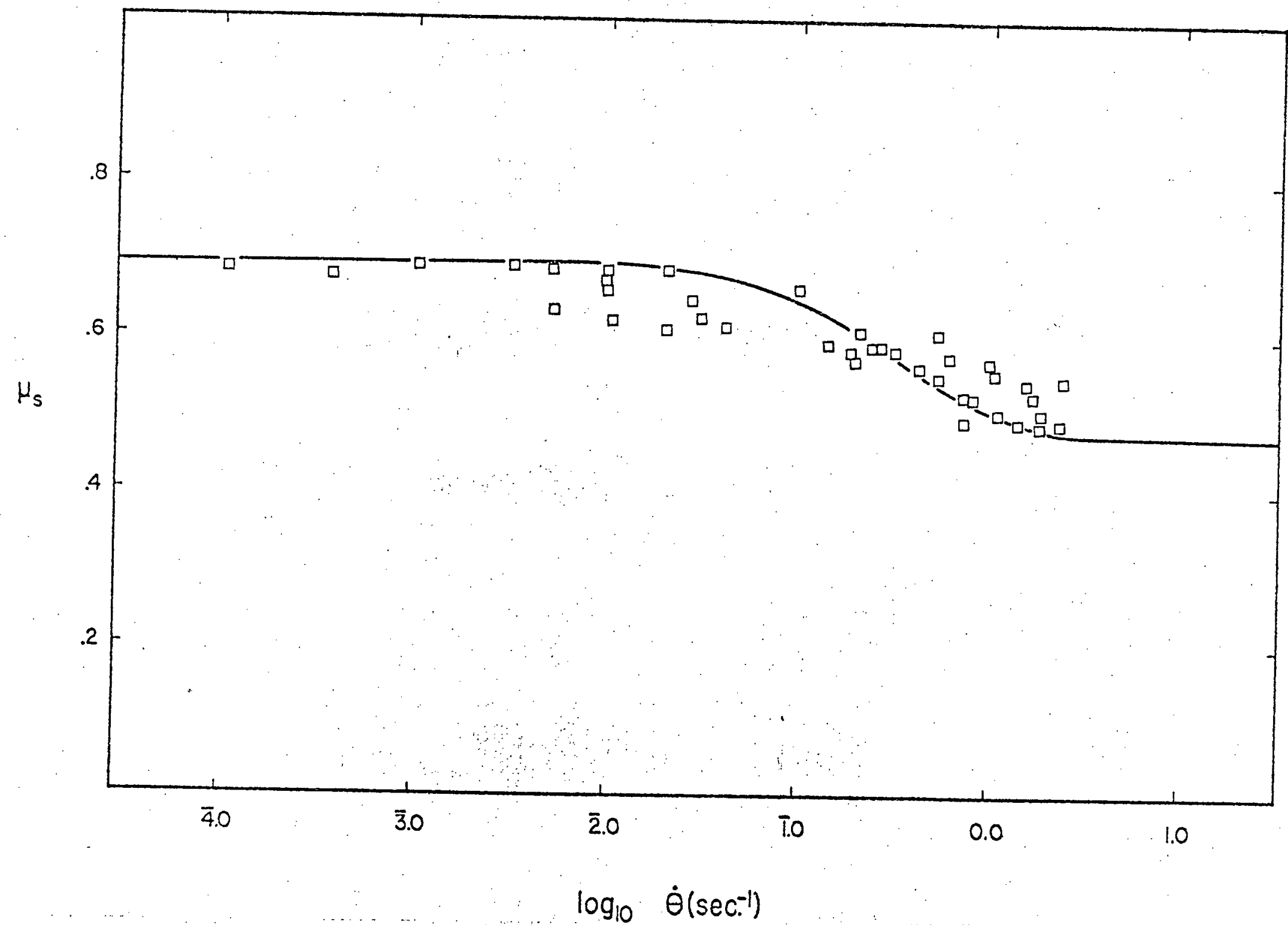

FIGURE 23. Experimental Data and Theoretical $\mu_{s}-\dot{\theta}$ Curve for Static Friction when steel Surface is Covered with $\mathrm{Fe}(\mathrm{OH}) 2$ Ol Monolayer. $\mathrm{pH} 4, \mathrm{~T}=20^{\circ} \mathrm{C}$. 


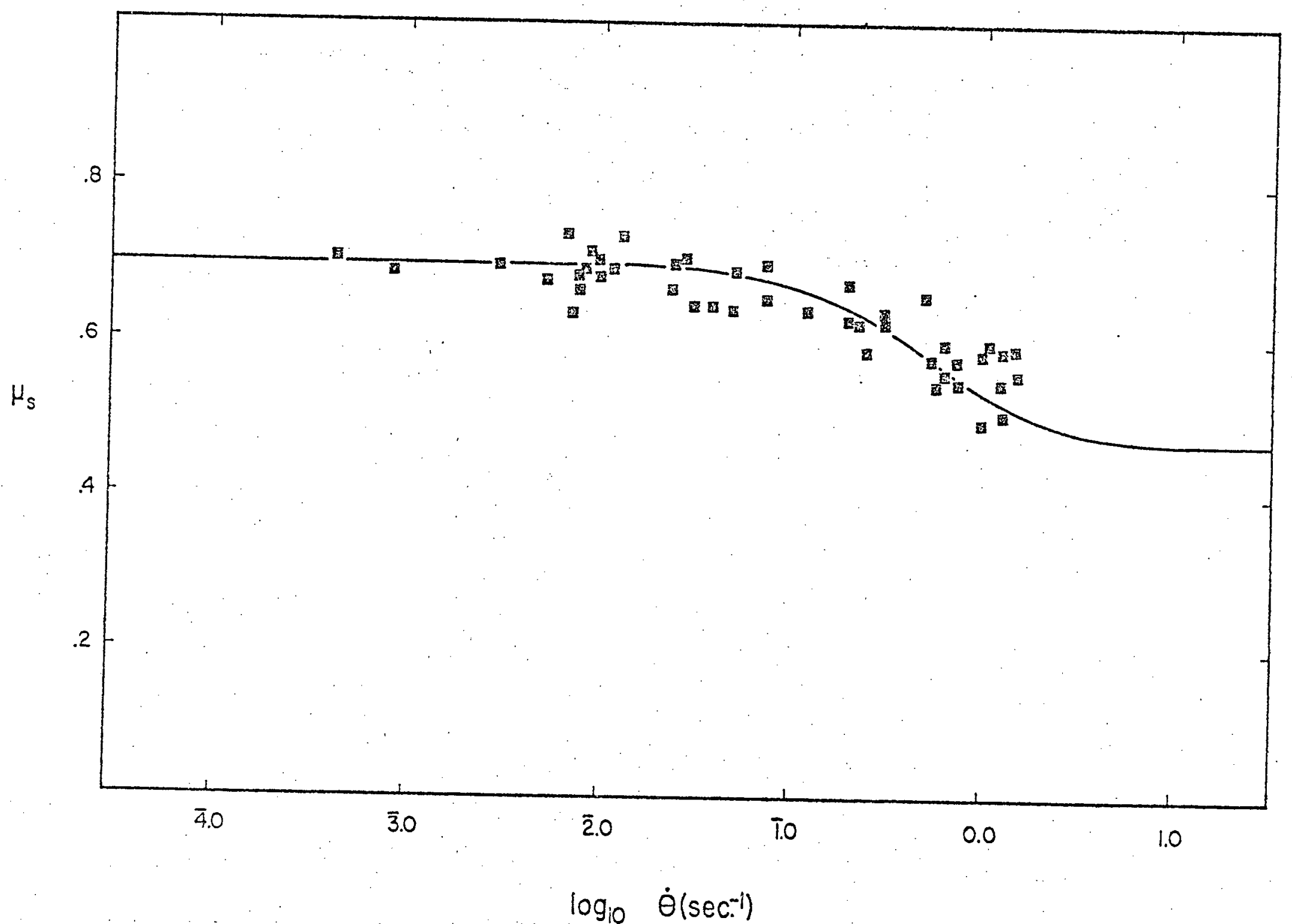

FIGURE 24. Experimental Data and Theoretical $\mu_{s}-\dot{\theta}$ Curve for Static Friction when Steel Surface is Covered with $\mathrm{Ca}(\mathrm{Ol})_{2}$ Monolayer. $\mathrm{pH} 9, \mathrm{~T}=20^{\circ} \mathrm{C}$. 


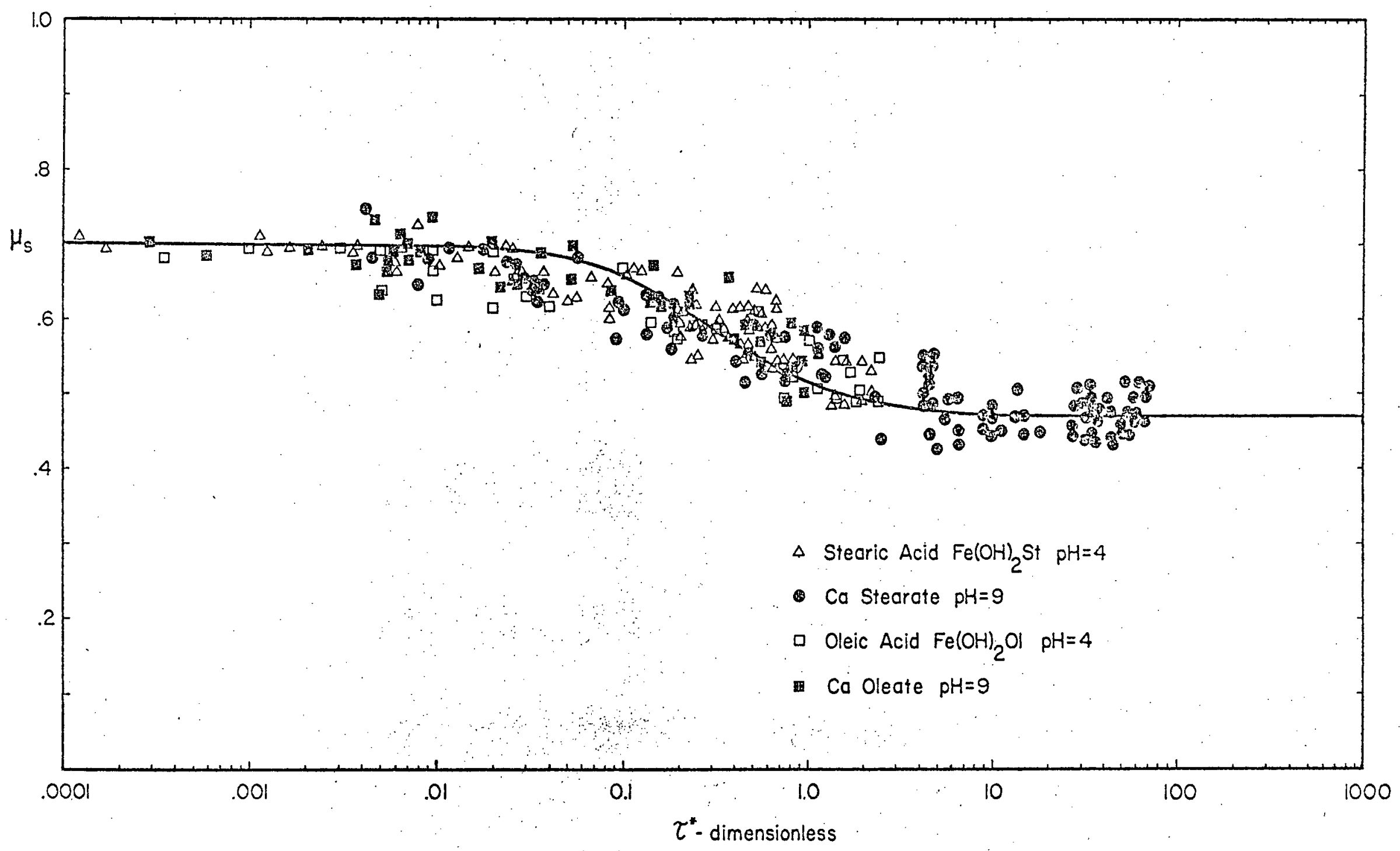

FIGURE 25. Experimental Data Collapses on General $\mu_{s}-\tau *$ Curve Predicted from Mathematical Model. $\mathrm{T}=20^{\circ} \mathrm{C}$. 


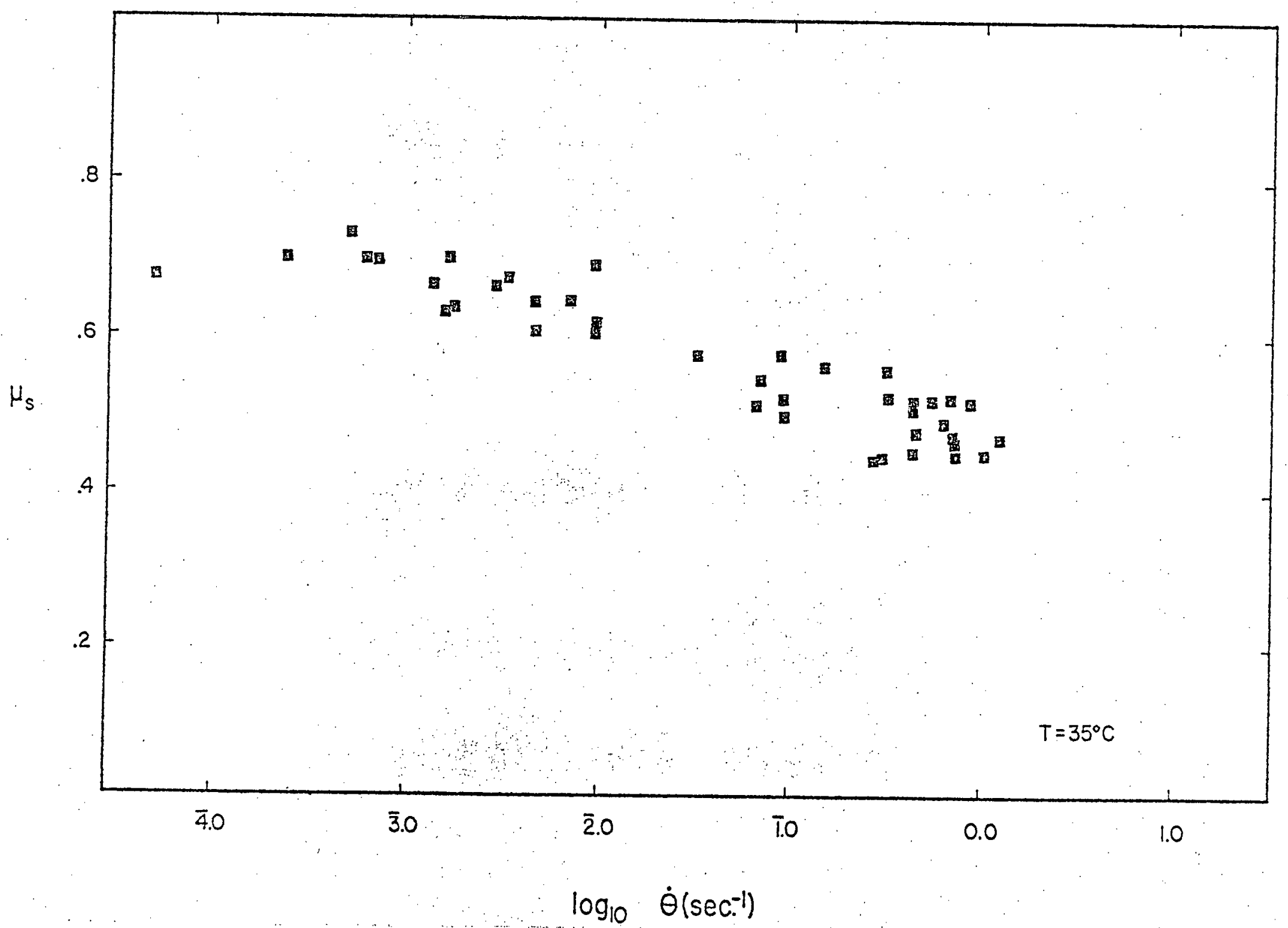

FIGURE 26. Effect of Raising Surface Temperature to $35^{\circ} \mathrm{C}$. Ca Stearate Soap Monolayer. 


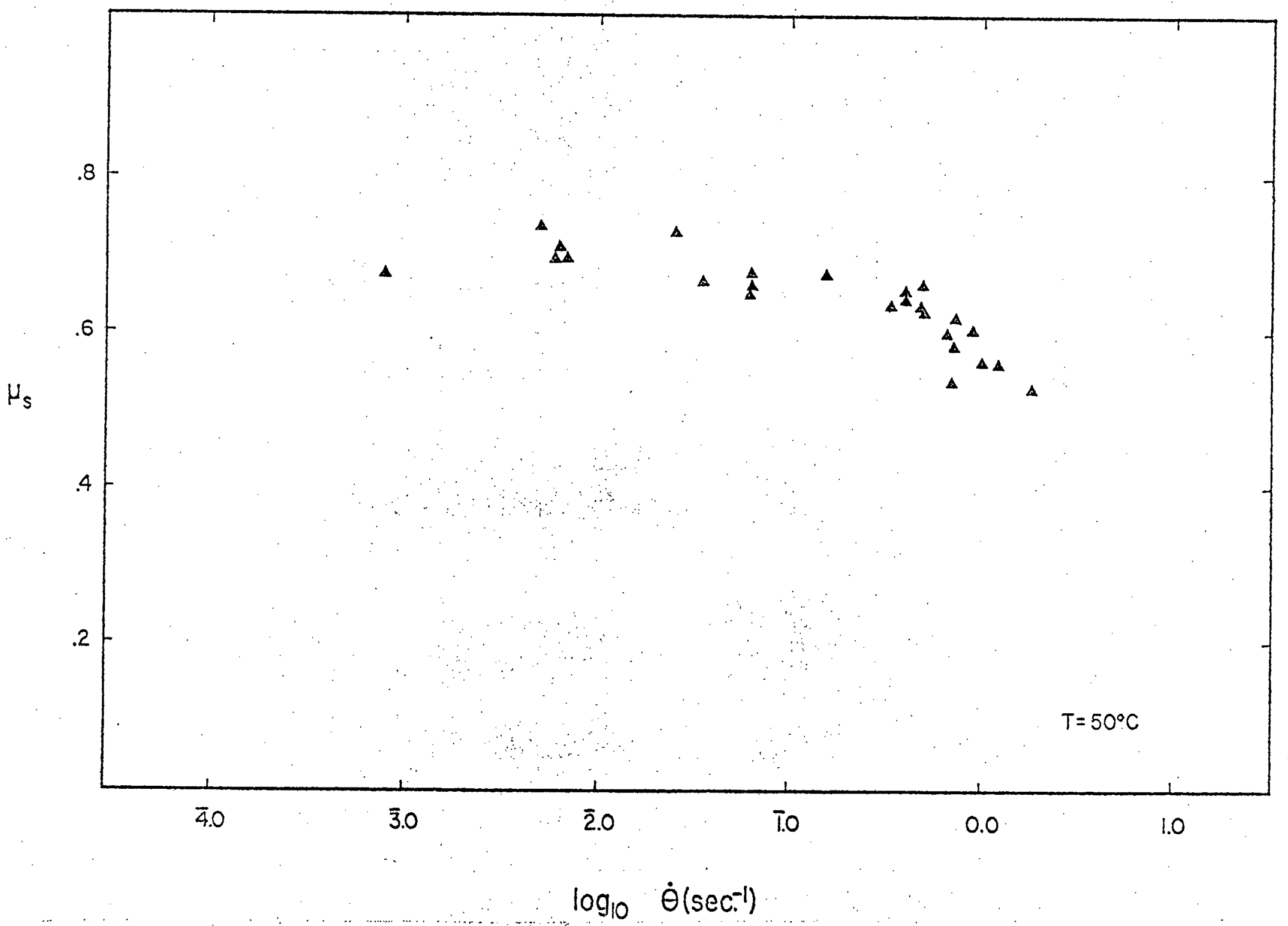

FIGURE 27. Effect of Raising Surface Temperature to $50^{\circ} \mathrm{C}$. Ca Stearate Soap Monolayer. 


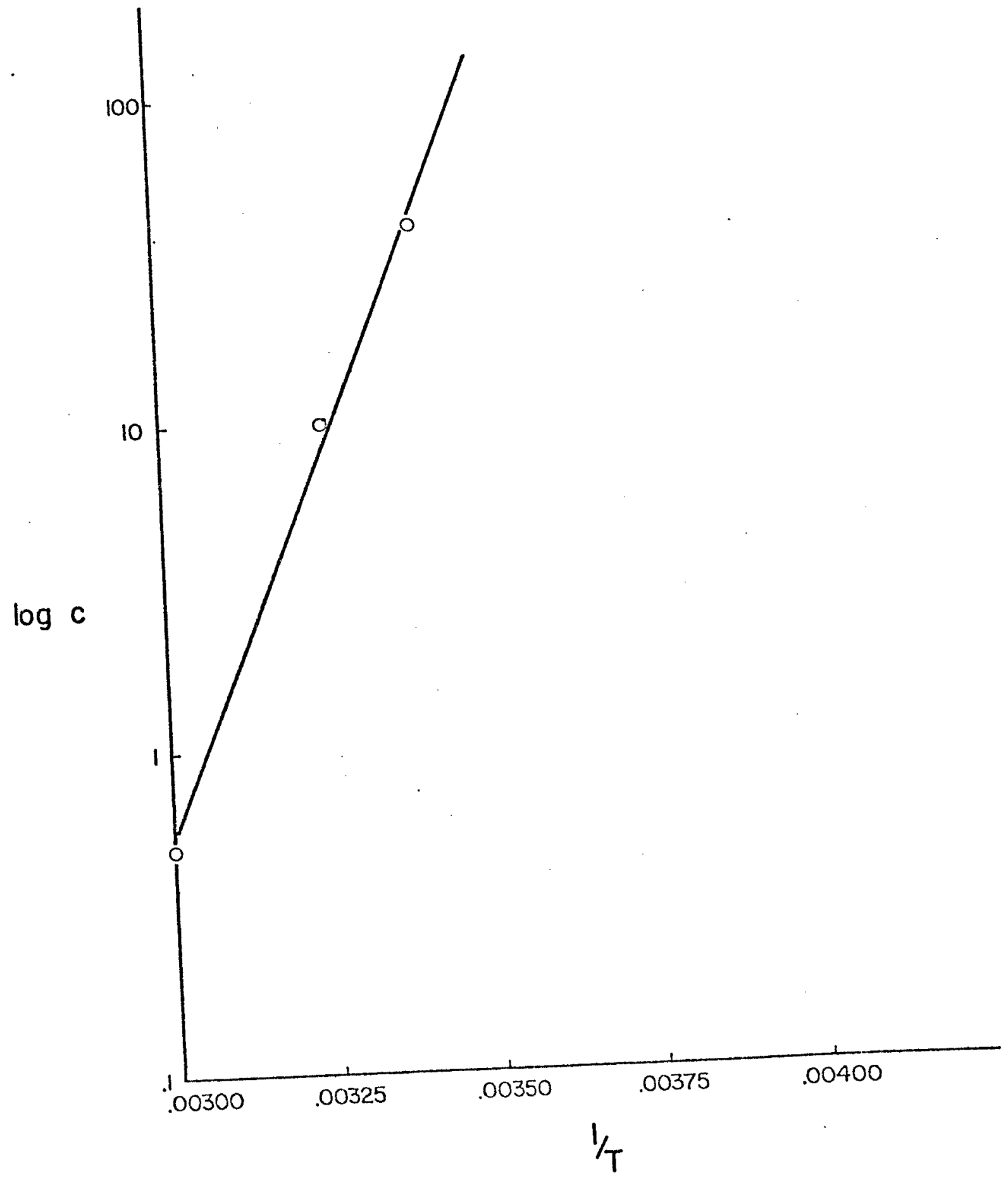

FIGURE 28. Log $\mathrm{c}$ vs $1 / \mathrm{T}$ for Calcium Stearate Soap Monolayers. Since $c(\mathrm{~T})=\mathrm{e}^{(\Lambda \mathrm{E} / \mathrm{GT})}$, $\triangle \mathrm{E}$ was Determined to be $28 \mathrm{~K}$ cals. 

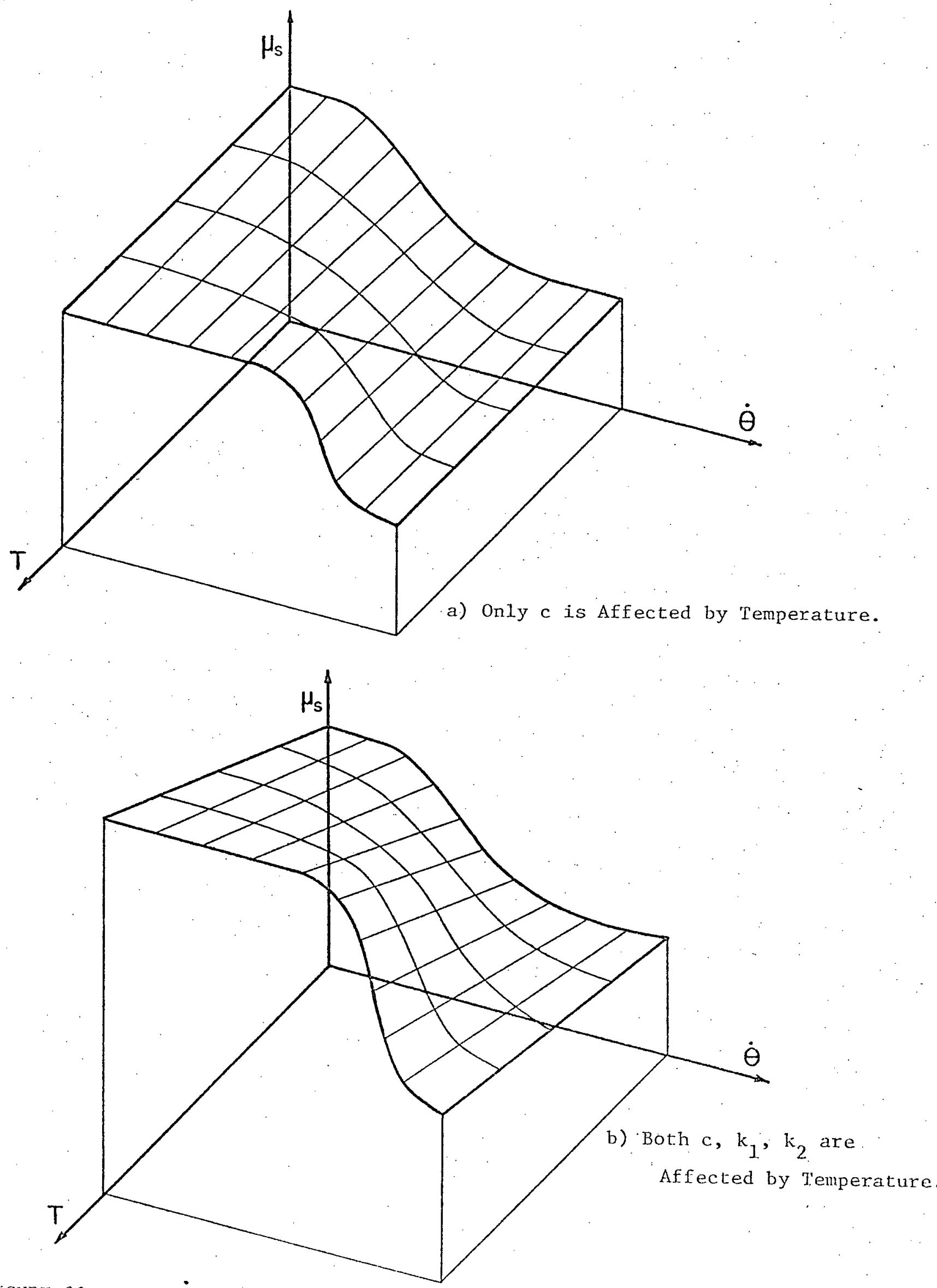

FIGURE 29. $\mu_{\mathrm{S}}-\dot{\theta}-\mathrm{T}$ Surfaces for Various Conditions. 


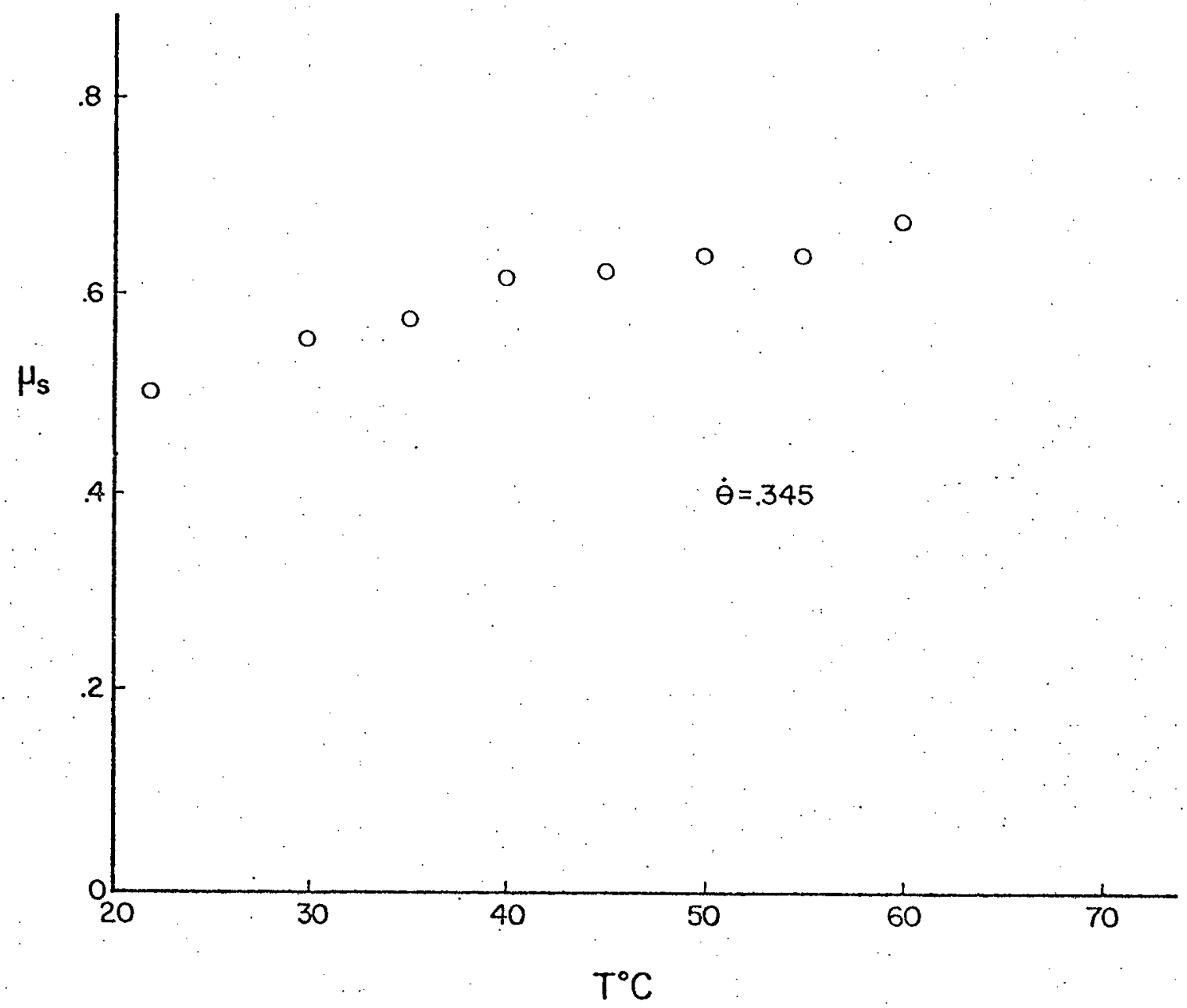

FIGURE 30. $\dot{\mu}_{s}-\mathrm{T}$ Characteristics of Steel Covered with Calcium Stearate Monolayer at $\dot{\theta}=0.345 \mathrm{sec}^{-1}$. 


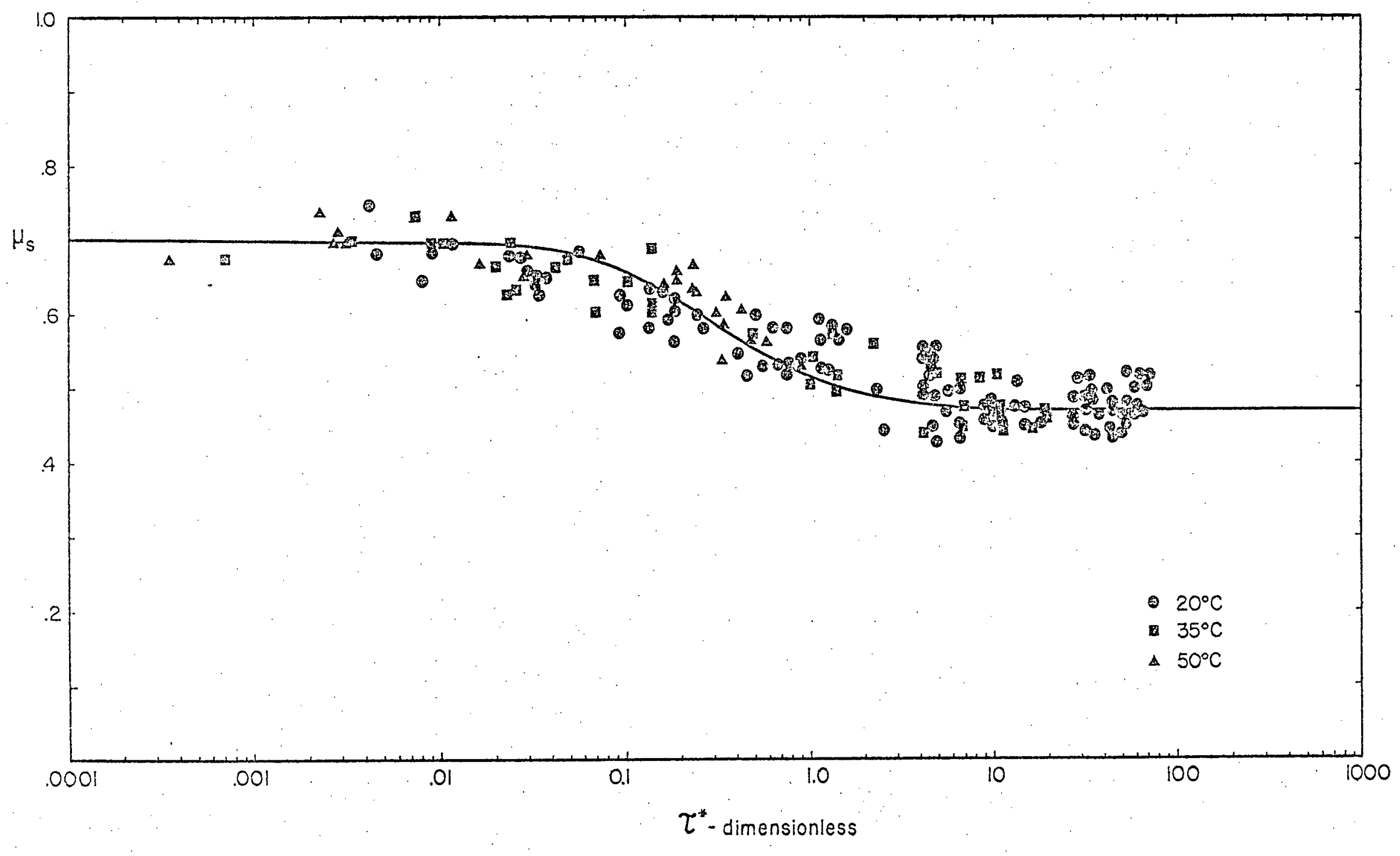

FIGURE 31. Experimental Temperature-Friction Data Also Collapses on General $\mu_{s}-\dot{\theta}$ Curve for Calcium Stearate Monolayer Covered Surface. 


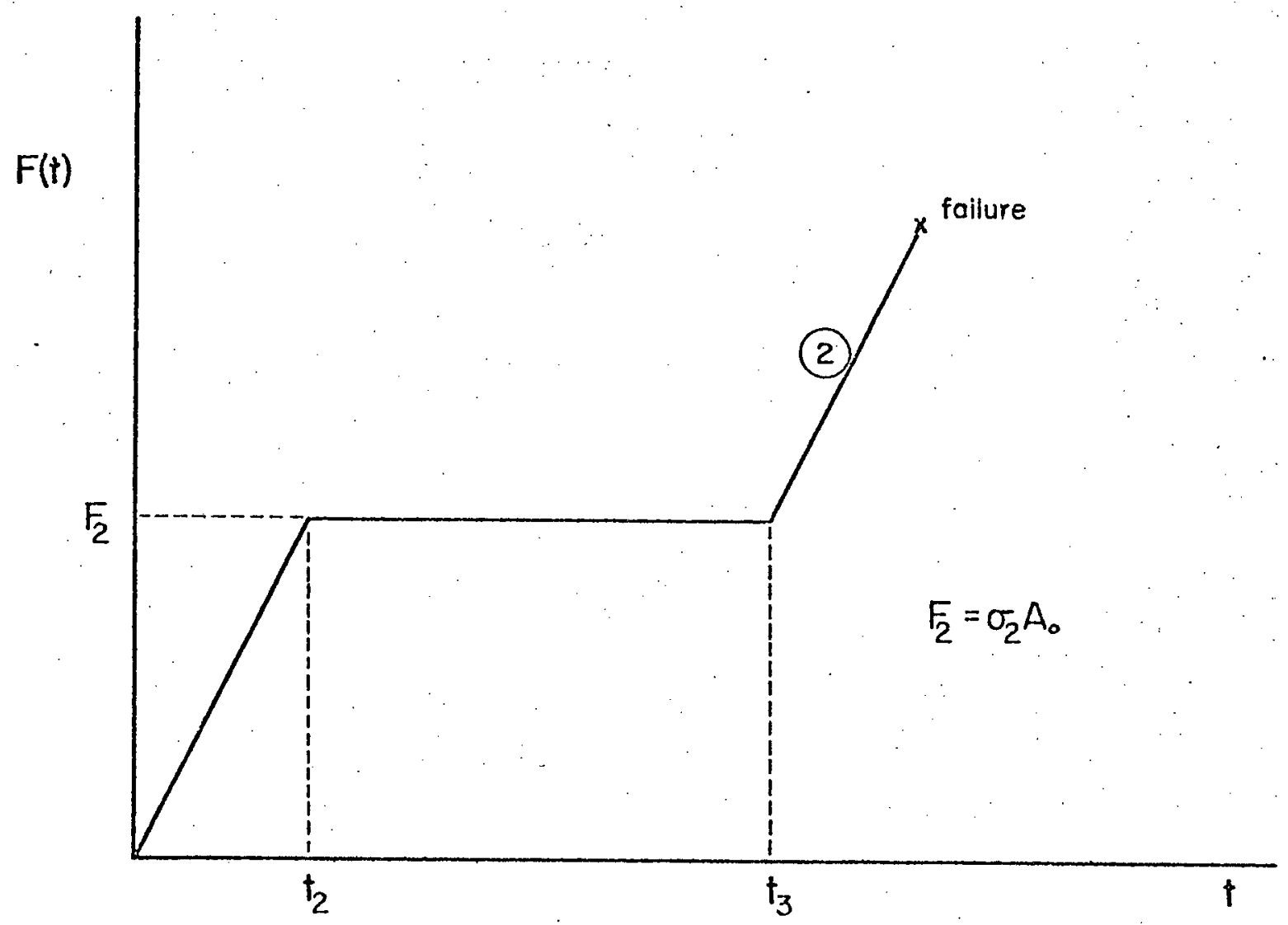

FIGURE 32. Loading History During Delayed Stick. 


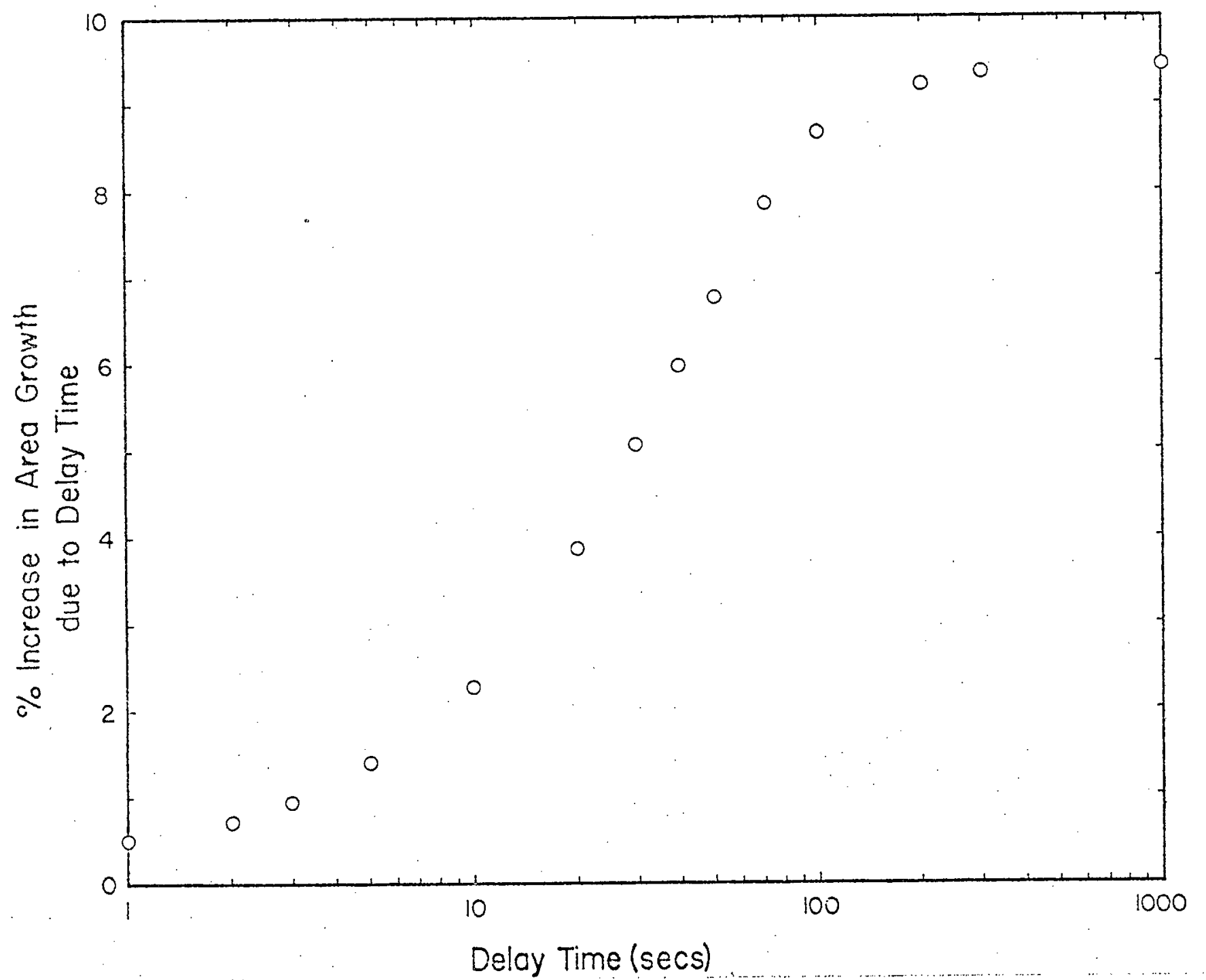

FIGURE 33. Area Growth Due to Delay Time if the System has a Relaxation Time of $40 \mathrm{Sec}$ 